Hainisch, Michael

Der Kampf ums Dasein und die Socialpolitik

$\mathrm{QH}$

366

H4 
Der

Kampf ums Dajein นกช

\title{
dite Sorialpulifik
}

\author{
2̧on
}

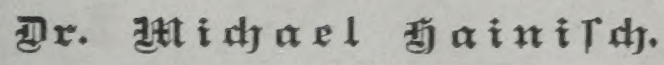

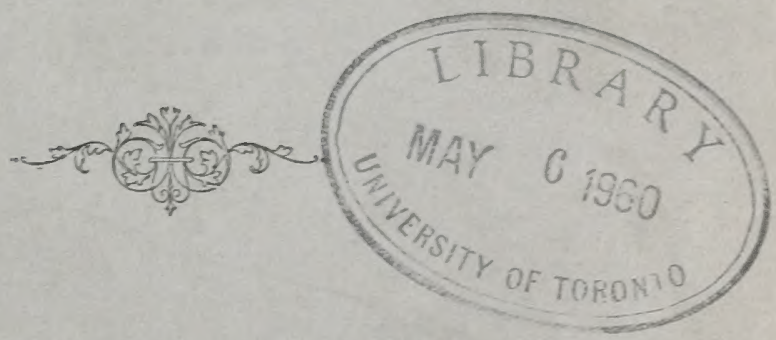

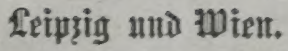

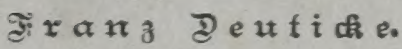
1899. 
Berlags $=\Re r .659$. 
Dex

\section{Kampf unts Dajein}

IIII

\section{dix sorialpolifik}

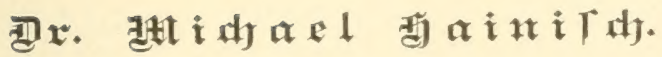

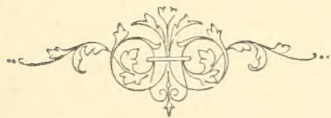

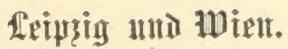

ב્ર" $x$ a 1899. 


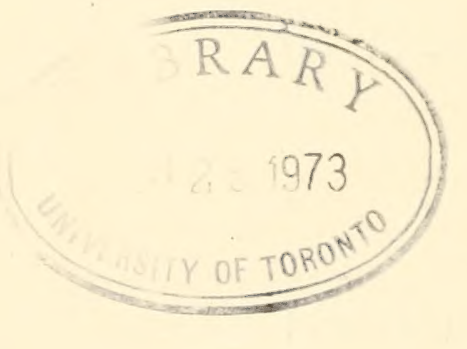

QH
366
H4

Rerfaga=?R. 659.

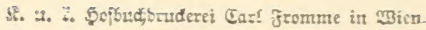




\section{1)orwort.}

Sine gröp̃ere 2 (rbcit, bie id) in nid)t allzu forner 3eit zum

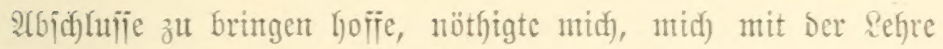
vom Rampie unts Dajein uno jeiner 2(nwenoung auj bie menich=

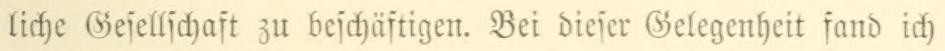
in ber Siteratur über bie Jrage zwar felyr viel Heberzengenbes,

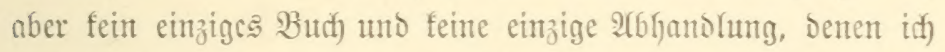

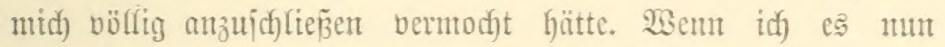

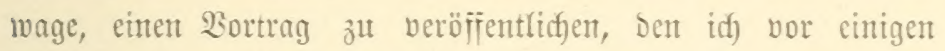
Wodjen in einer Sejellid)aft von Socialpolitifern gehaltent Gabe, jo leitet midy wentiger bas Strebcn, bie Riteratur burd)

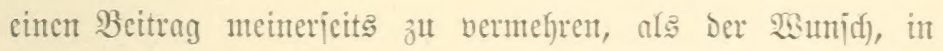
Sïrze Darzuthut, Daj̃ man nidjt, wie bies nod) inmer zut ge= idjehen pflegt, aus ber Refre Darwin's : Soctalpolitif iafmieden faun.

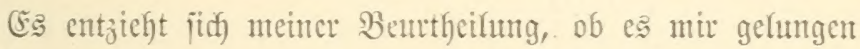

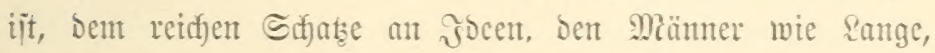

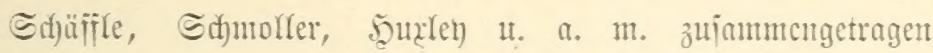
Gaben, einen einzigen neuen (S)ebanfen Ginzuzuïgen ober audf) mur bicjen Borrath originelf zu gruppiren. Denn bie überreidge Siteratur über bieje Jrage in affen Culturipradhen zu überblicfen, ijt beinahe ein Ding ber Unmöglichfeit. Fajt mö(d)te id) glauben, 


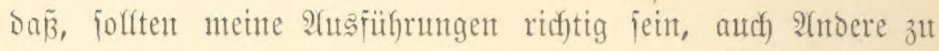
Demielben (ergebnifile gelangt fint ober Dod) gelangen werden. Denn won Den focen, jagt Sialton, gilt Dasjelbe, was von Den Aepfeln gilt. Wenn fie reif werben, fallen fie vom Banme, weldyer aber zuterĩt füflt, Gängt von allerlet Nebemumitündent ab, bie wir als 8 ufall z̆ bezeidynen pfígen.

Wien, im 2 (pril 1899.

Dex Derfallux. 


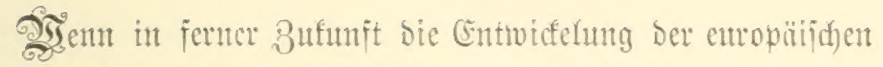
Bölfer in ber Beit vout Entoe des 17. Jafrefunderts bis ints

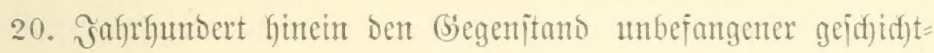
lidjer Betrad)tung bitben wirb, jo bürfte fein Blweifel Darüber

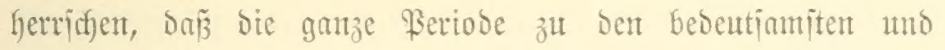

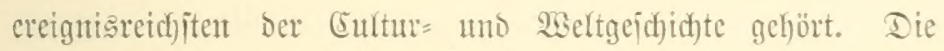

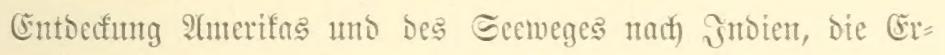

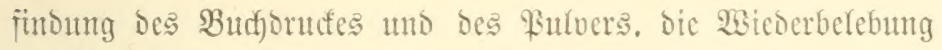
Der clajiiifjen Studien uno Die Emancipation bon ben mittel=

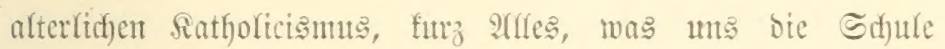

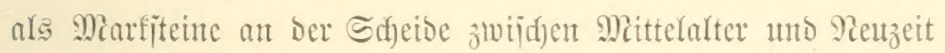

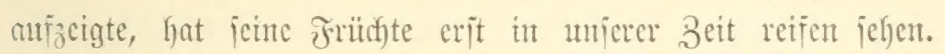

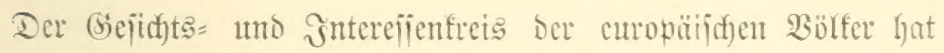

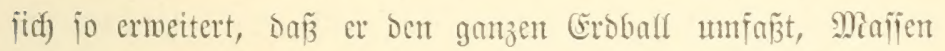
von Sugwanderern, gegen dic bic Stämme ber Bölferwanderung

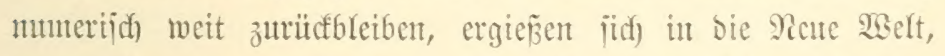

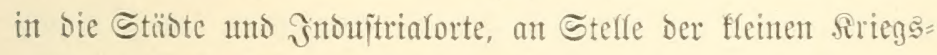
völfer Dce Mittelalters fino bie Mitllionentreere getreten, uno

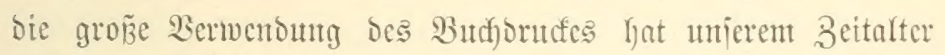
bereits ben Spottnumen des papierenen eingetragen. 2(tud) bie Wisilien=

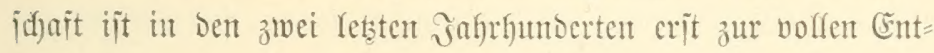
faltung gelangt, theils invem fie firf in zaflecidje Special=

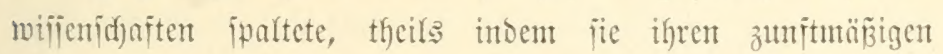


Cfyarafter abjtreifte uno Genteingut alfer Gebilocten murbe.

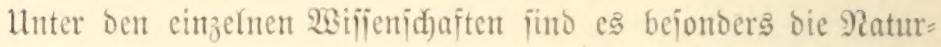

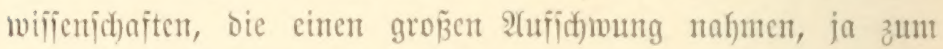
Theile erît ifgre Begrïnoung fanten.

So jefr uns mun aud bie ganze (Entwidfelung cine organiid)

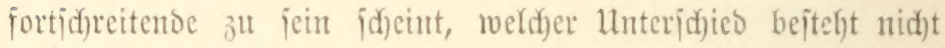

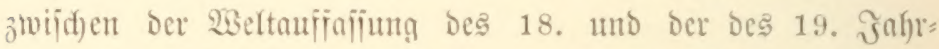
funterts? Dic füfrenden Seijter bes 18. Jafrlfunderts bejeclt

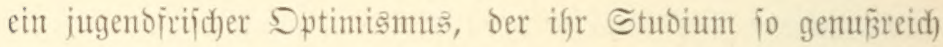
madft. Wie fid bem Manne mit Dem Talisman bie veriperten

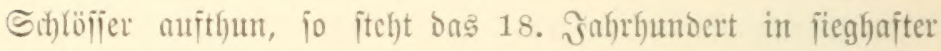

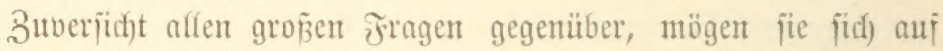
religiöjent ober jocialem Gicbiete betwegen. Sm Śegenjaze ljerzu erifheint bas 19. Jahrfumbert fait als eine 3eit Des Raben:

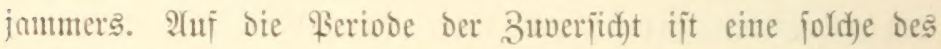

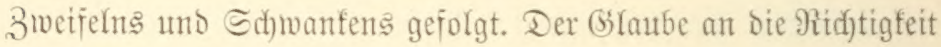
Des Rationalismus unto Der a priori gewonntenen Grfenntnis ijt gewidyen, ohne einem neuen affgemein anerfamten Slauben Flats zu machen. So jehen wir Denn, wie aut affen ben Ǵe= bieten, auf meldyen unjere Grop̃oäter uno Bäter eine gejid)erte Erfenntnis zu bejitisent vermeinten, ber größjte Theil ber pofitiven

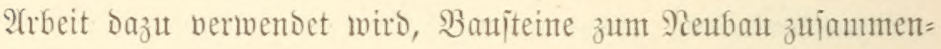
zutragen. Itno zwar jucht man Dieje Baujteme zunäd)jt in Der Bergangenleit; aus thr will ntan bie Gegenmart begreifen und Blicfe in bie Bufunft uncrien.

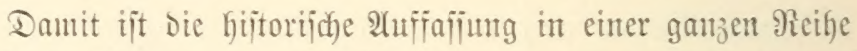
von seifienjidaften 3 ur affeinterridjenden ober mentgitens mit= bejtimmenten gemorden. Die Iheologie wirb hijtorijich wie die

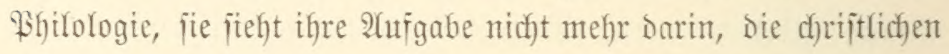
Dogmen unit Den Jorberungen Der Bernunft in Crinflang zut 


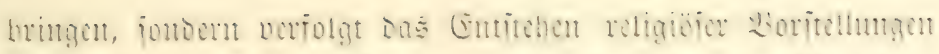

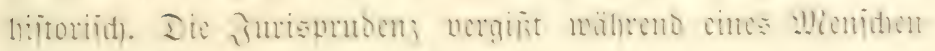

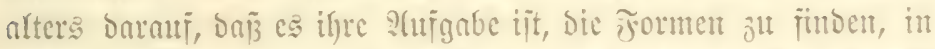

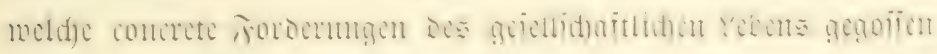
werben jolfen, uno gibt jid) volfitünoig dem Etubium Der (be=

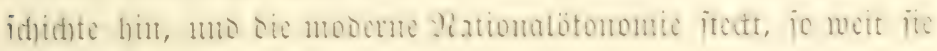

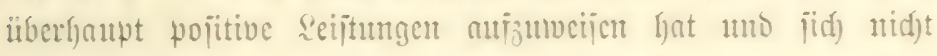

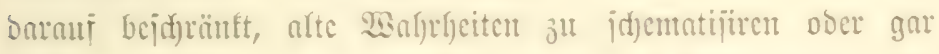

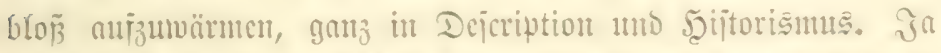

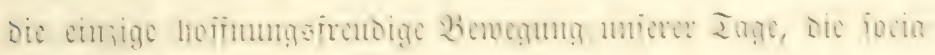

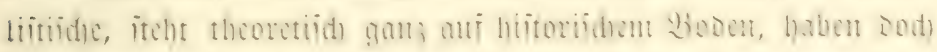

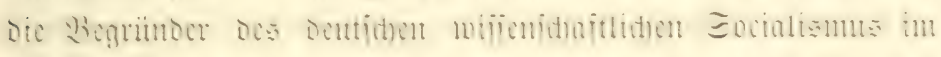

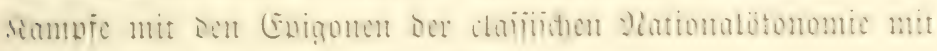

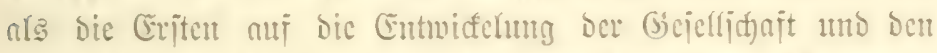

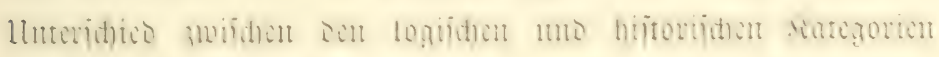

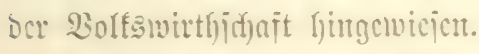

Diag man mun nod) jo jelyr über bic 3aghaftigteit Des gejdjidytlid)cu Pielativismus überall bort, wo es ju handeln gilt, ungeljalten jem, nag man aud) Dem flammenden Proteitc,

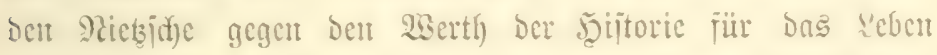

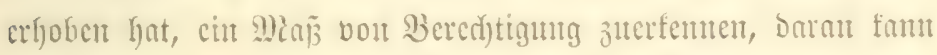

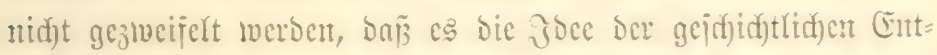

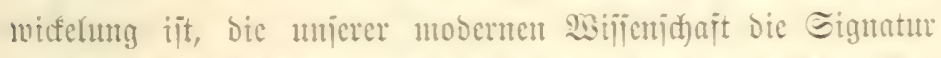

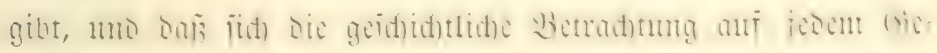

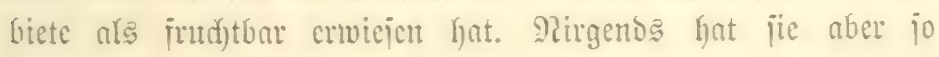
revolutionirend gewirft, wie in ben ?atumbijemidartent.

Jatte anj Dent Gebiete sct Tifronomic jeit Saplace

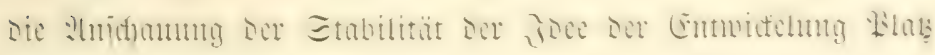

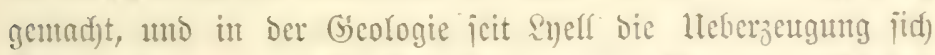

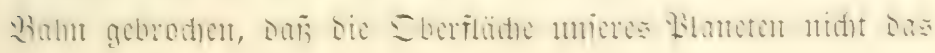




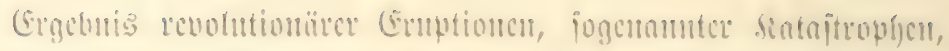

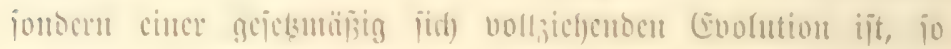

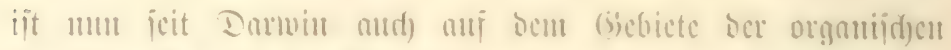

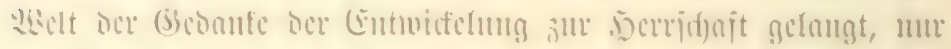

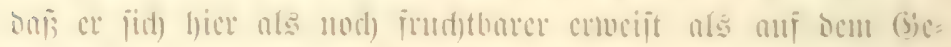

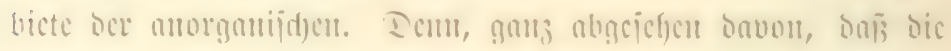

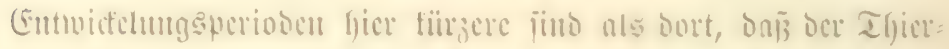

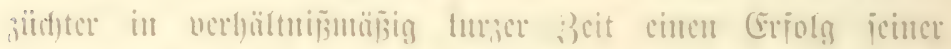

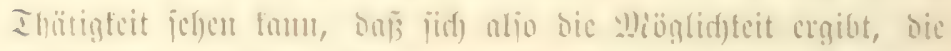

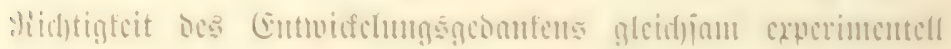

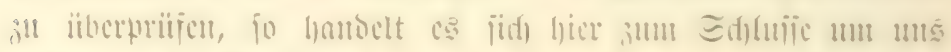

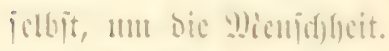

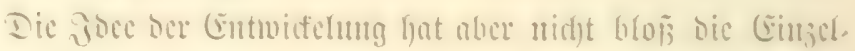

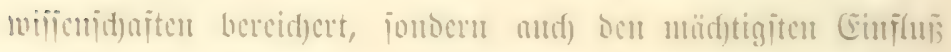

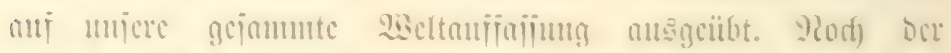

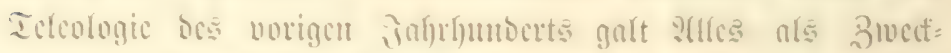

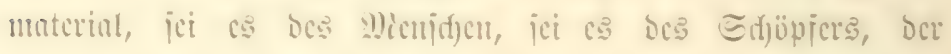

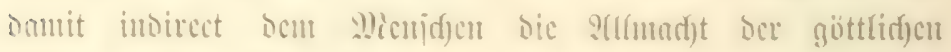

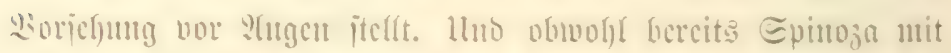

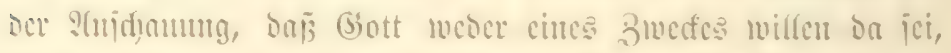

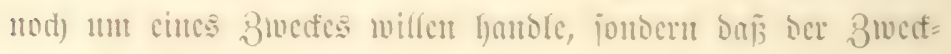

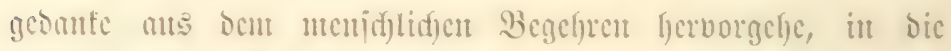
Icleologie cute Brejefe gelegt hatte, jo blicb es bod) Darmin

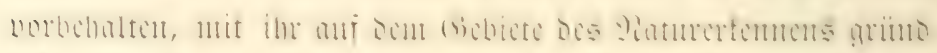

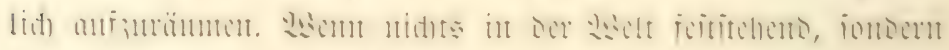

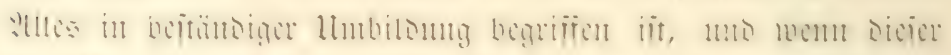

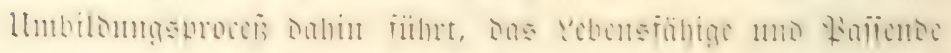

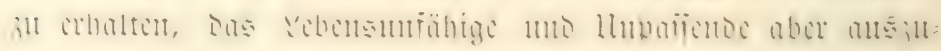

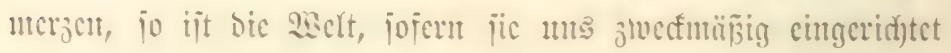

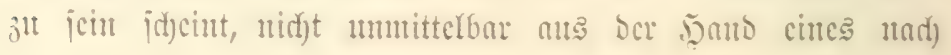




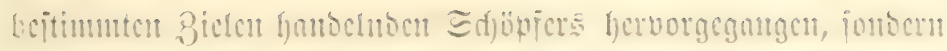

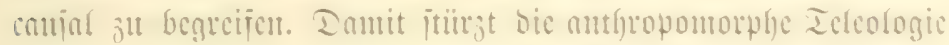

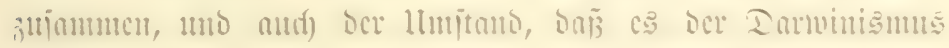

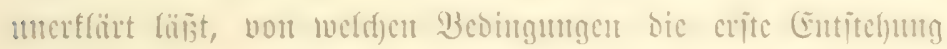

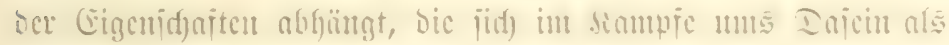

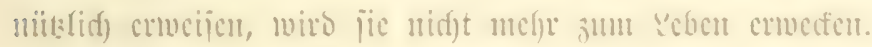

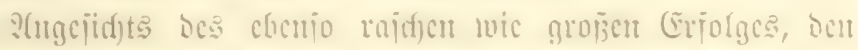

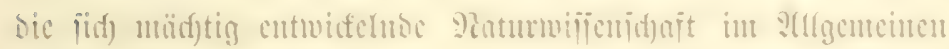

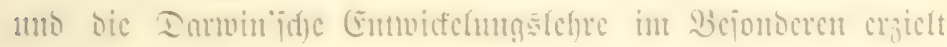

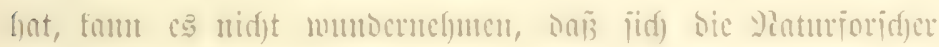

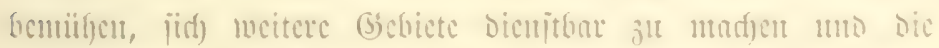

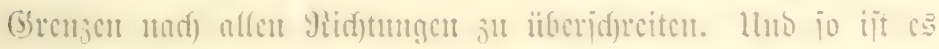

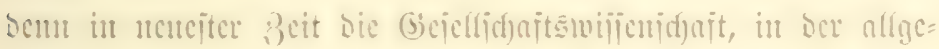

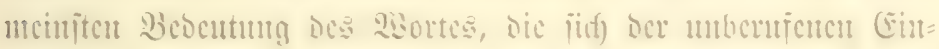

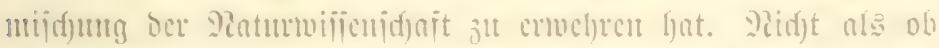

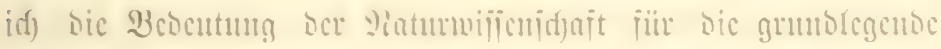

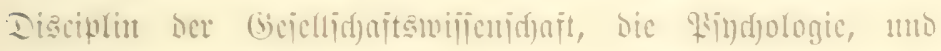

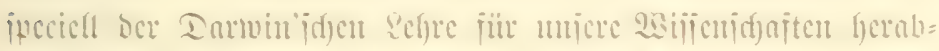

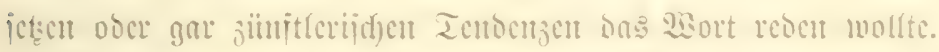

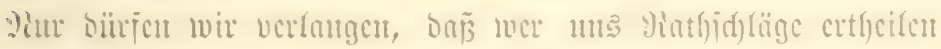

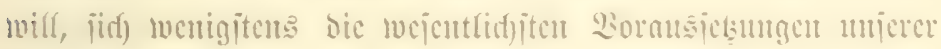

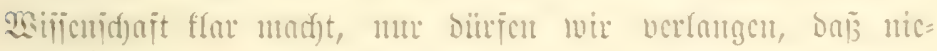

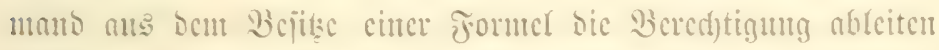

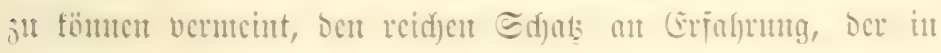

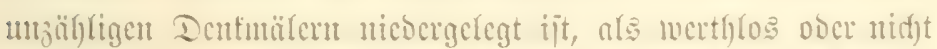

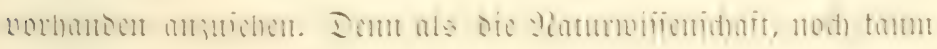

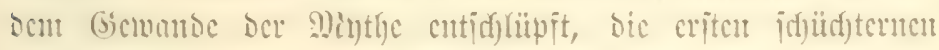

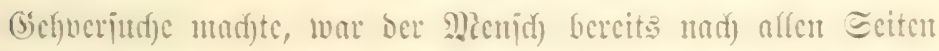

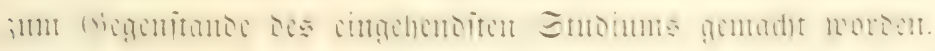

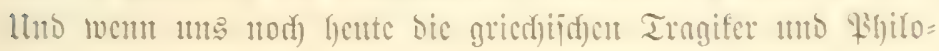




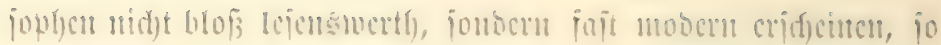

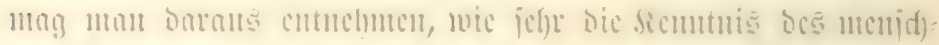

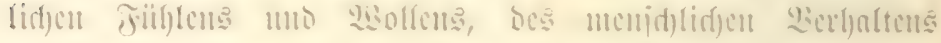

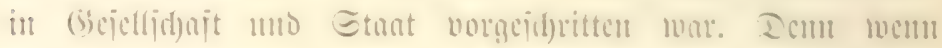

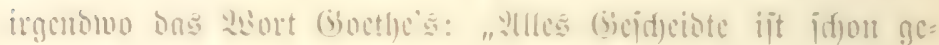

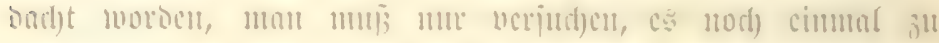

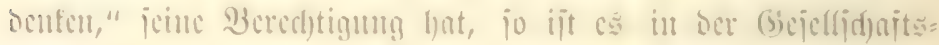
mijīm(l)nit.

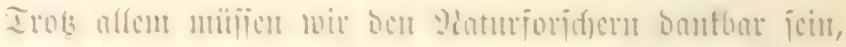

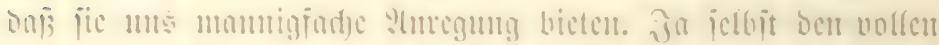

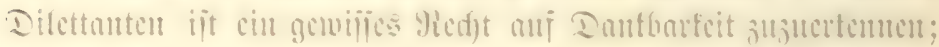

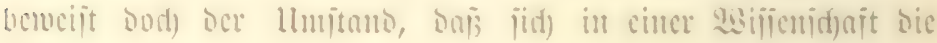

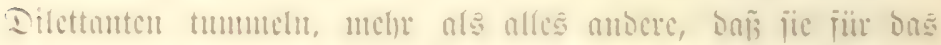

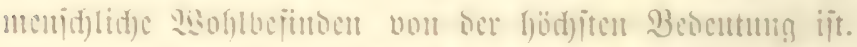

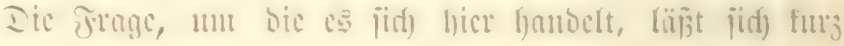

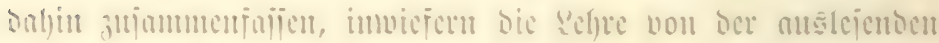

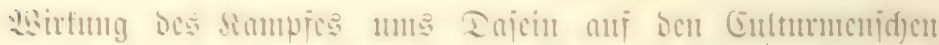

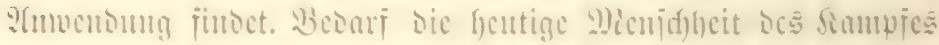

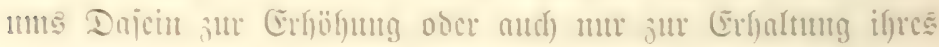

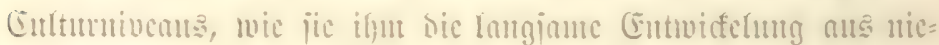

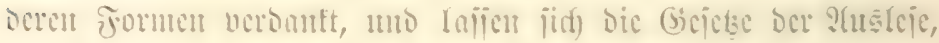
Die ganj ucjentlid) ber Betrad)tung bes Ifjex= uno Fiflanjen=

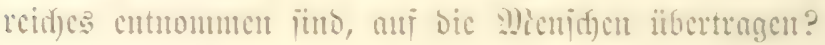

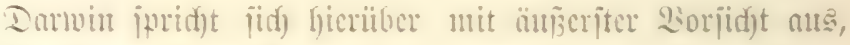

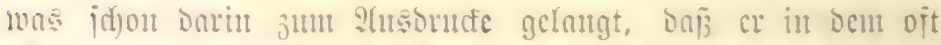

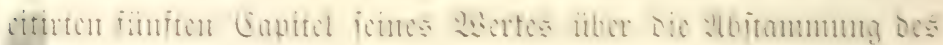

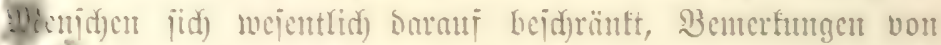

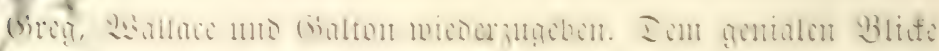

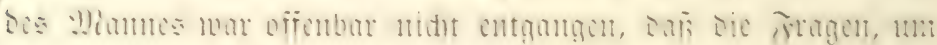

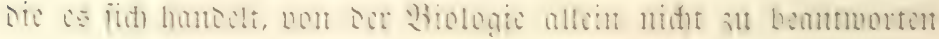




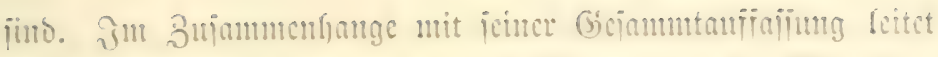

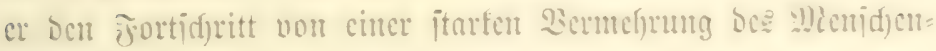

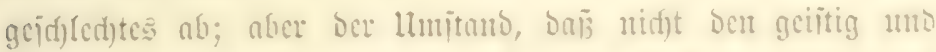

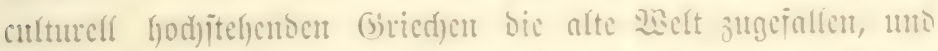

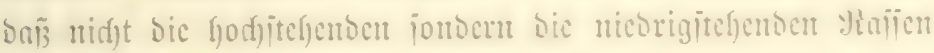

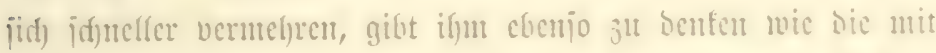

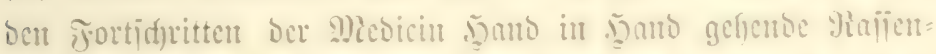

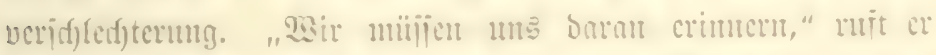

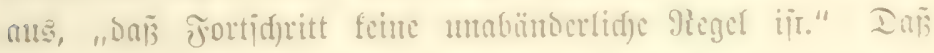

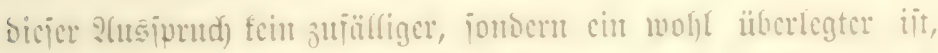

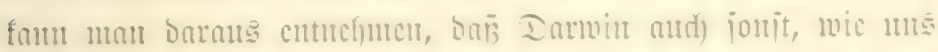

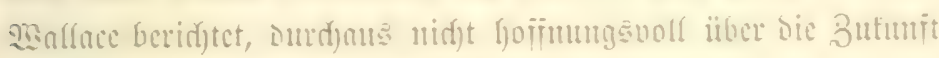

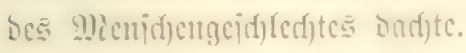

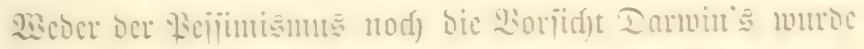

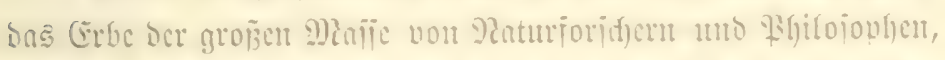

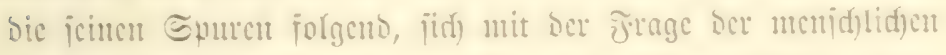

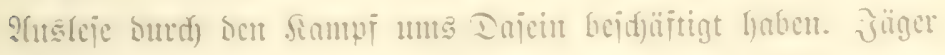

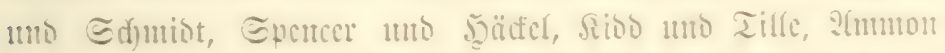

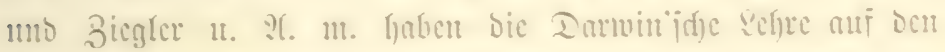

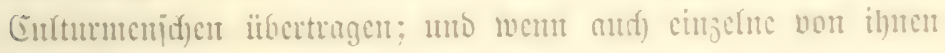

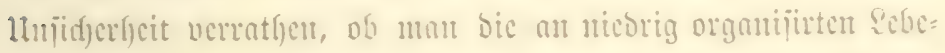

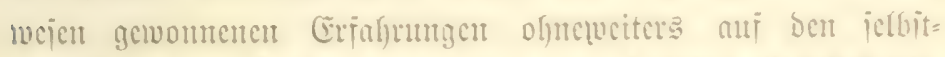

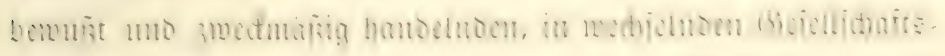

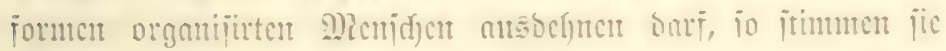

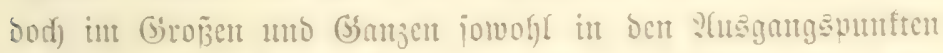

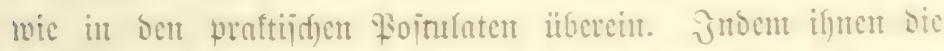

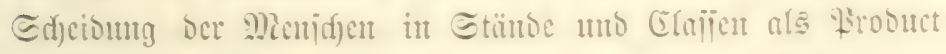

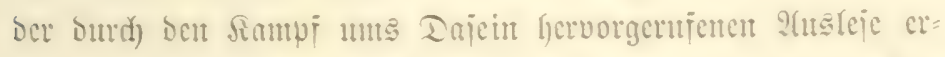

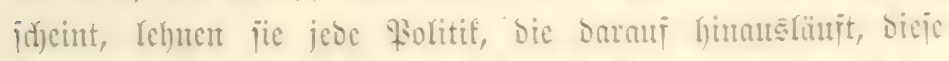

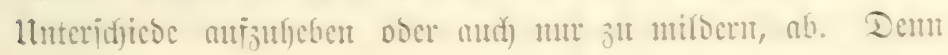




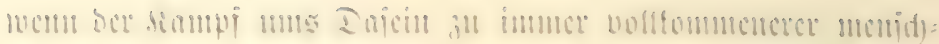

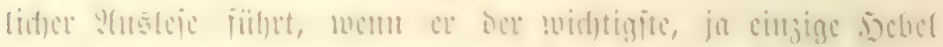

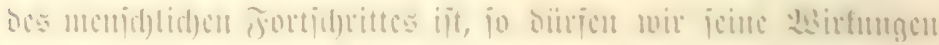

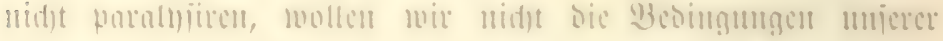

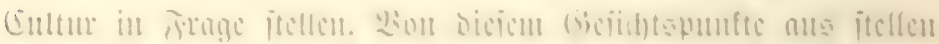

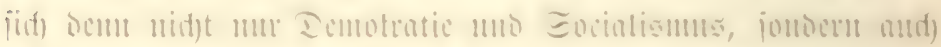

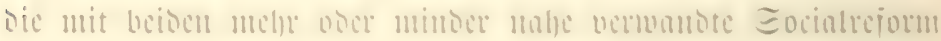

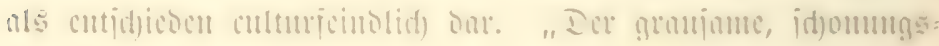

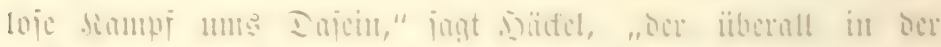

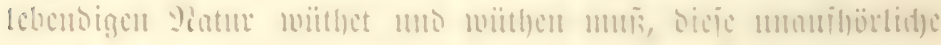

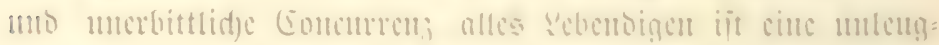

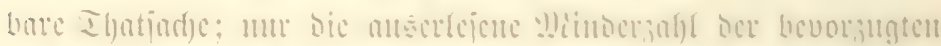

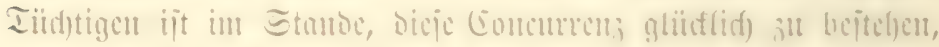

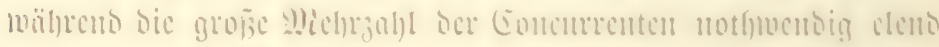

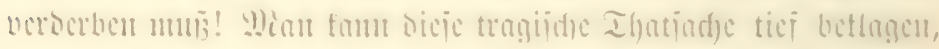

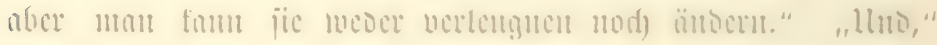

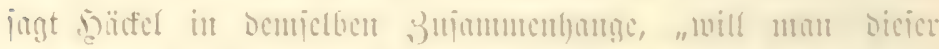

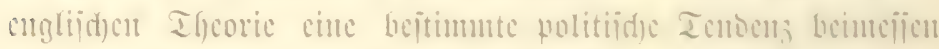

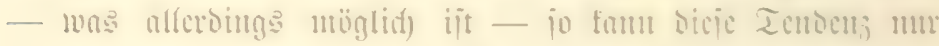

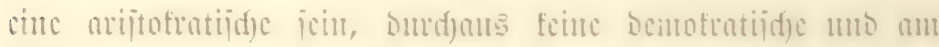
monigiten cine jocinliptiidse."

Bevor wil jut Sirtif bicicr ?(nj)

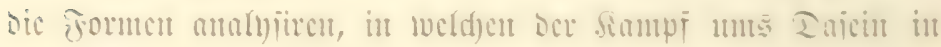

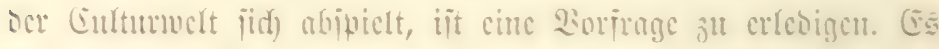

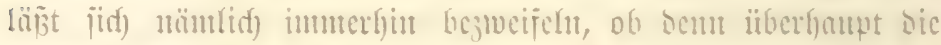

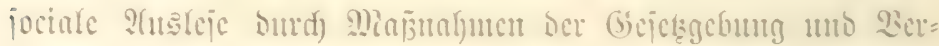

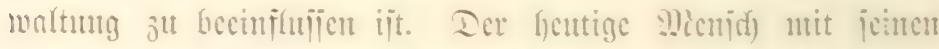

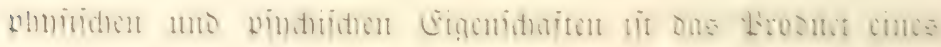

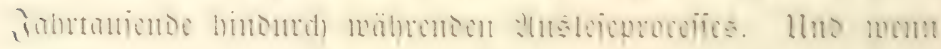

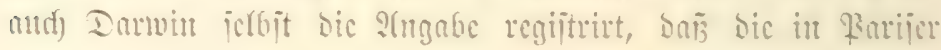




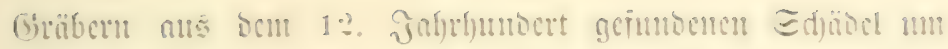

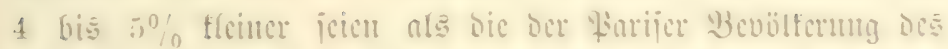

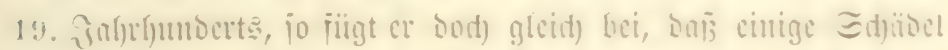

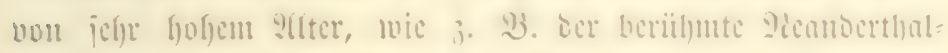

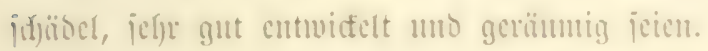

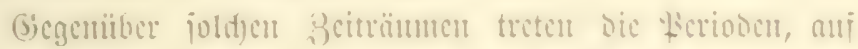

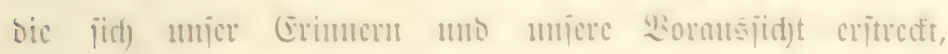

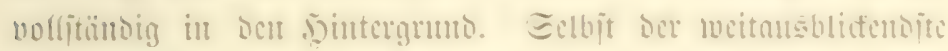

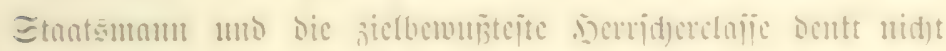

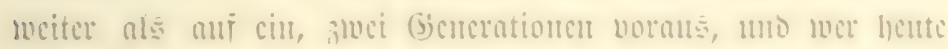

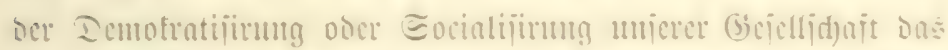

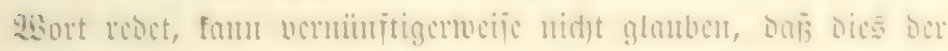

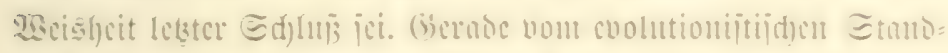

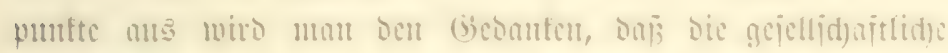

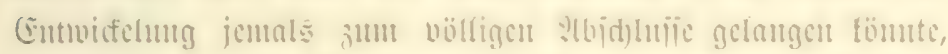

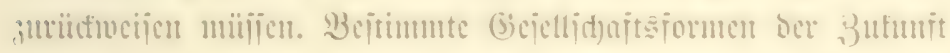

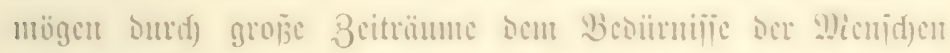

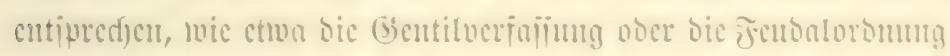

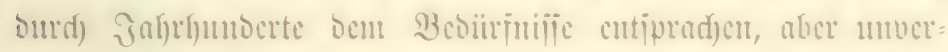

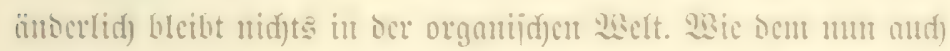

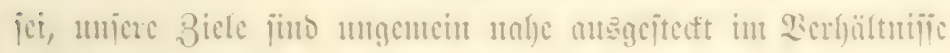

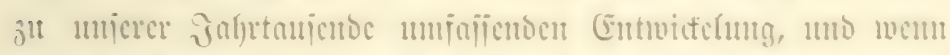

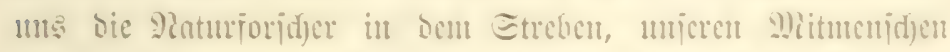

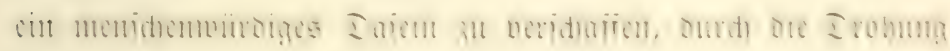

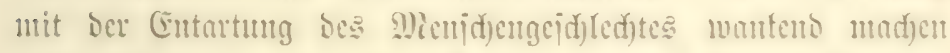

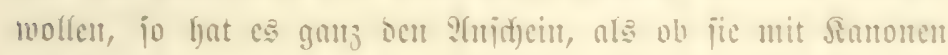

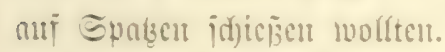

Dies gilt bejontrers non Denjenigen Platuriorid)en, bic jift) ber vou 2secismant mobificiten Darvinijden sefle ange= idflofien bathent. 


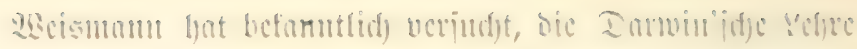

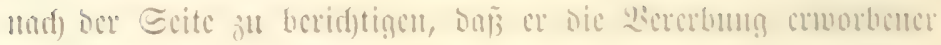

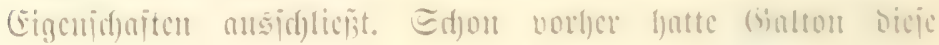

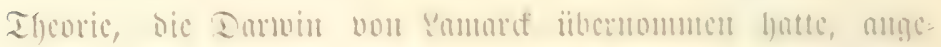

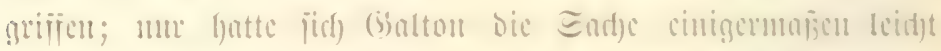

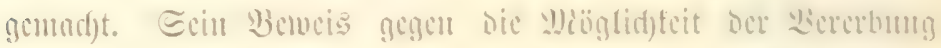

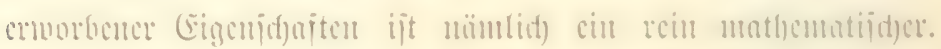

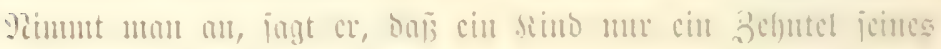

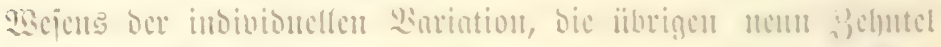

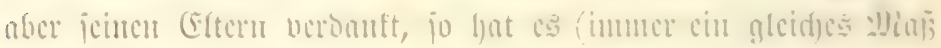

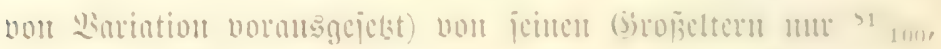

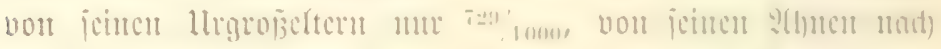

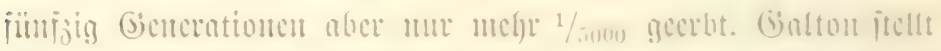

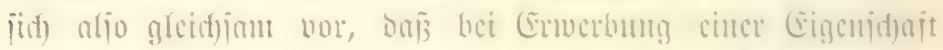

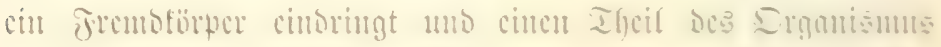

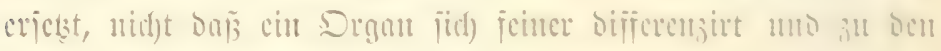

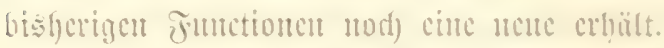

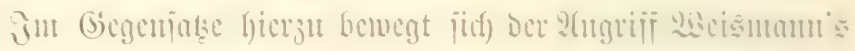

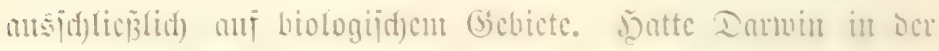
Ifycoric bout ber jogennunten Fangencits angentonumen, daj

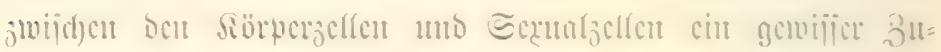

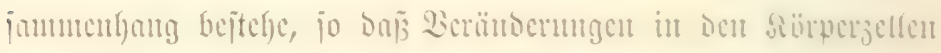

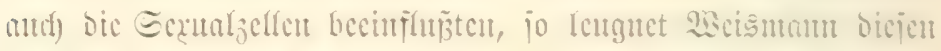
8ujumucuthang. Sicimprotoplasma und Sïrperprotoplas̄ma

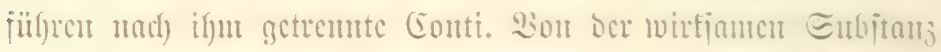

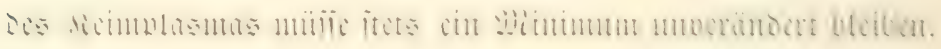

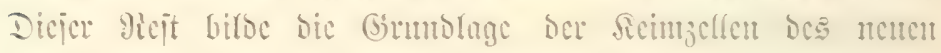

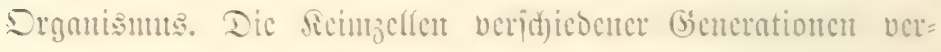

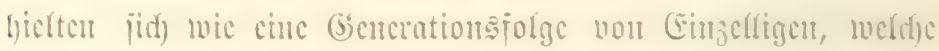

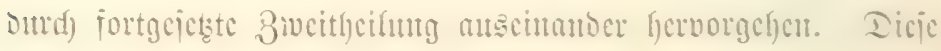




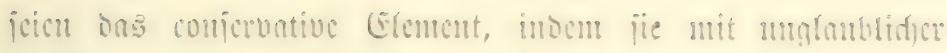

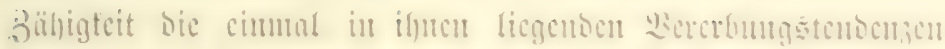

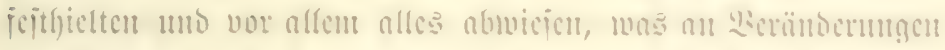

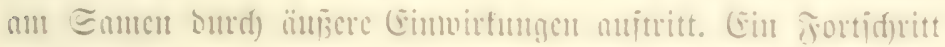

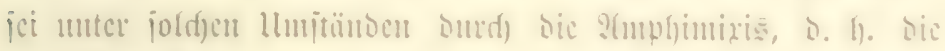

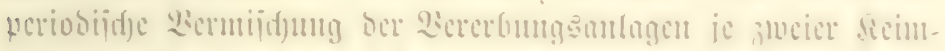

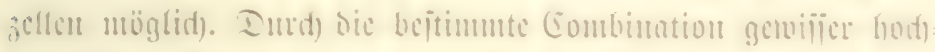

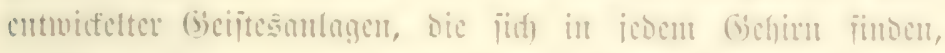

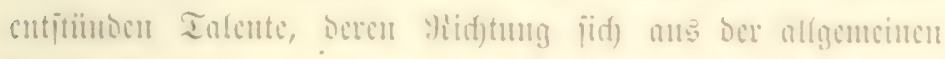

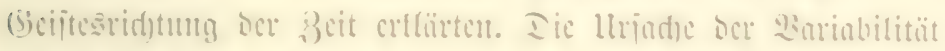

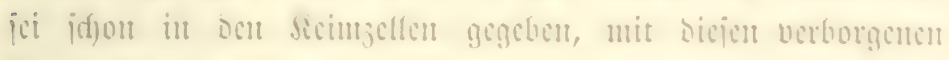

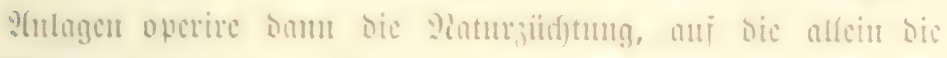

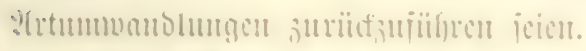

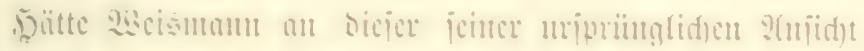

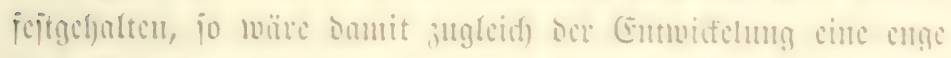

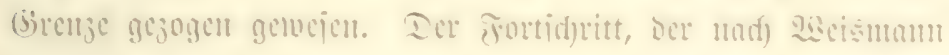

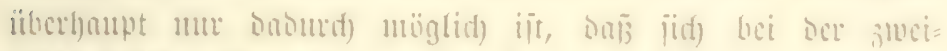

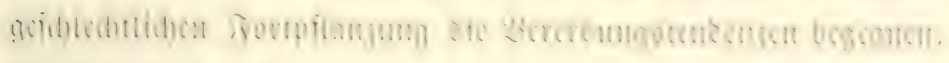
bic jujummen che günjtige Combination ergefon, bätte feme

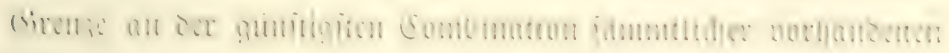

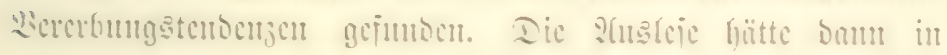

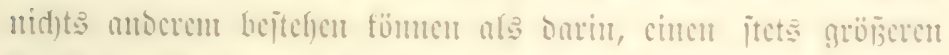

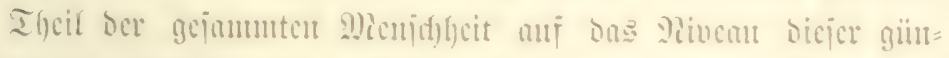

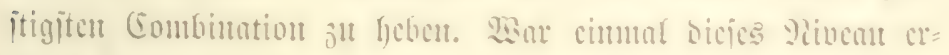

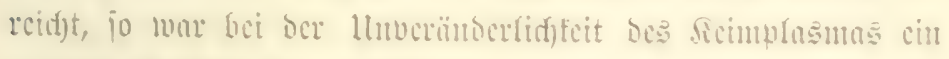

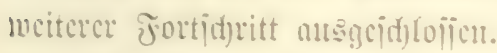

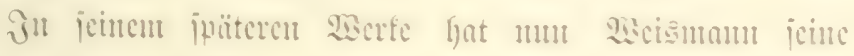

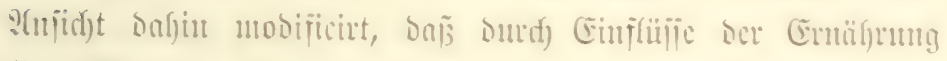
ciute P(enoermug ber cingeluen Biopforen uns Determinanten

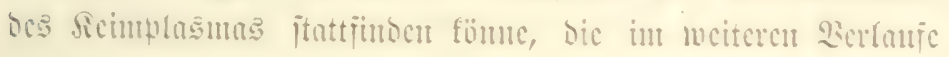




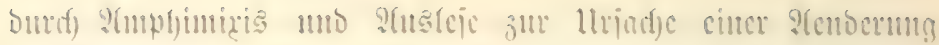

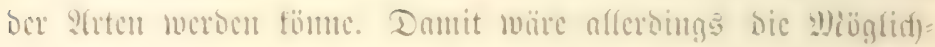

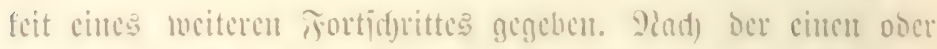

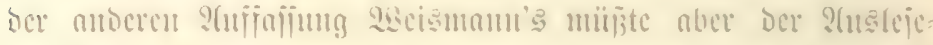

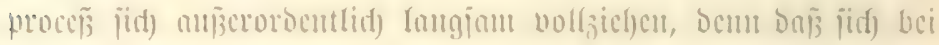

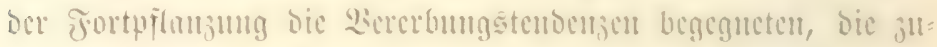

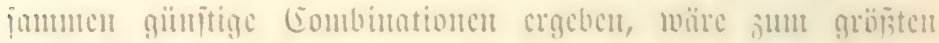

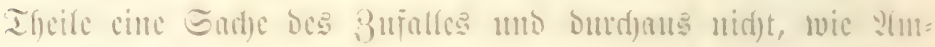

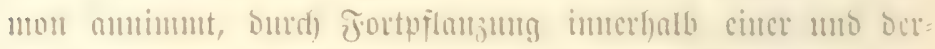

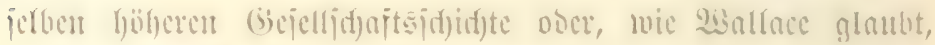

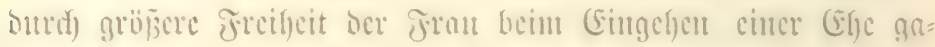

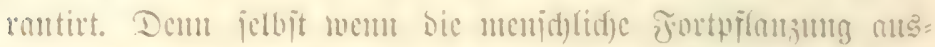

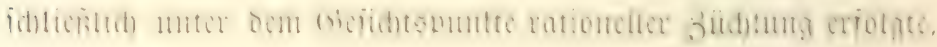

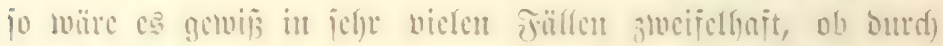

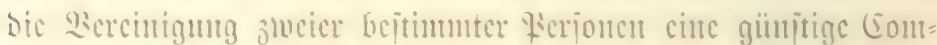

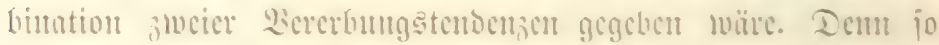
cimpad) wie in bem Beriptele, bas me Ginlton giht, liegen bie

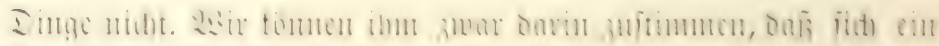

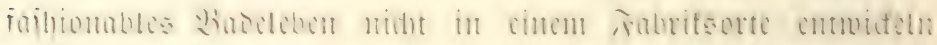

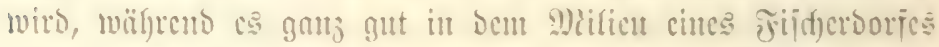

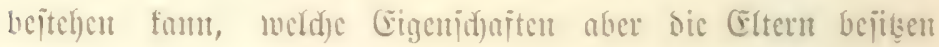

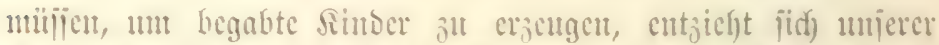

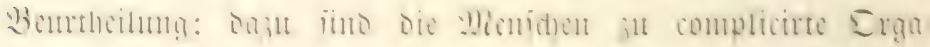

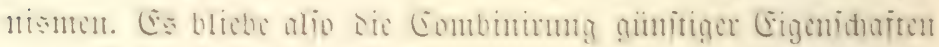

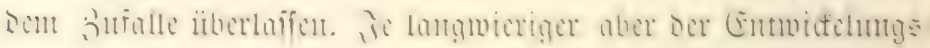

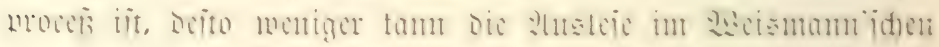

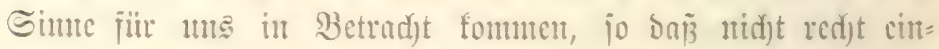

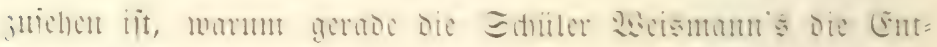

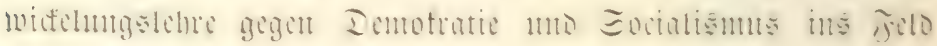
füf)ten. 


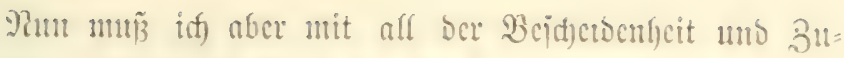

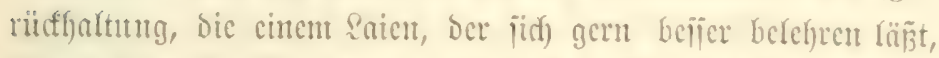

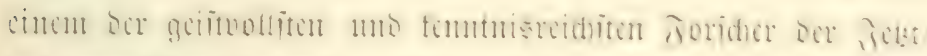

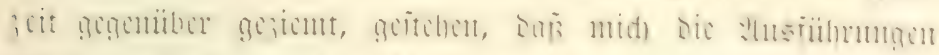

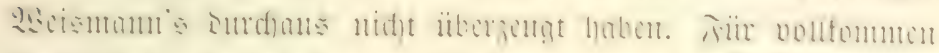

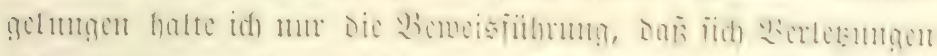

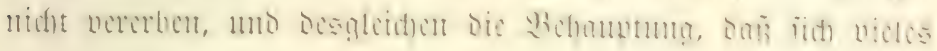

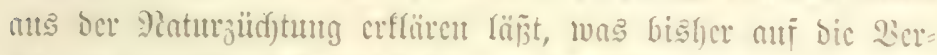

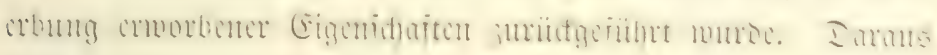

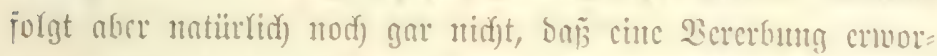

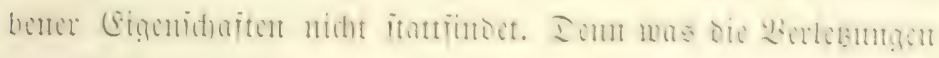

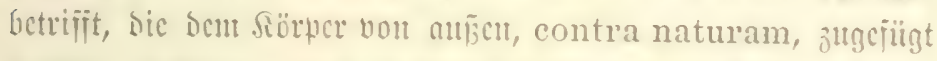
werocn, jo folfen jie mit ben Ëigemidgnften uno Fäfigfeiten,

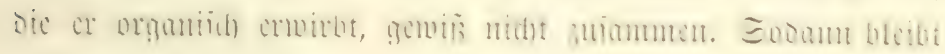

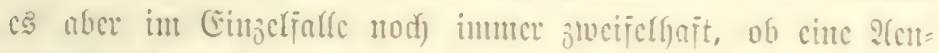

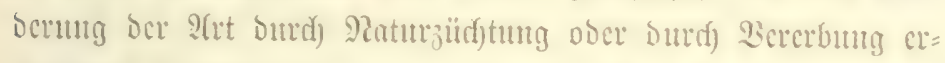

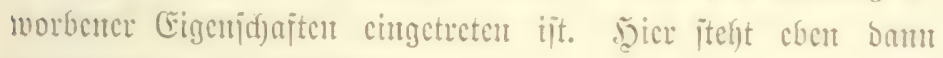

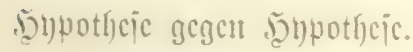

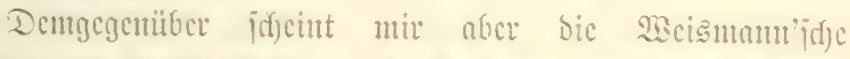

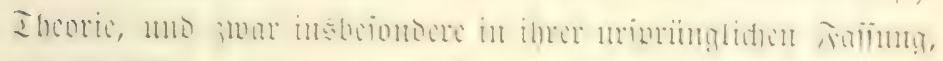

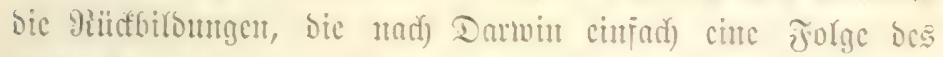

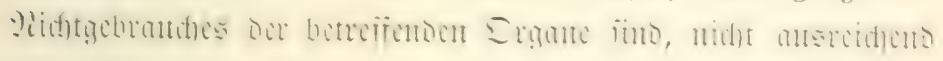

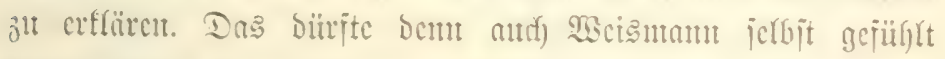

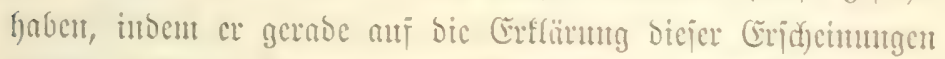

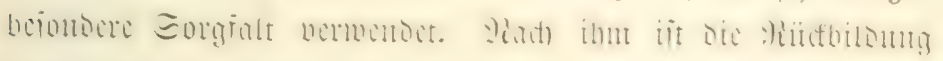
cuncricits bas Frobuct ciner gewifien Sefontomic in ber Pintur

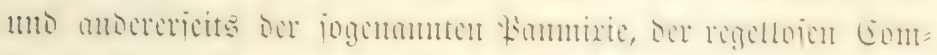

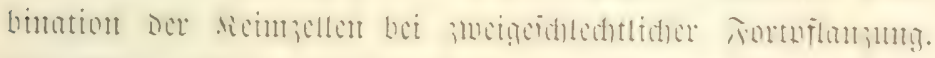

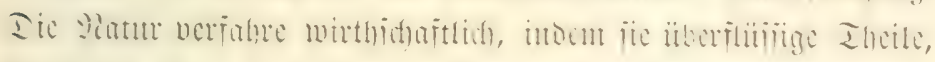

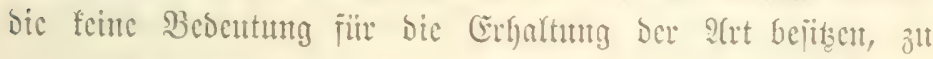


Gimpten mberer climinire. So jei bas. ?tuge bes birotten-

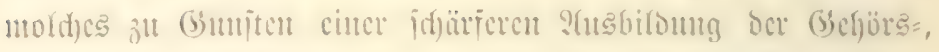

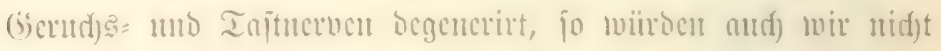

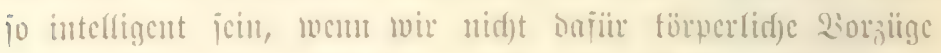
unjerer ?(f)nen cingebriijt fü̈ttur. Der Jortid)ritt nuf ber cincu

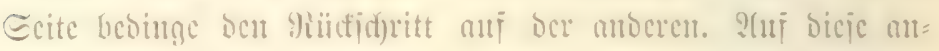

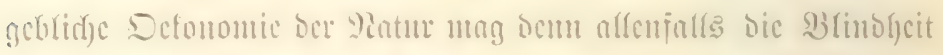

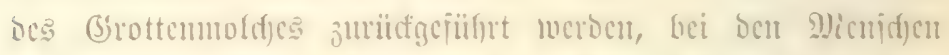

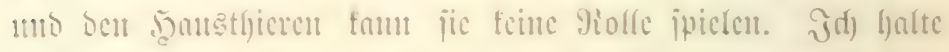

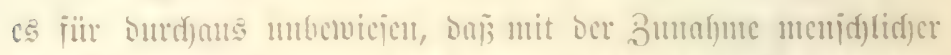

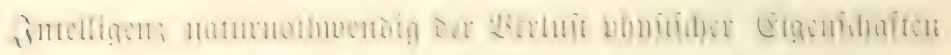

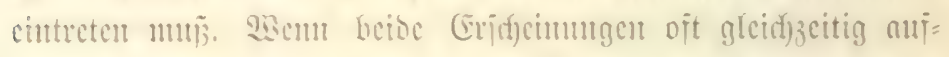

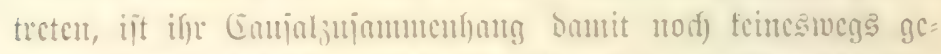

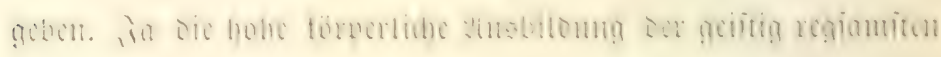

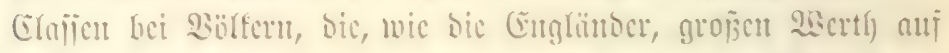

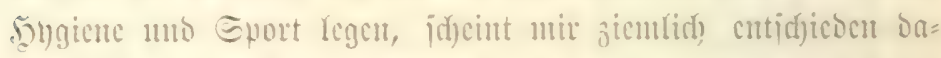

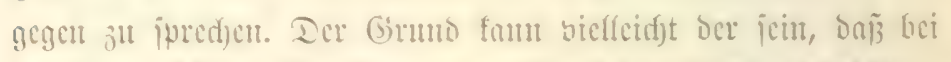

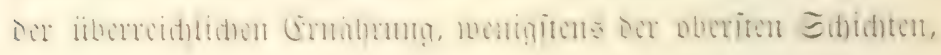

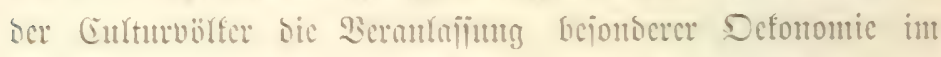

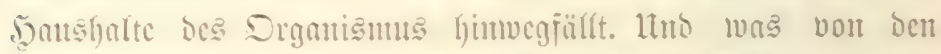

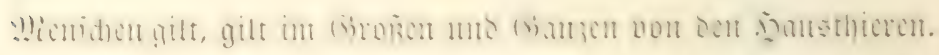

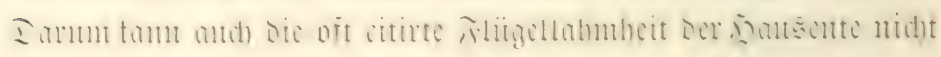

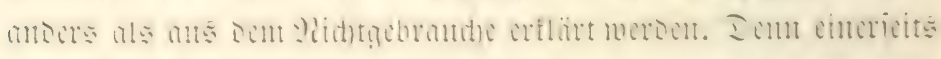

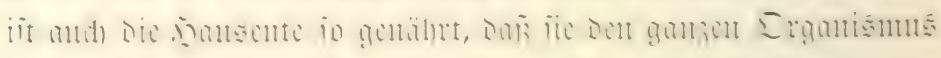

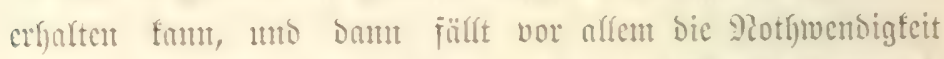

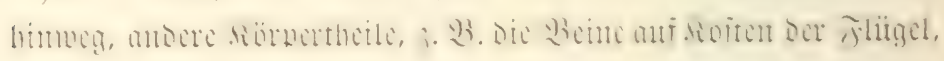

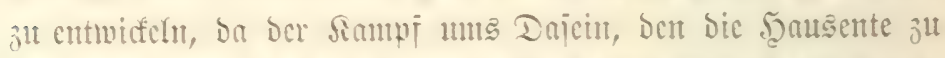

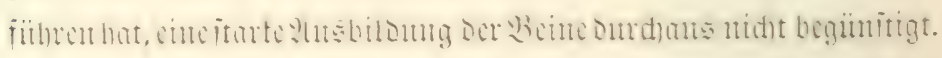

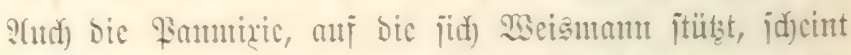

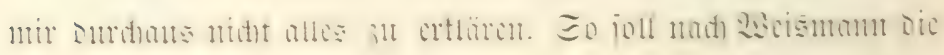




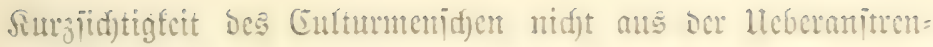
gung hervorgelfen und jobann vererbt merden, jondern viefmefys

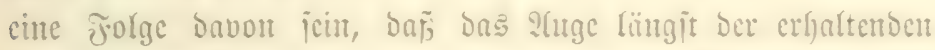

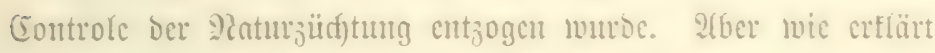
bie Fanmixic bic Thatjadje, Daj in cin mo berjelfocn $\Xi$ djulc

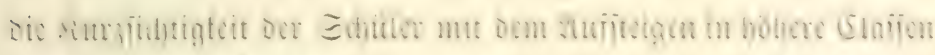

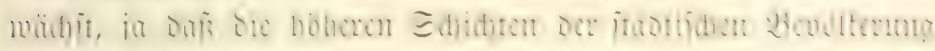
furjïd)tiger jimb als bic nicorigeren mo dieje wicber fur

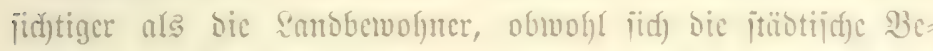
vöfferung jum Theile ats ber Eanbbevölterung crgängt mo ob=

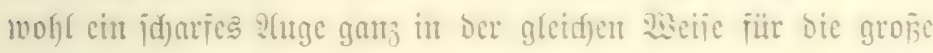

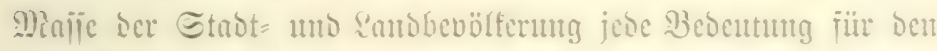
Santuf ums Dajein verlorent hat? lleberfantpt jufint cs mir

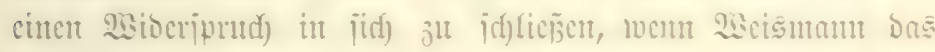

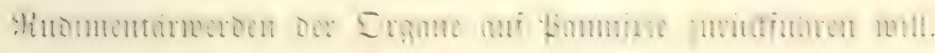

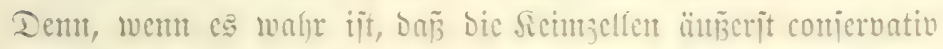

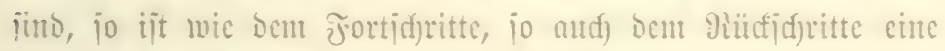
enge (jirenje gejogen.

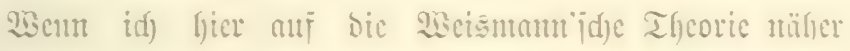
cingegangen bin, io gejdyah es nidgt beshalb, weil jie hente ben

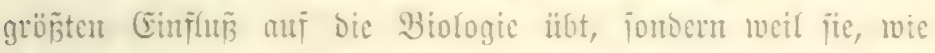

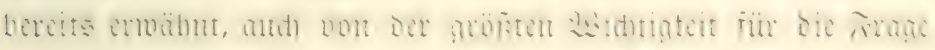

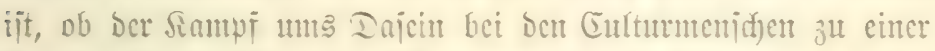

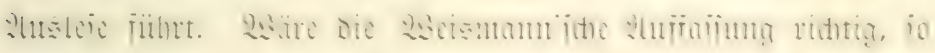

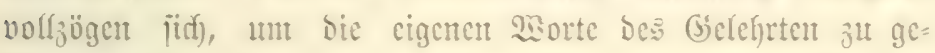
Graudjen, "Dic Sieründerungen Des Srganisntus in fleiniten Sdjritten", jo Don jie für mijere jeitlid) jo eng begrengtent

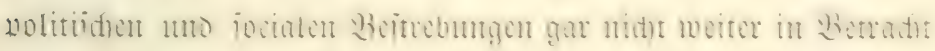

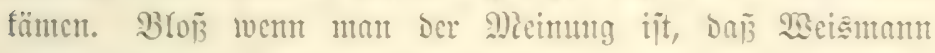

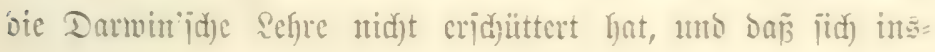




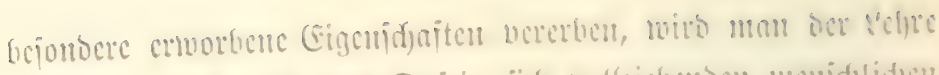

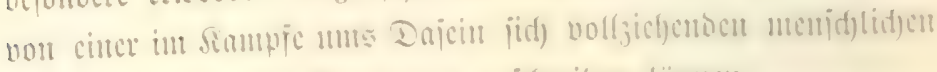

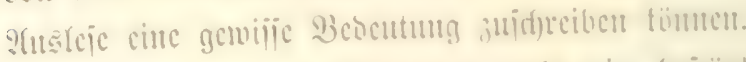

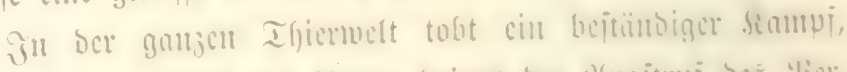

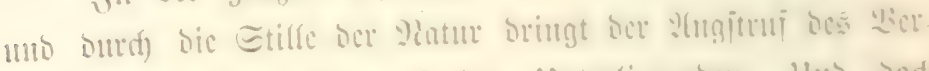

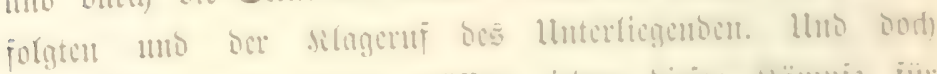

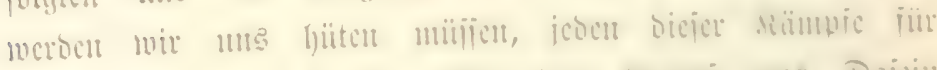

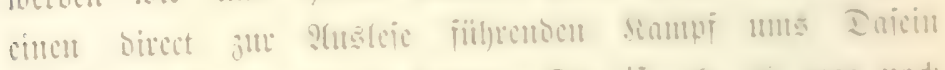

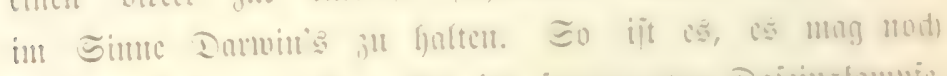

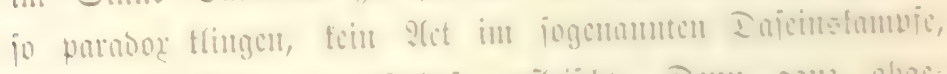

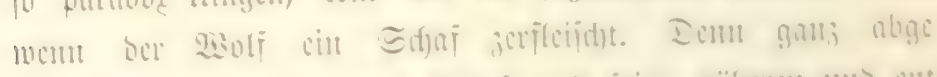

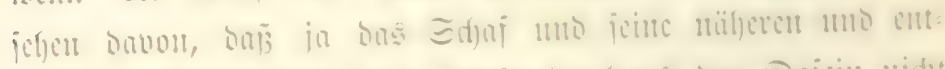

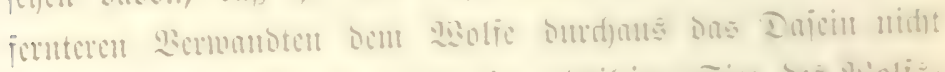

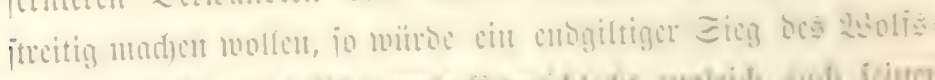

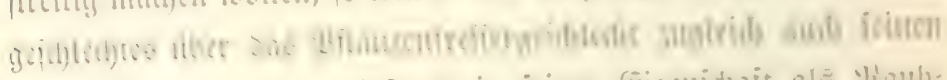

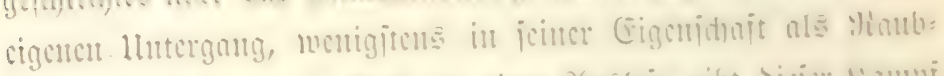

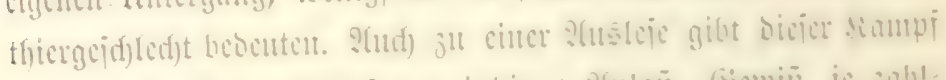

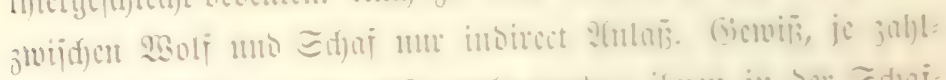

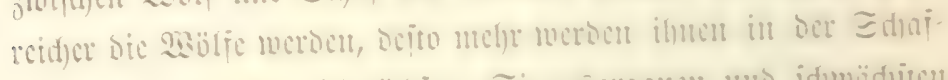

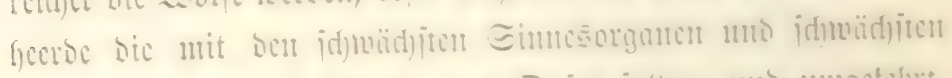

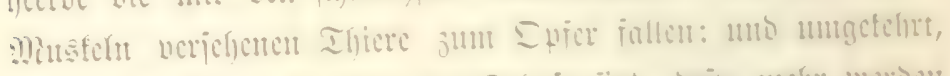

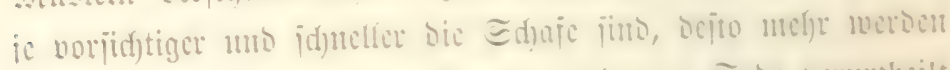

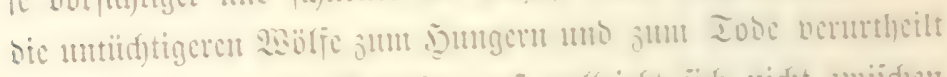

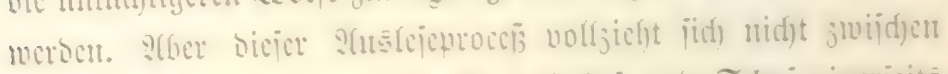

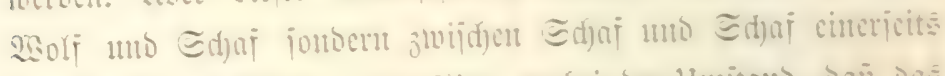

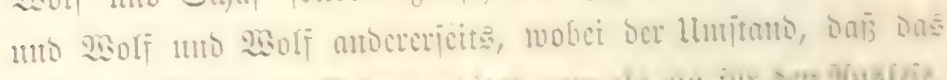

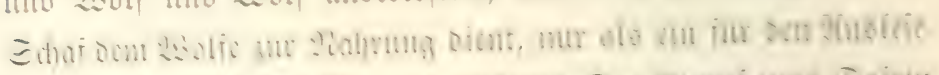

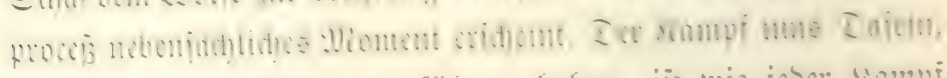

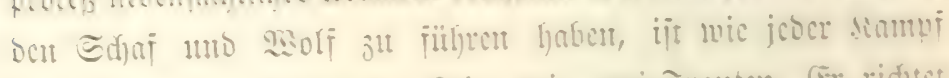

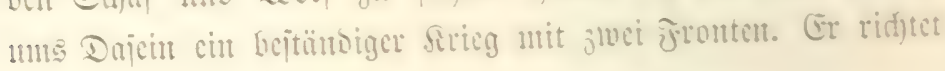




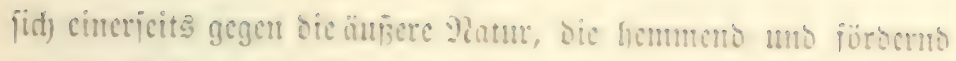
in bie Exiftenj ber :lut cingreijt, mo moererjeits gegen alle

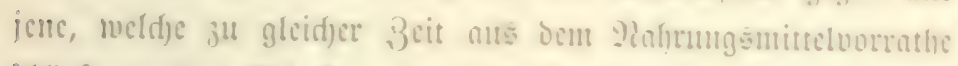

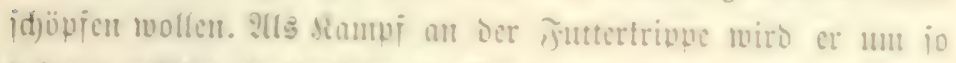

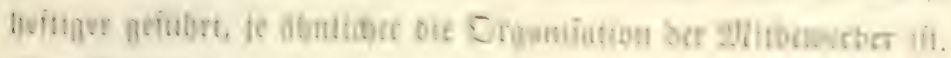

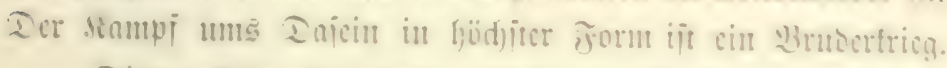

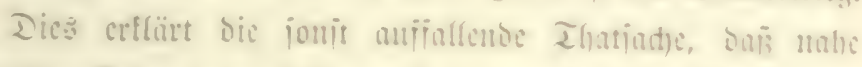

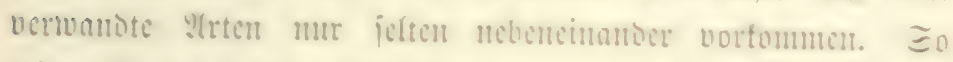
wimmelt ces iberall von Frimilu, ater bic Primula veris mäd)it vormiegeno nui gaicien, Dic Primula vulearis in Wälocm, uno an cin umo serielfen Etclle trifit man beise mu

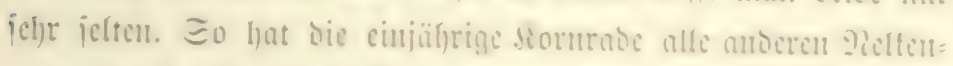

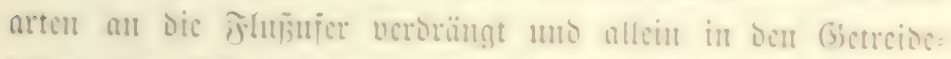

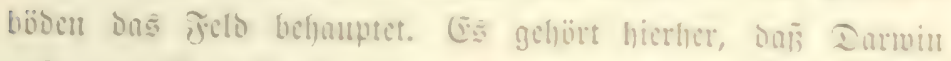

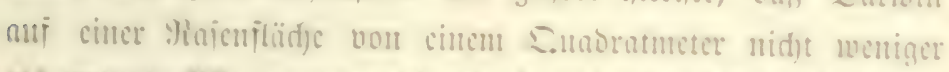

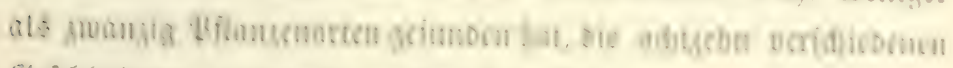
(iscid)led)tern uns adft nutürlid)en Erbmungen mughörten, cin

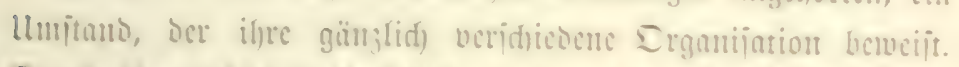

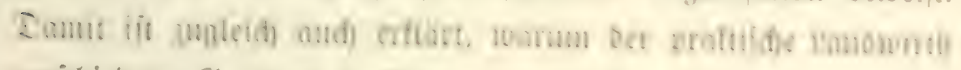

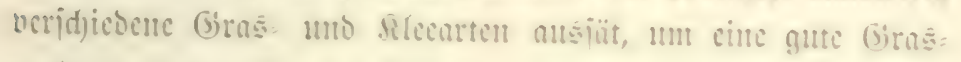
nathe ju erhalten, unto marmu jolde ssiejen mit gentid)ten

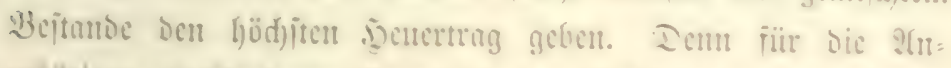

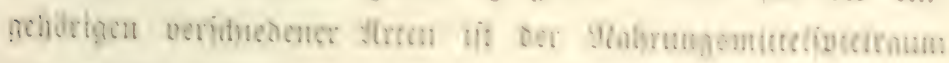
cin relativ weiterer, weil iffe verid)iedente Erganijation ber: idjesene 2lälyritolie criorsert.

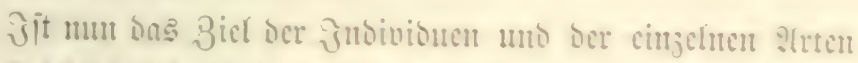

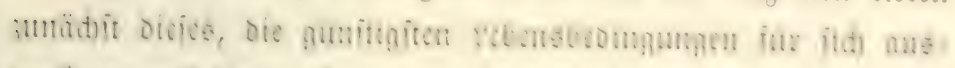

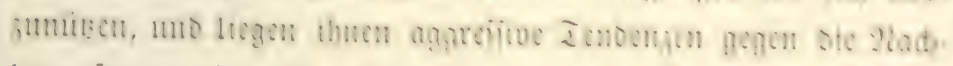
barn iern, wiro alio ber Sampi unts Dajein indirect gerïhrt,

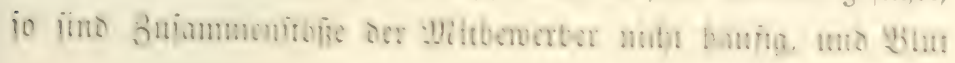




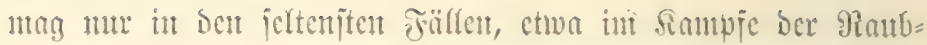

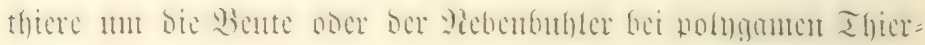

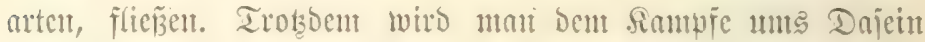
bie S(ttribute bes "Utnerbittlid)en" uto "Grampanten", bie ijut

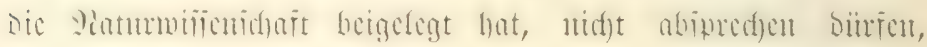

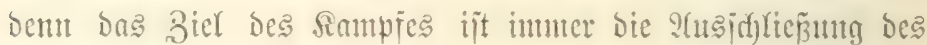

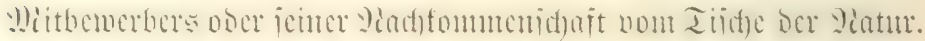

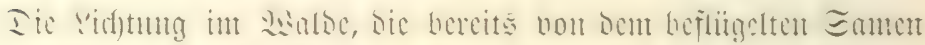
Der Birfe beoceft iit, fann päter von einer anderen Bamnt=

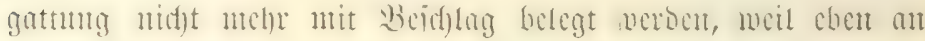
Der Stelle, two mur jül cincut Bamu Bratz ijt, nid)t zloci

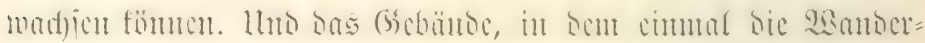

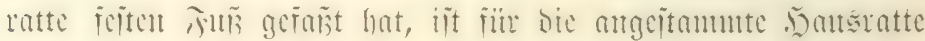

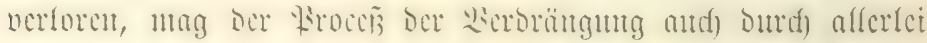

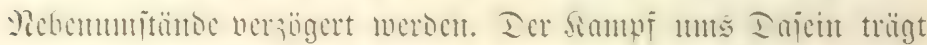

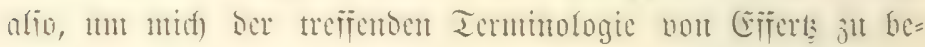

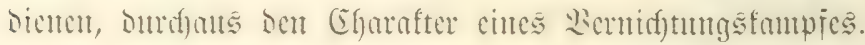

Into Juer ijt Der Sieger in Diejent Sampie; wer bleibt nad)

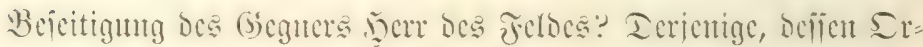

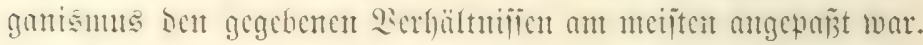
Ser Faliendite iit aber, mo bas milijen wir uns jür bie Folge merfen, ourd)uts nidjt ber an uteijten Pifjerenjirte ober gar

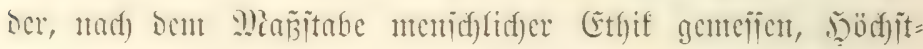

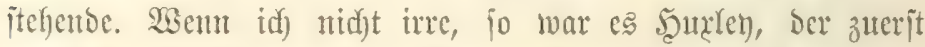
gegat bic mthropomorphe Ientung oce Iarminidfen sefre 3it Felde gezogen ijt. Wenn mier Groball inmer mehr

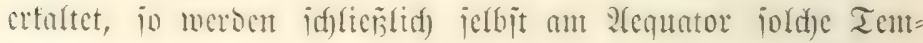
peraturberbältuijie herridsen, wie hate am Deropol. Bei

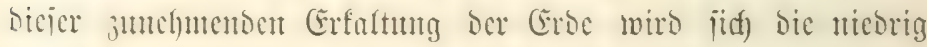
organifite Flora bes Morbents in ber Midytung gegen 


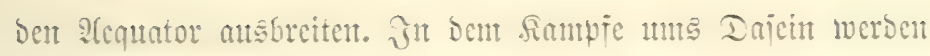

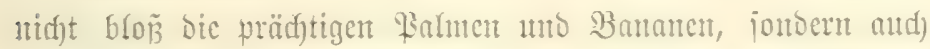

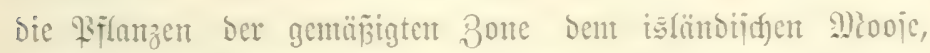

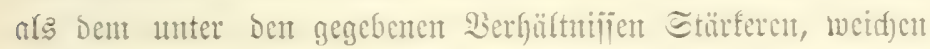

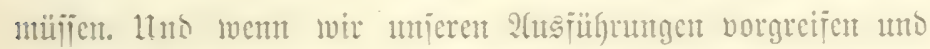

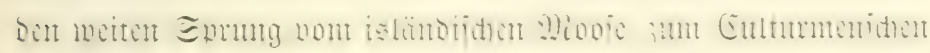

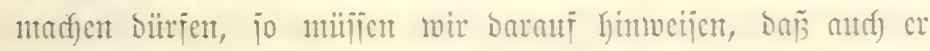
feinestvege inmer Der Eieger in Dajeinsfampre ijt. Jut ben Iropent wito er bas Spjer bes gelfen Fiebers ober anderer Siranffyciten unt unterfiegt bafer int Sampie ums Dajeitt Den

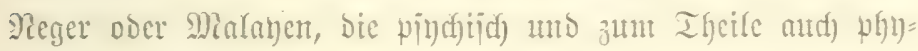
iiidi) ticī unter ifut itehen.

Uno was vom Sempje ums Iajein gilt, gift aud) bon

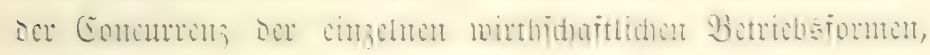
Die öfter mit jentent berglidyent inurde. 2(ut) in Conturrenz=

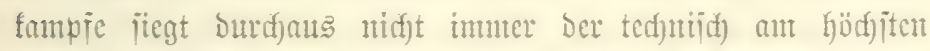

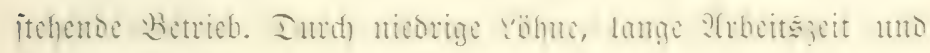

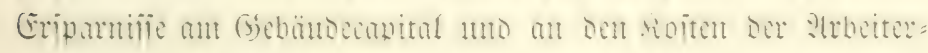

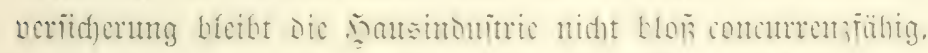

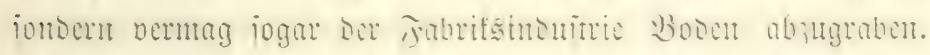

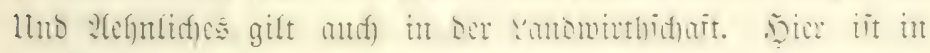

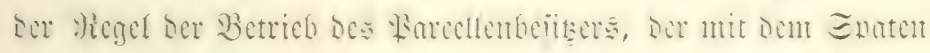

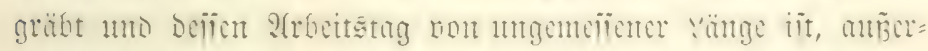

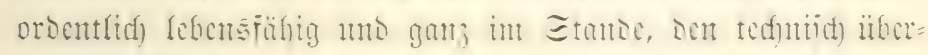
Iegenen Mittel= unto Grop̈betrieb zu verorüngent.

Reben Dicjem eigentlidjen Sampie ums Dajein gibt es nut in ber शatul Rämpre mo Berfältnifie, bic idf nad)

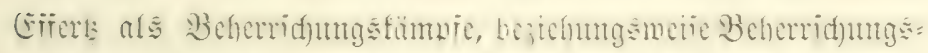

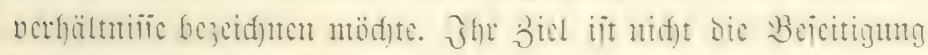
jondern bic Danembe Putgbarmadfung des (Segners jür Dic 


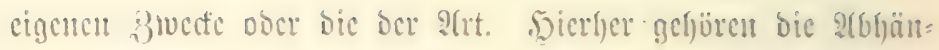

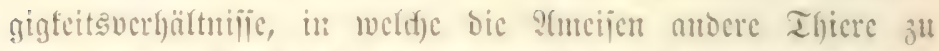

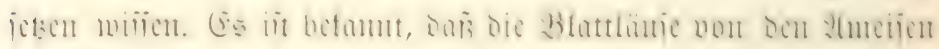

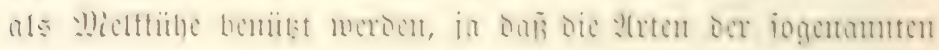

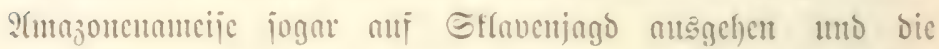

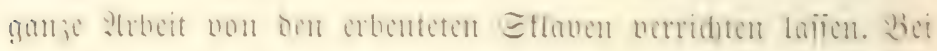

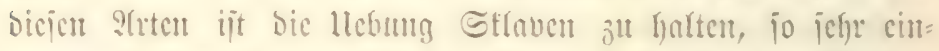

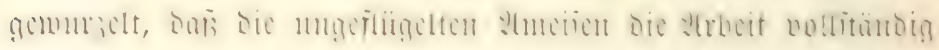

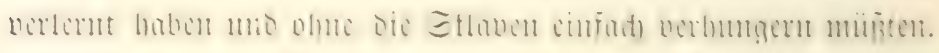

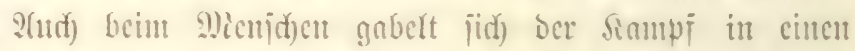

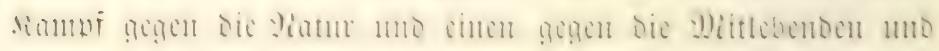

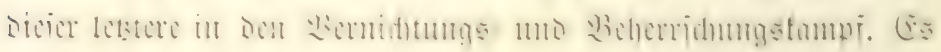

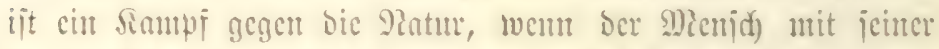

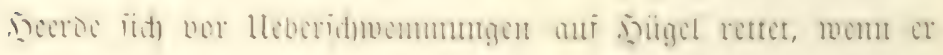

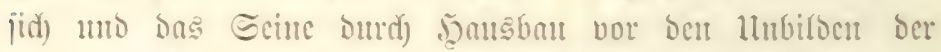

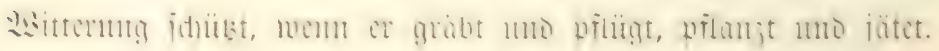

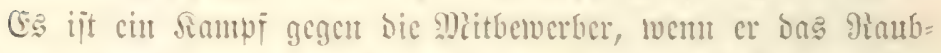

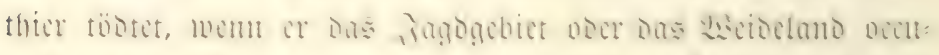

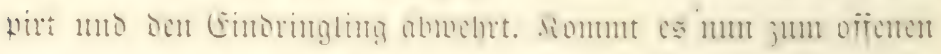

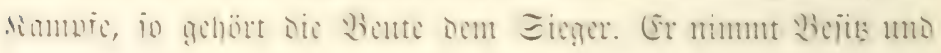
fan ben Bejiegten vernidjten. (E) thut dies aber nidjt inmer.

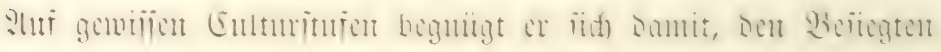

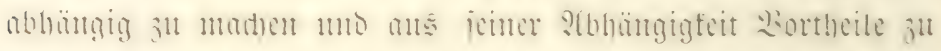

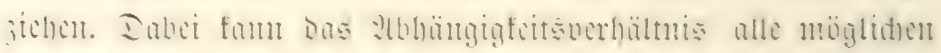

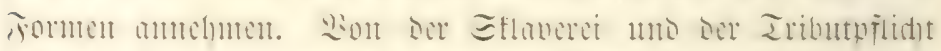

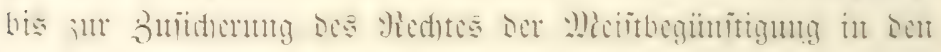
Zoll= unb Danbelsucrträgen ober gar Des Red)tes, mit Dent

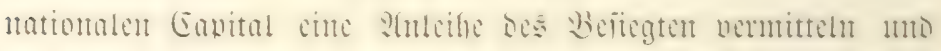

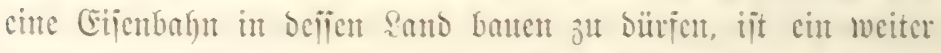
?(bitano; in \&rincipe brüdt jid) in bem cinen wie in bent 
anderen, in ber Sflaveret und in ber Tributpflid)t wie itt Dent

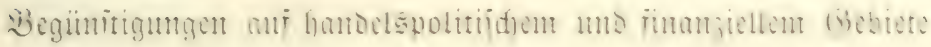

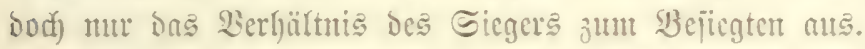

So gibt ç Dem and unter ben slenij)en, wie in ber

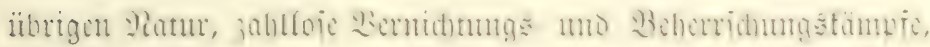

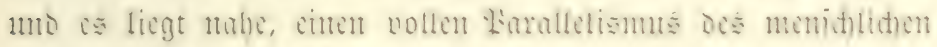

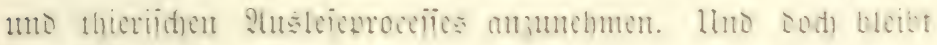

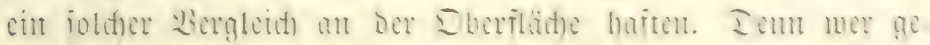

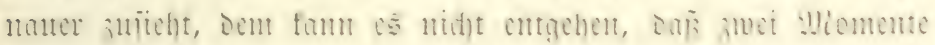

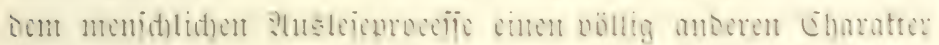

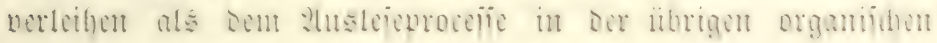

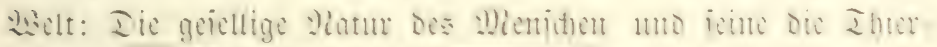

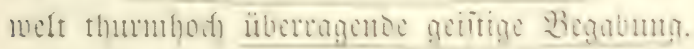

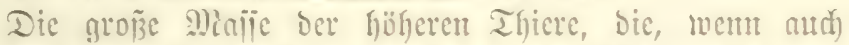
enternt, mit Dem Wieniben vergliten meroen fömen, lebt im

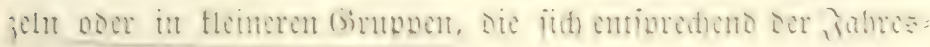

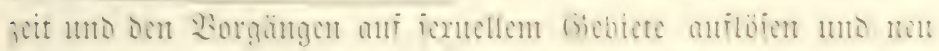

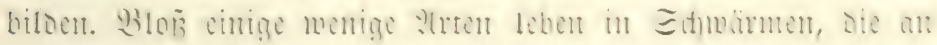

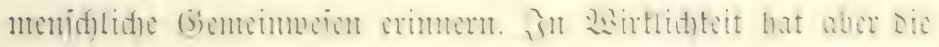

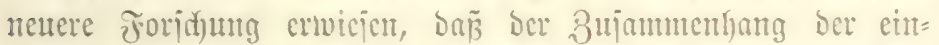

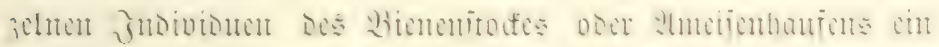
jefre lojer ijt, unto dajß man jowohl bic Jntelfigenz wic bie

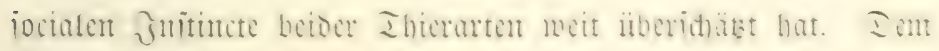

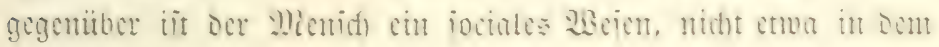

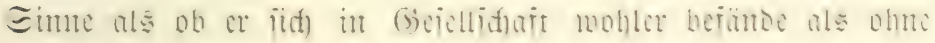

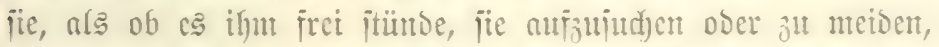

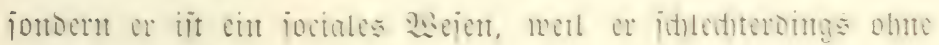

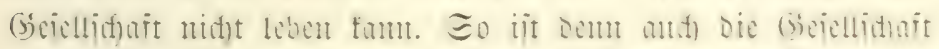

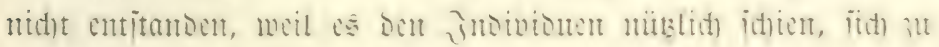

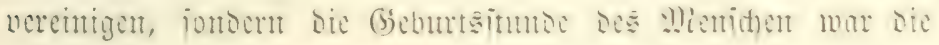




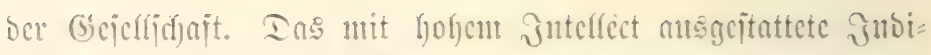

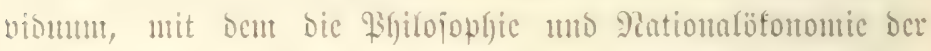

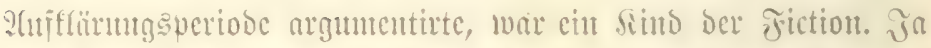

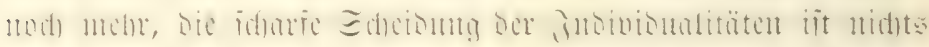
antoces als bas Pirobuct cince langen Entwicfelung. Je tiejer

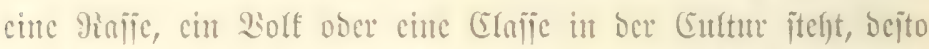

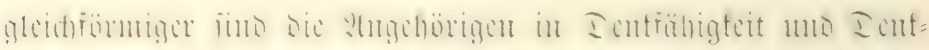

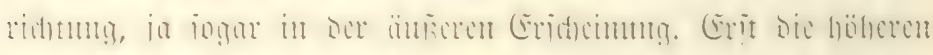

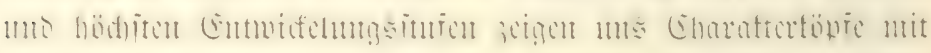
marfanten Bügen, uno wir müfīen Jerbert Epenter in biejer

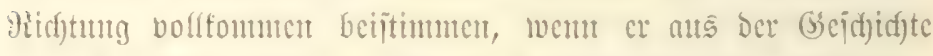

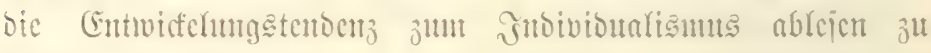
föm glaubt.

Dic gejelige शratur geitaltet Don Simuj ıms Dajein

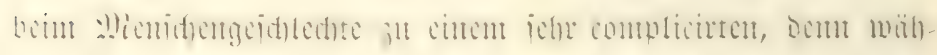

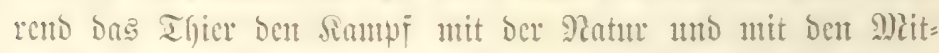

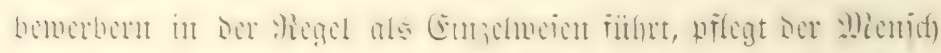

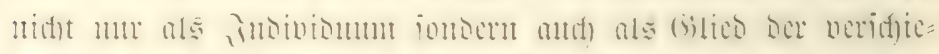

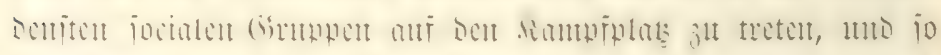

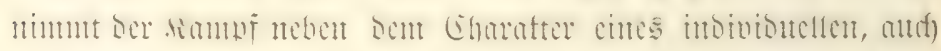
Ben cintes collectinen ant. Je sifferenjirter eme (seicllichaft, in ocjto

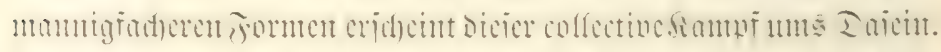

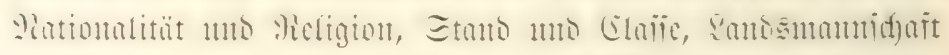

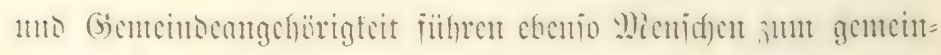

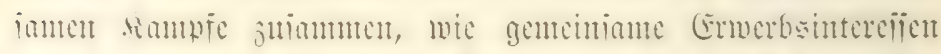

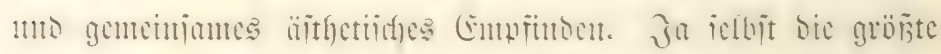
Imt iejtejte Erganijation, ber Etant, fïlnet ben fiampi un jeine

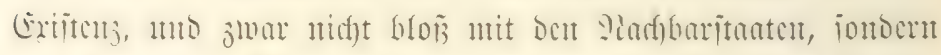

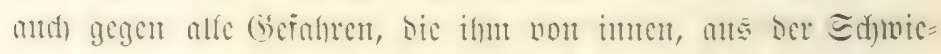

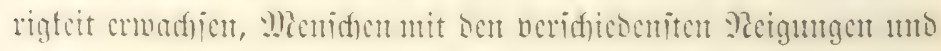




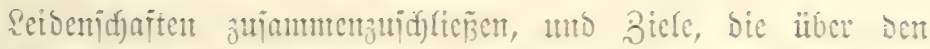

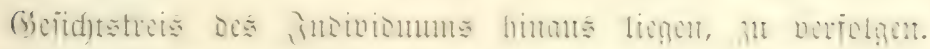

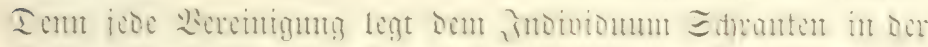

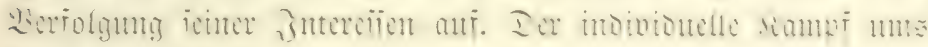

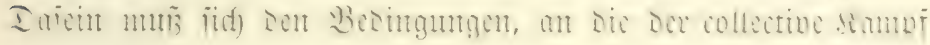
gctnïpit ijt, unteroronen, er findet icine Girenje ant ber @olt=

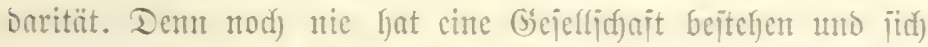

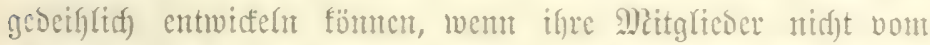

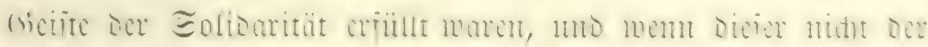

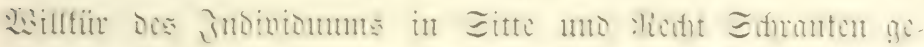

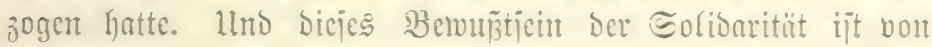

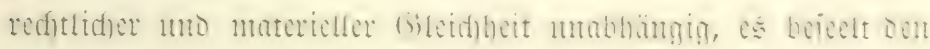

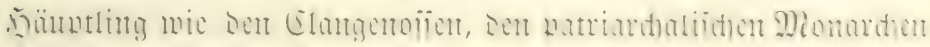

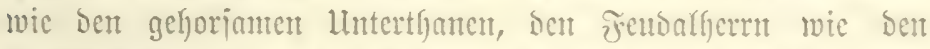

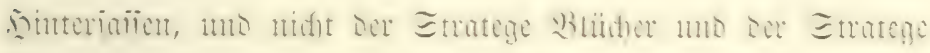
Babeţfy, jonbern Der Bater Blüdjer uno ber Bater Oia=

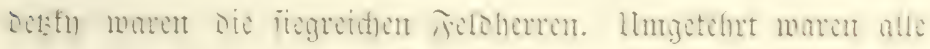

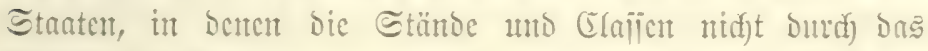

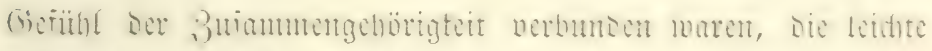

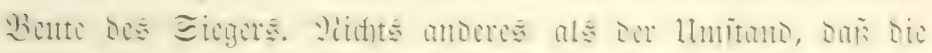
itrenge Sonderung in Sapten cin gemeinjancs Cumpïmben

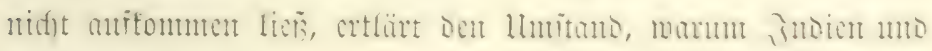

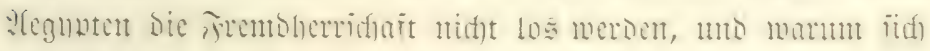

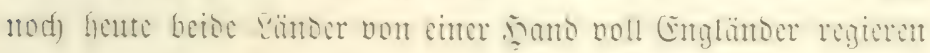
Iaijent.

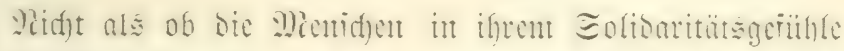

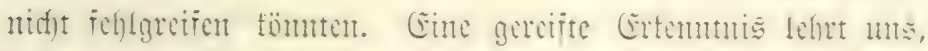

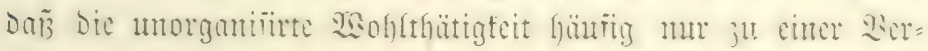
id)menoung ber Whittel iührt, ohne bas llehel mejentlid) ju

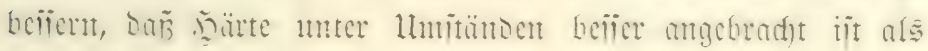




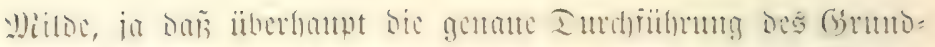

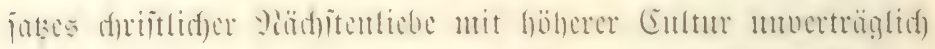

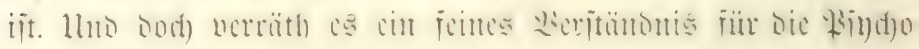

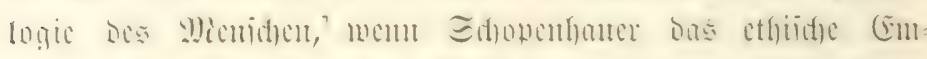

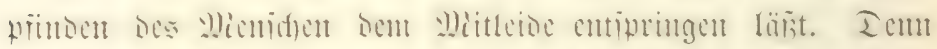

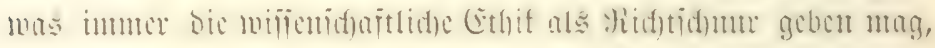

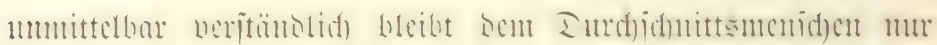

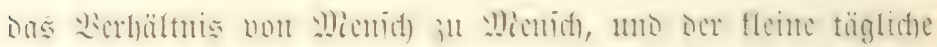

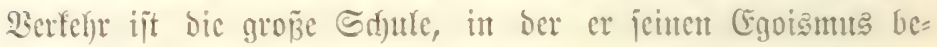

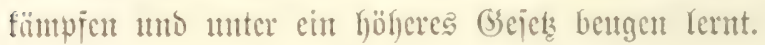

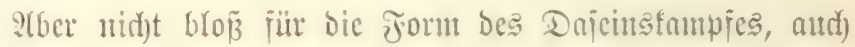

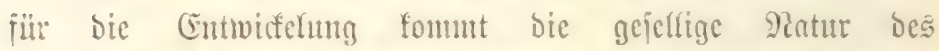

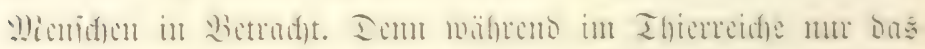

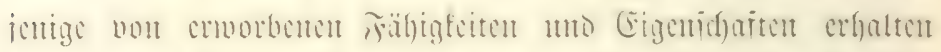

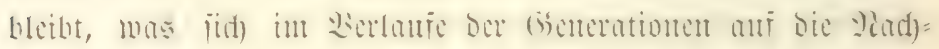

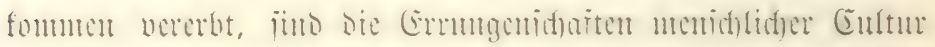

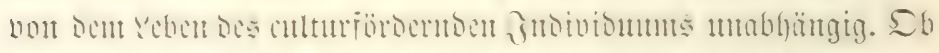

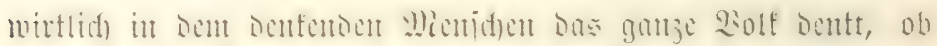

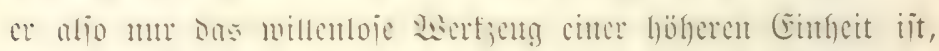

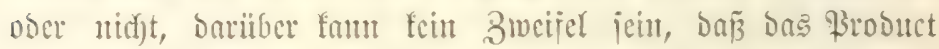

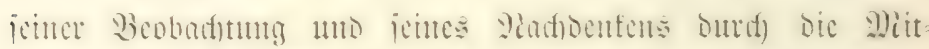
thcilung an scitgentiten mo Pind)fonmen cin iefbititündiges,

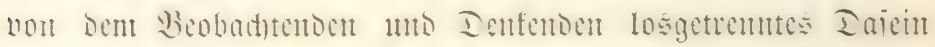

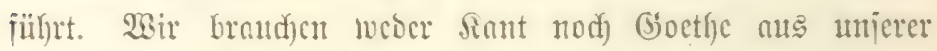

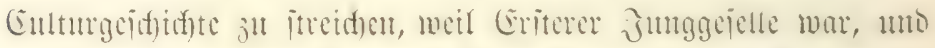

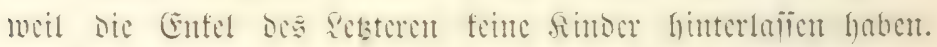

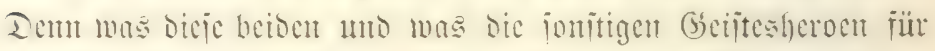

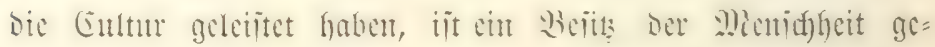
worben, ber utu verntefrt werben, aber nie mefre verforen gefen fant. So banfen wir bent ber Ǵejellidaft unjere 


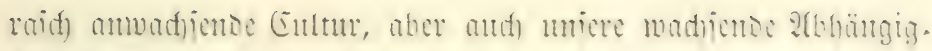

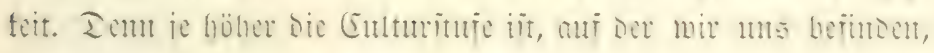

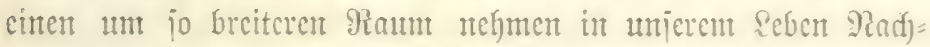

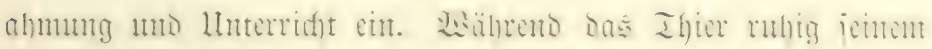

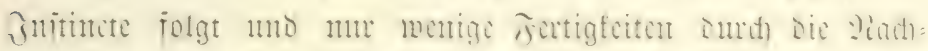

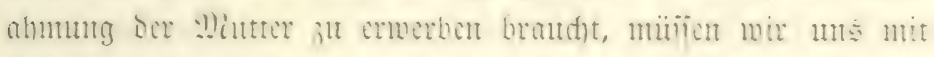

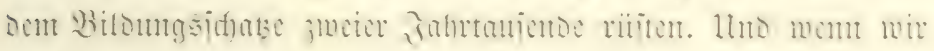

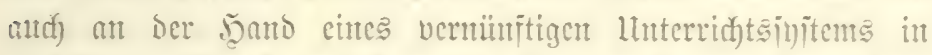

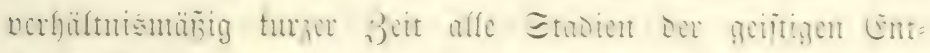

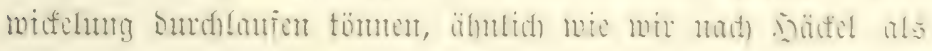

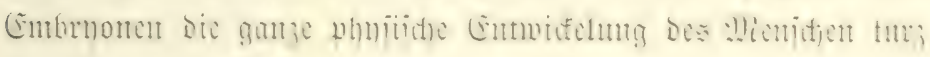
wieberfolen, jo fant bodf miere begrenzte Rebensjeit ju bom

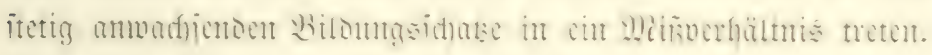

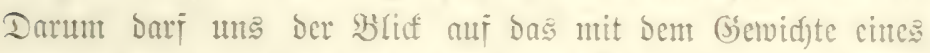

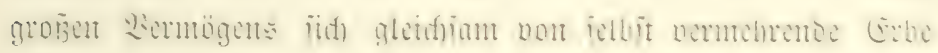

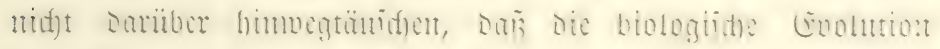

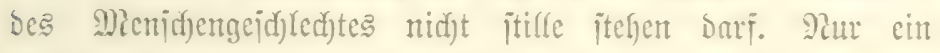

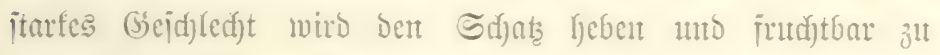
Intadjen wijien, cin idfwadjes fann unter jeinter Sajt er=

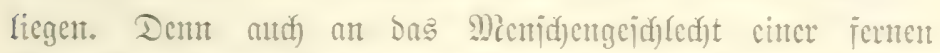

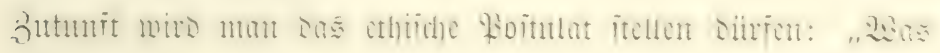
Du ererbt von Deinen, Bütern hajt, crmirb' cs, 1 m es ju bejitsetr."

2on biejem Stantopunte aus werden wir benn and cine

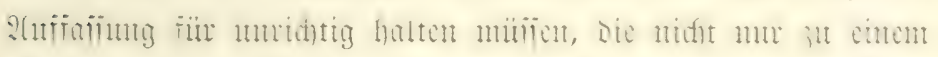

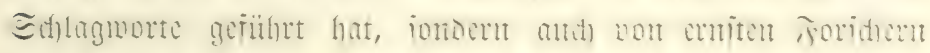

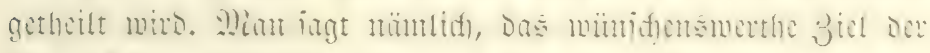

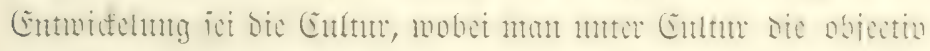

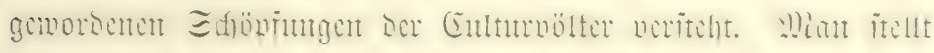

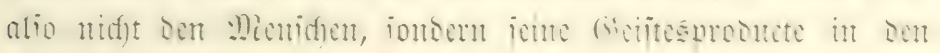




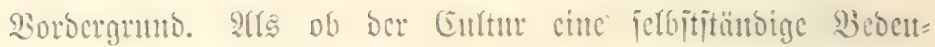
tumg jufüme, nts ob jie losgelöit von ber Sicnjdyeit geond)t

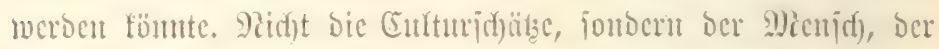

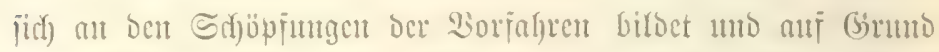

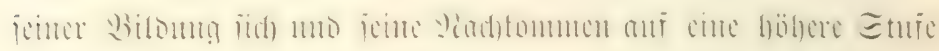

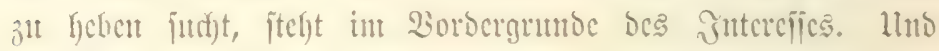

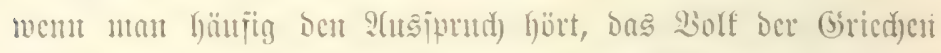

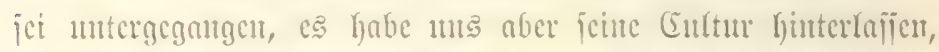

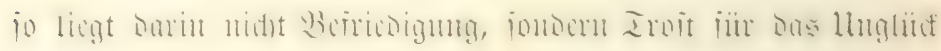

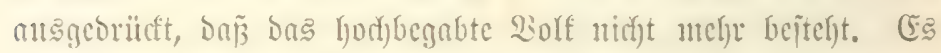

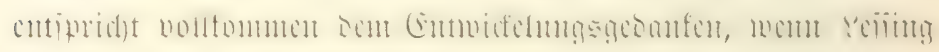

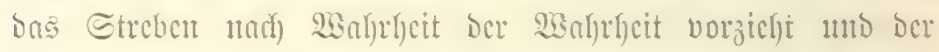

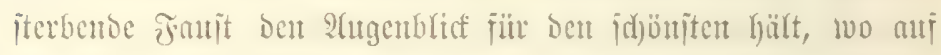

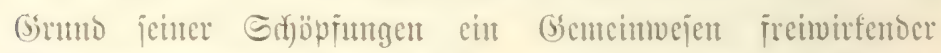
:I)

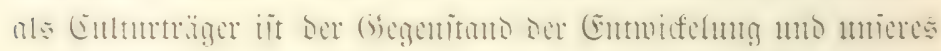

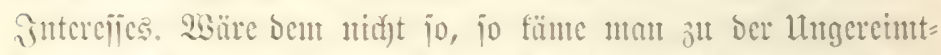

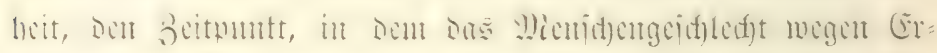

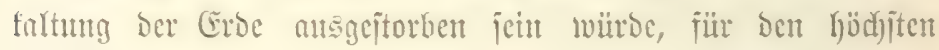

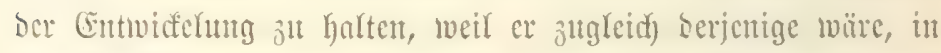

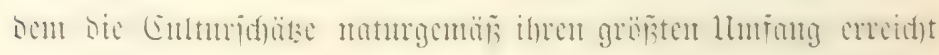
baben แüis̄ten.

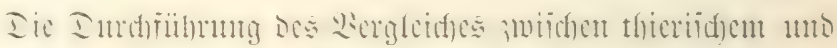

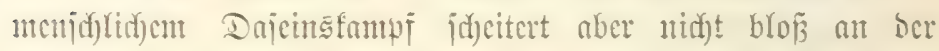

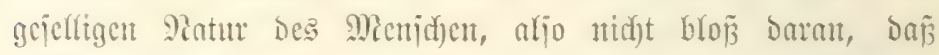

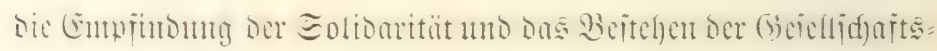

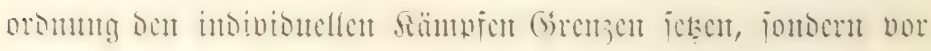

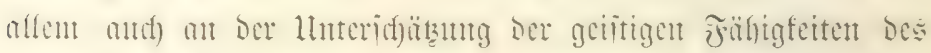

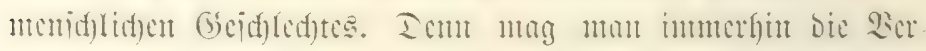

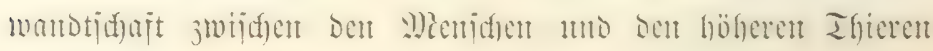




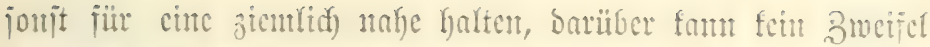

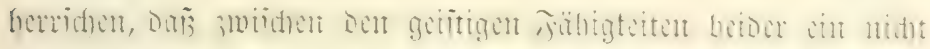

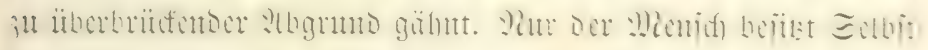

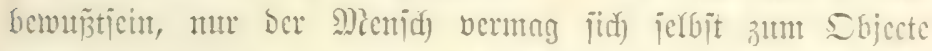

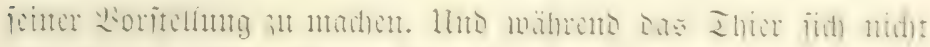

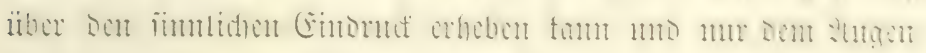

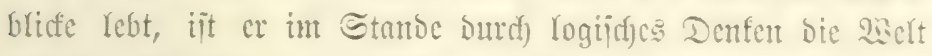

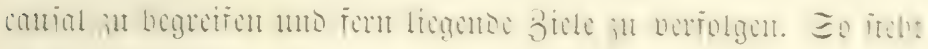

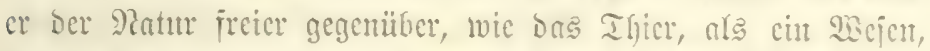

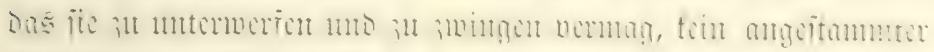

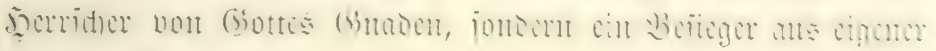
Diad)toollfommenfyeit.

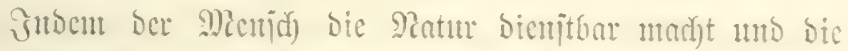

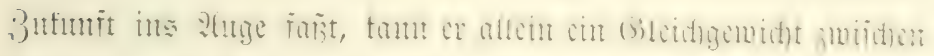

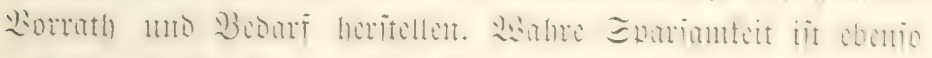

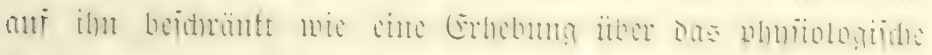

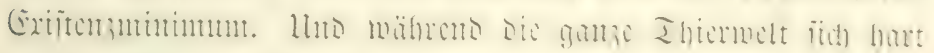

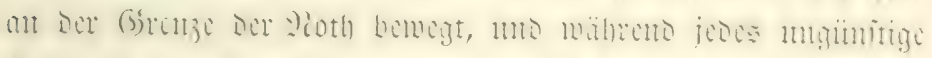

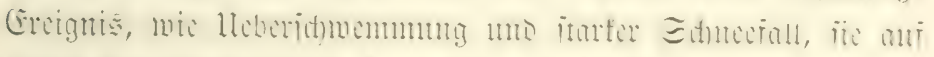

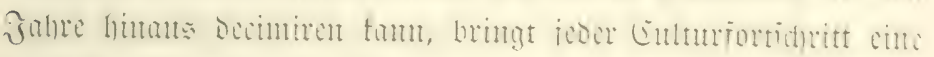

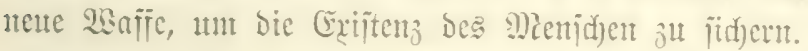

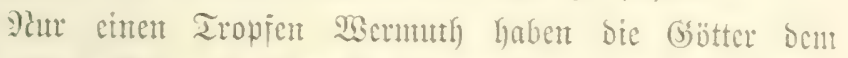

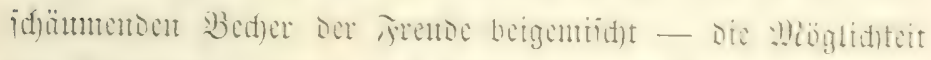

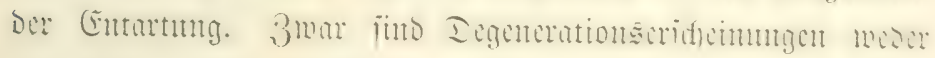

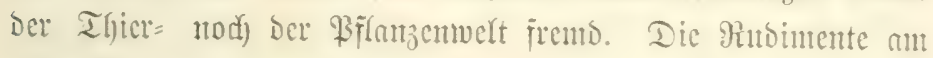
Thietförper fint bas Ergebnis einer Degencration it Folge langen Ridj)tgebrautecs cinjt nolf entwicfelter Stgane, unto

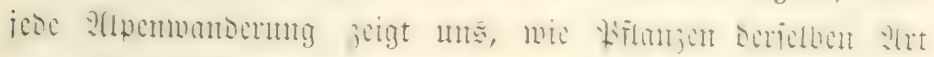

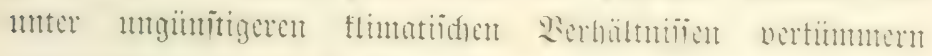
umb verfeüppeltr. 2(ber inturer ijt bie Degeneration cine Jolge 
ber Roth, ciner geringeren Błhatcirentation in ben begencriren=

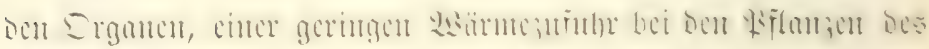

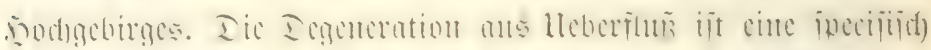

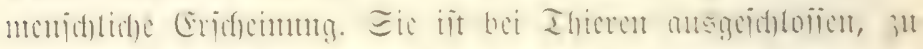

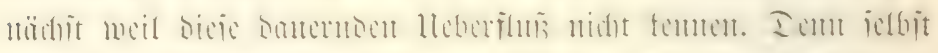

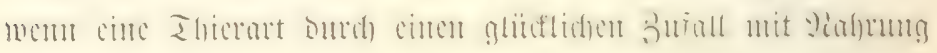

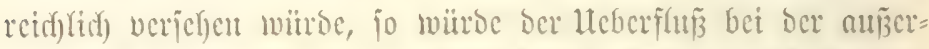

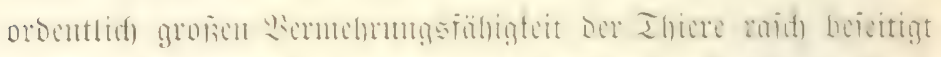

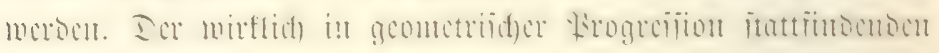

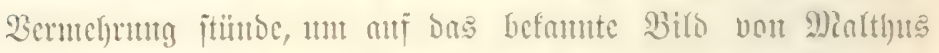

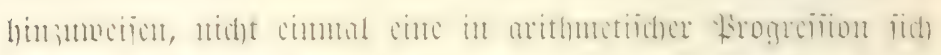

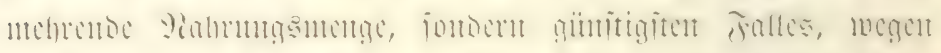

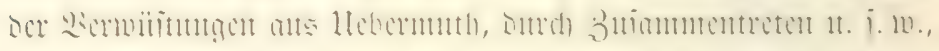

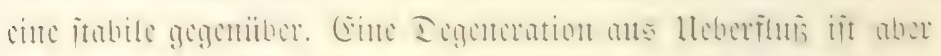

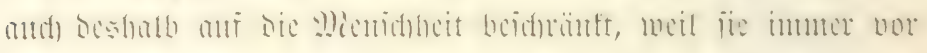

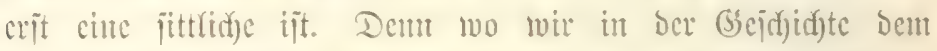
Berfalle ches Bolfes oder cincr Clefic begegnen, ba war ces nic

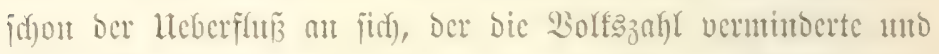

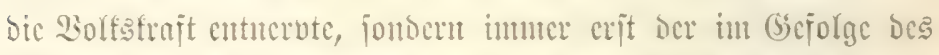

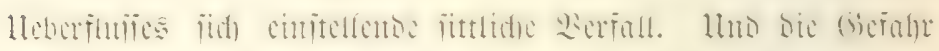

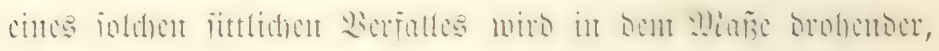

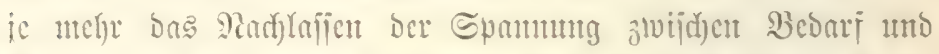

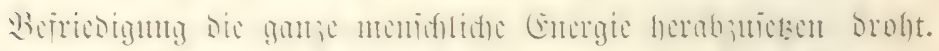

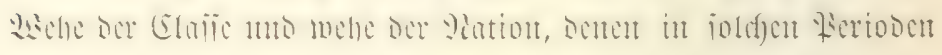
Der Bebaglidffeit bie Joenle nangelt, bie jie ju verutefyter

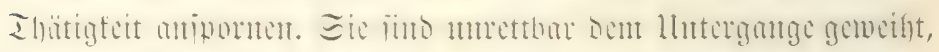

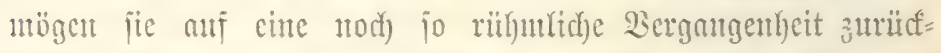

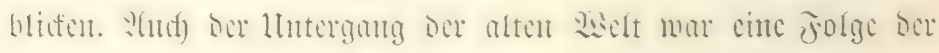

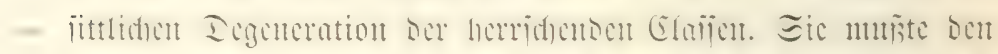

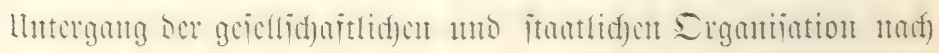




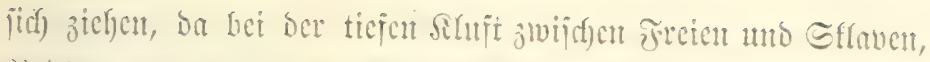

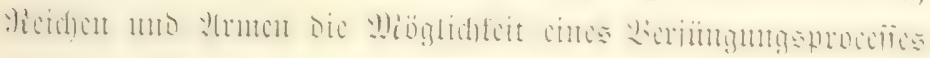
volt unten for atsggid)lofîcu war.

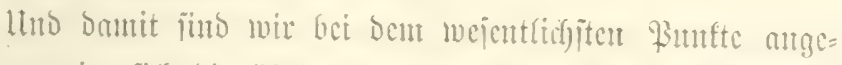

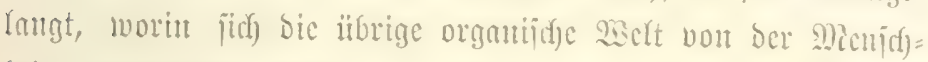

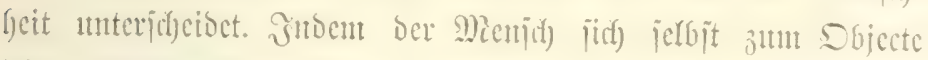

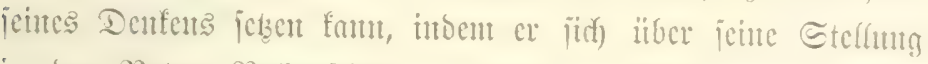

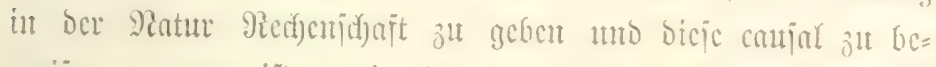
greijen vermag, ijt er in ber sage, anf bie Evolution jelbjt

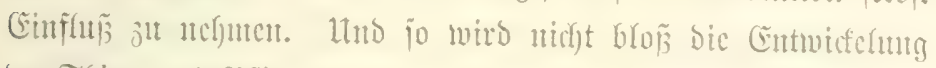

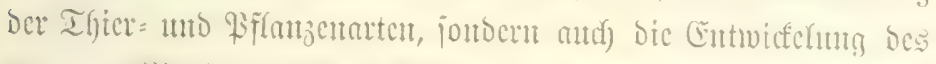

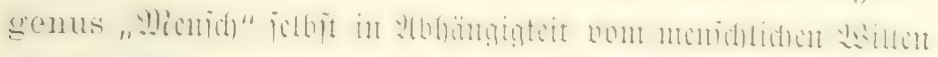

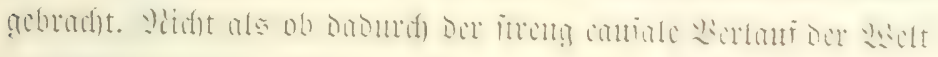

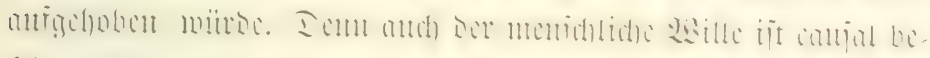

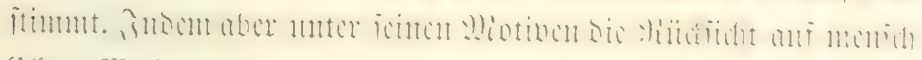

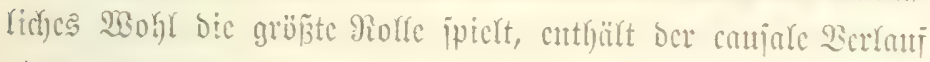

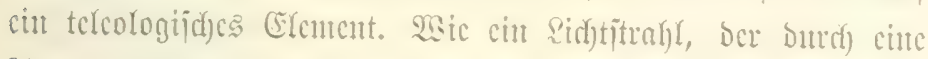
¿inje fülrt, abgelenft wirb, jo wirb ber canjale Berlañ ber

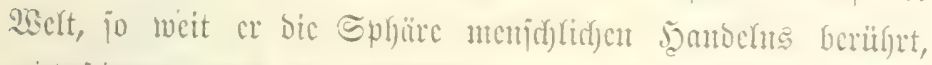

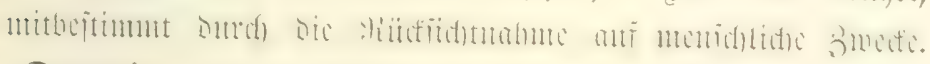
"Dem in bent Bwecfe," jagt Jifering, "jtectt ber Mentid),

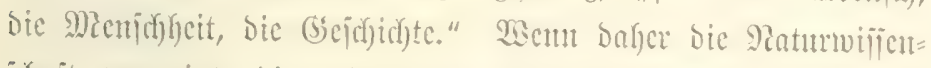

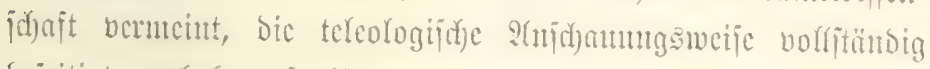

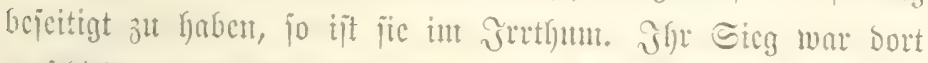

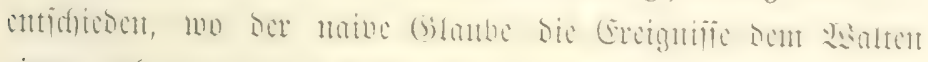

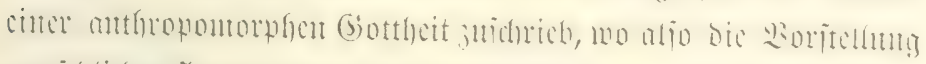

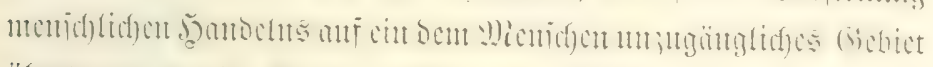

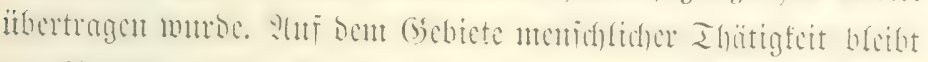

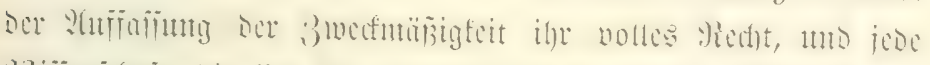

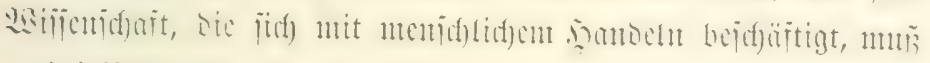




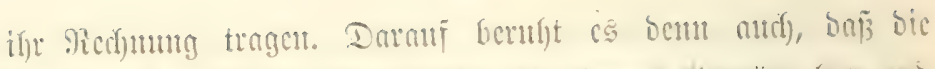

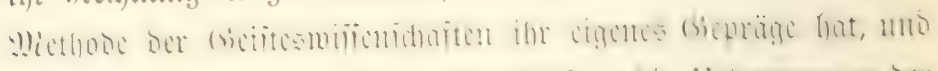

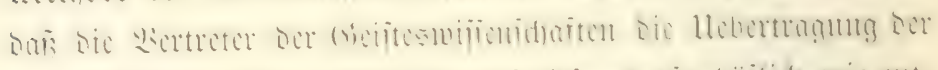

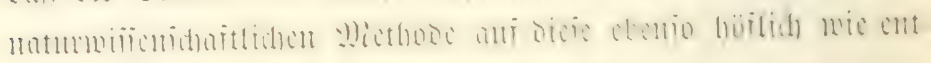
idjecocut ablefinen.

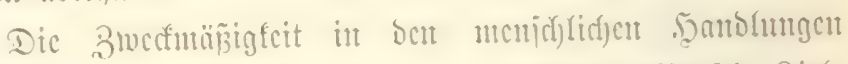

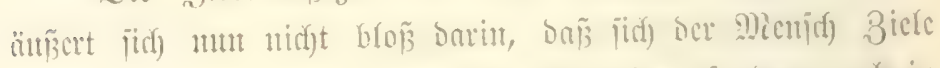

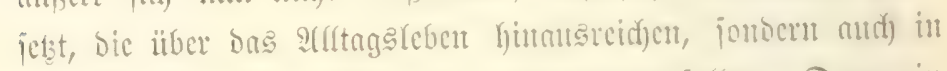

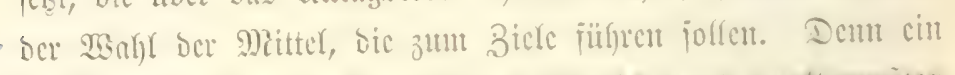

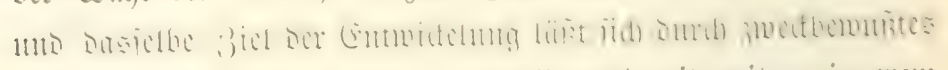

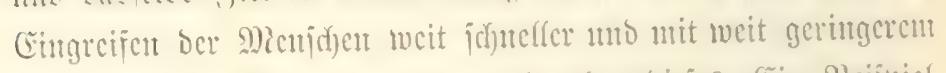

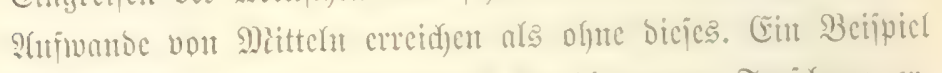

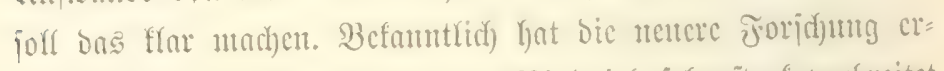

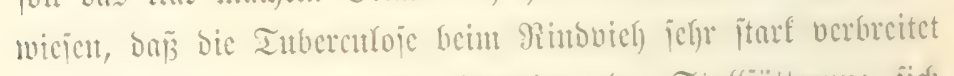

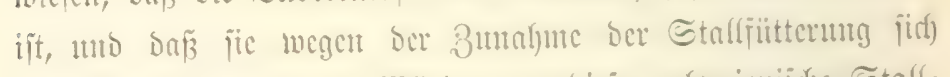

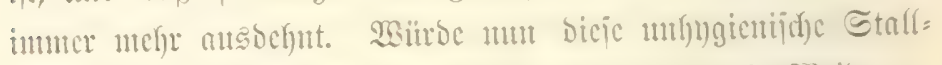

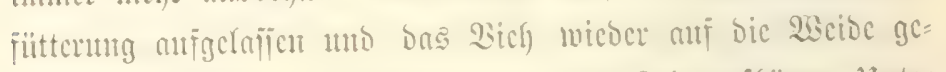

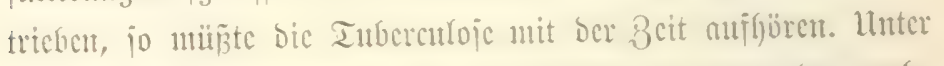

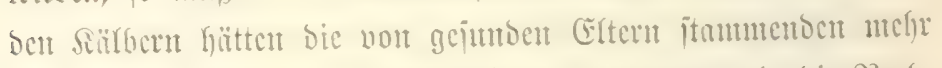

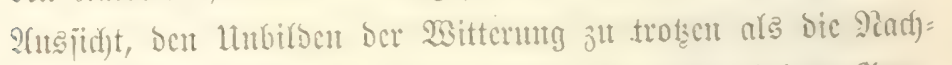

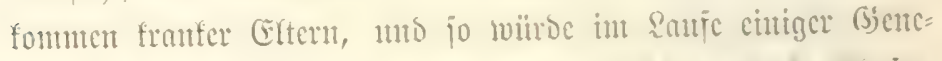

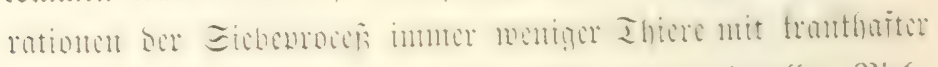
P(ntlage übrig Yaifent. Demgegeniber fant cin rationelfer Wief)=

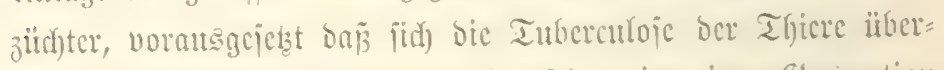

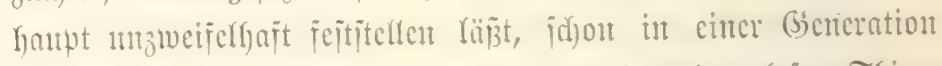

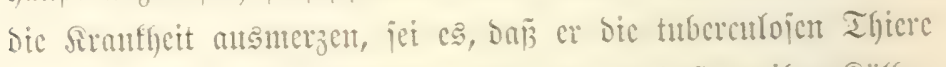

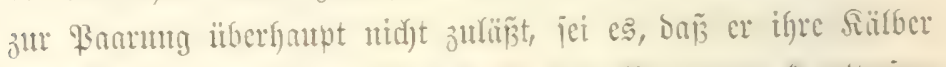

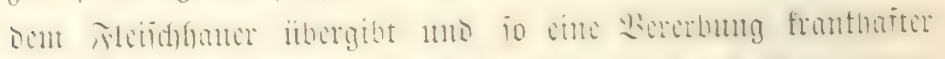

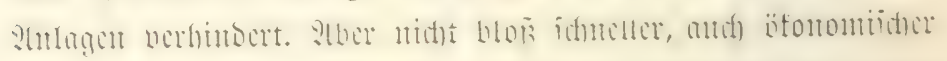
ijt bicjes ziel crecidjt worben. Es iit erreidgt morben, oljuc 


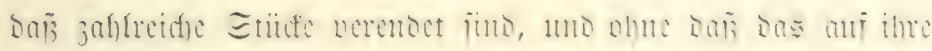

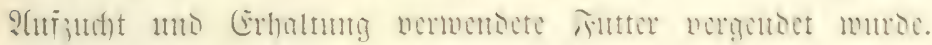

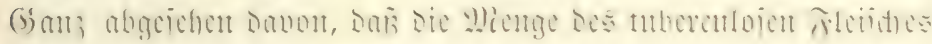

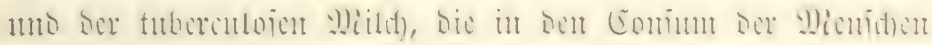
ïbergchen, in biejent falfe cine weit geringere wäre nbs im

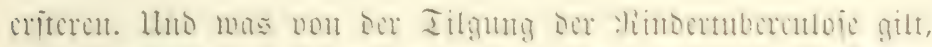

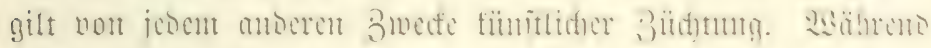

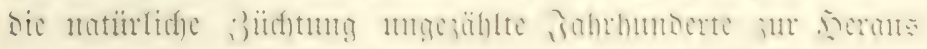

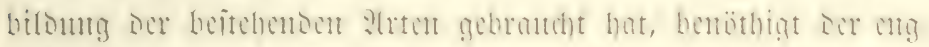

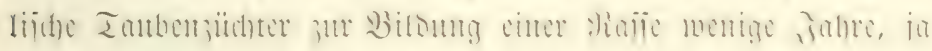
cr ijt jeines Erfolges jo jidjer, ba jer gentan ben 3citpuntt be=

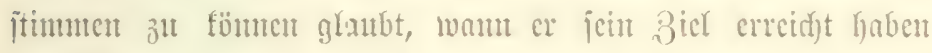

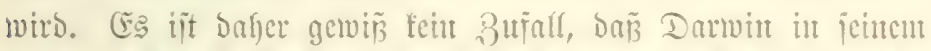

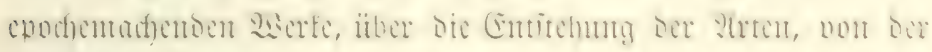

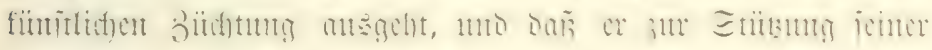

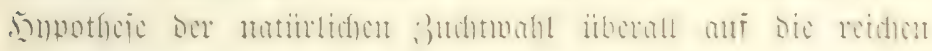

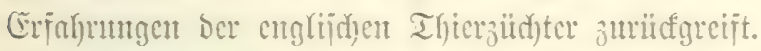

Und jolfte man angejidyts bce chenjo rajd)en wie glän=

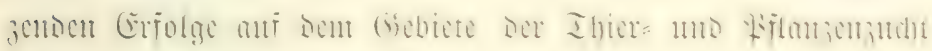

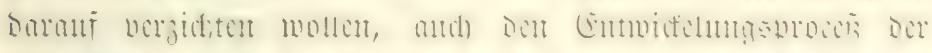

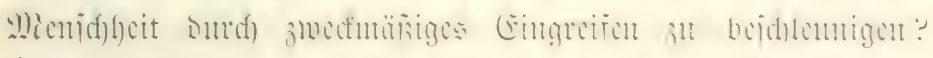

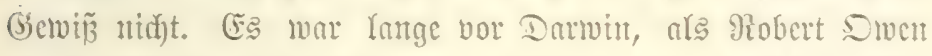

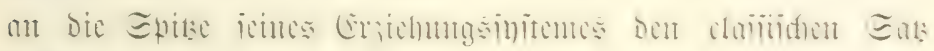

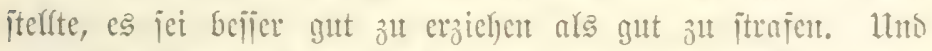

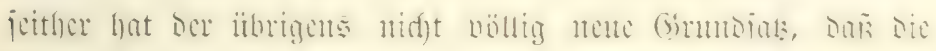

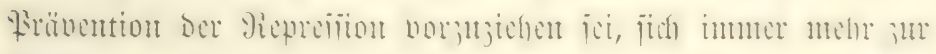

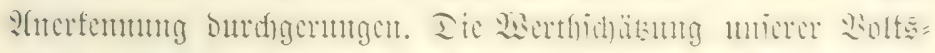

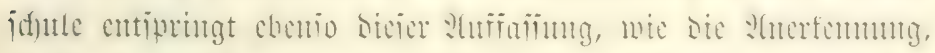

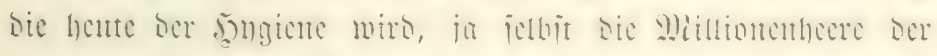

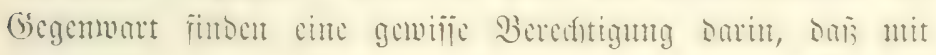




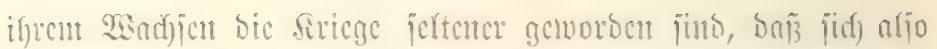
ber Grunbjan: si vis pacem, para bellum, wentgiteñ in neuciter Beit bewalyrifeitet bat.

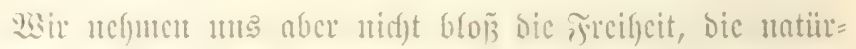

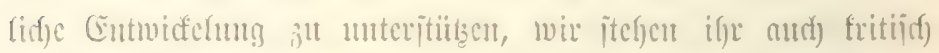

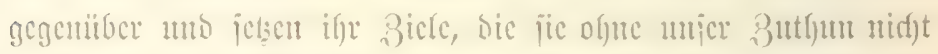

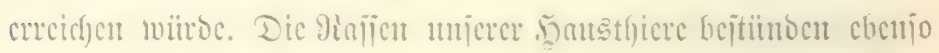

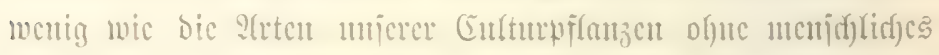

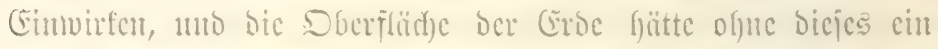
gant anderes : :

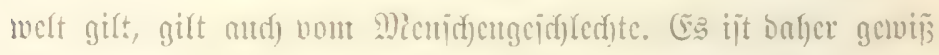

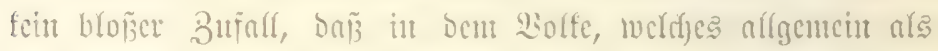

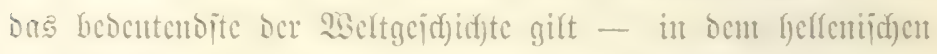

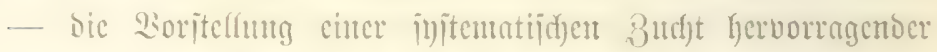

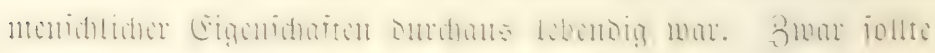

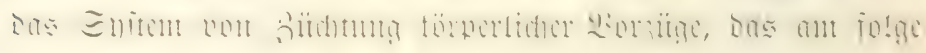

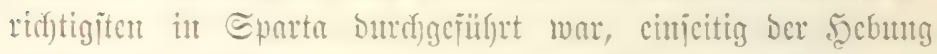

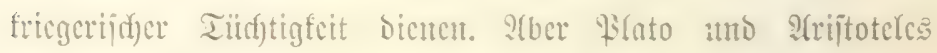

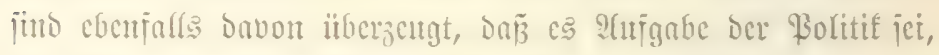

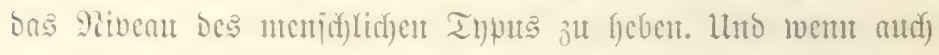

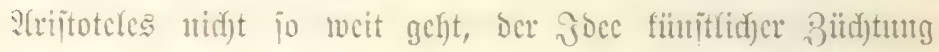

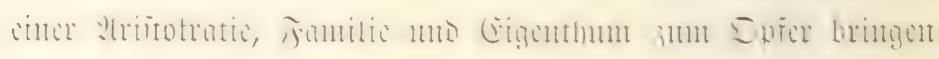

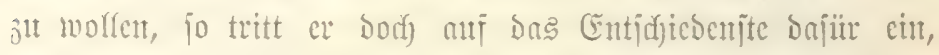

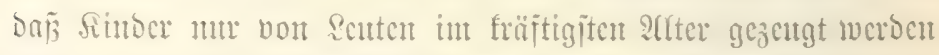

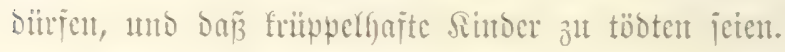

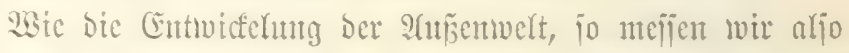

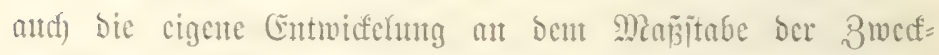

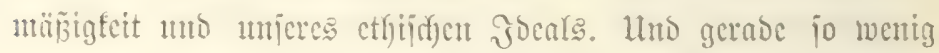

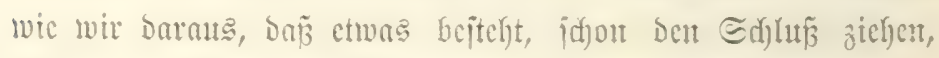
bar es and vernüntig jei, gerabc jo wentig jüb wir geneigt, 


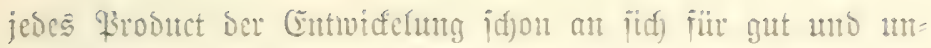

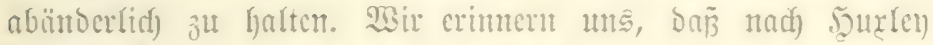

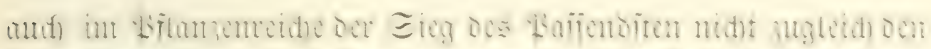

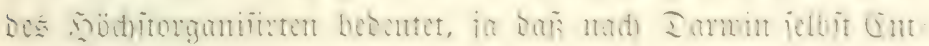

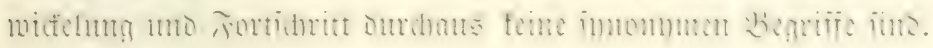

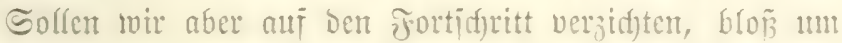

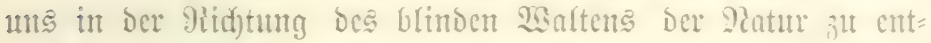

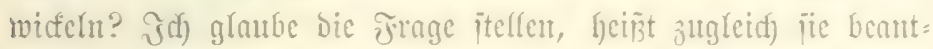
morten. Ties mmjomelfr, als wir aud) jonjt bet jeoen Edjritte

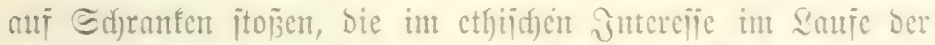

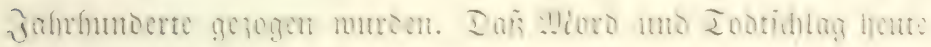

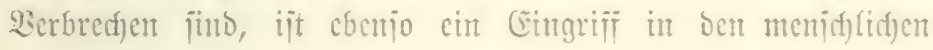

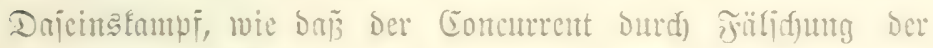

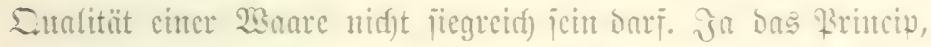
ben Sampi uns Dajein im cthijd)en intercile ju regeht, ijt

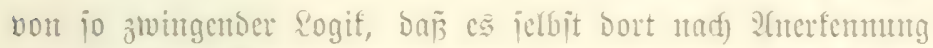

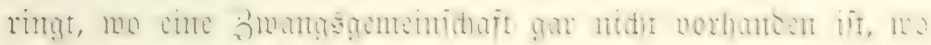

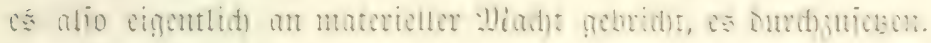
In:

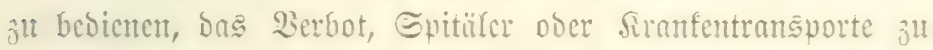

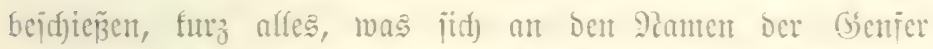

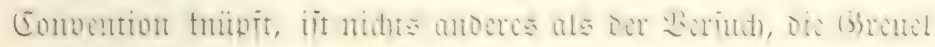

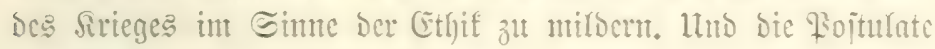

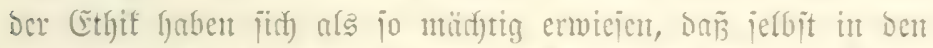

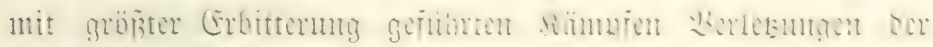

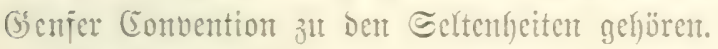

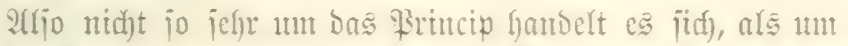

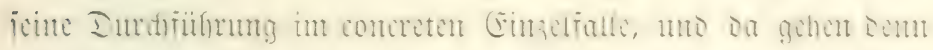

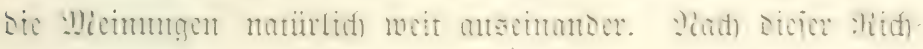

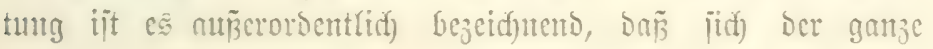




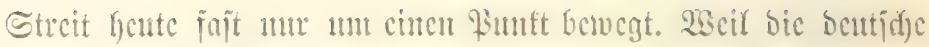

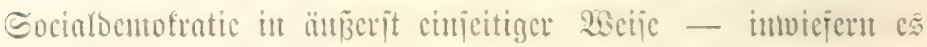

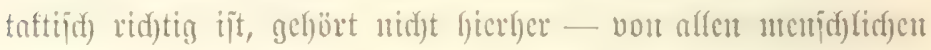

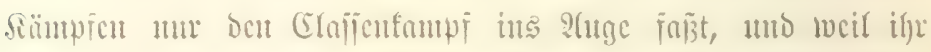

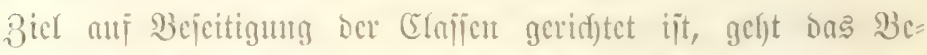

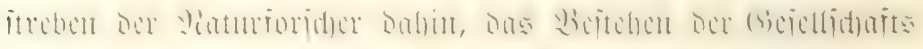

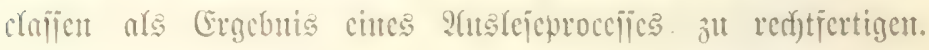

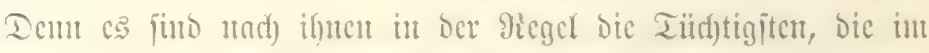

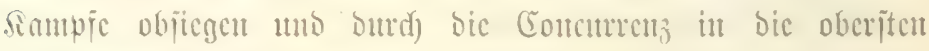
Steftutgen gehobent weroent.

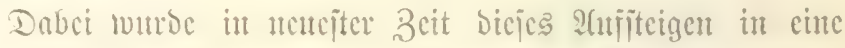

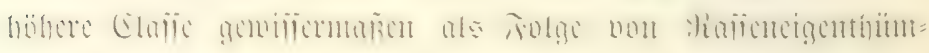

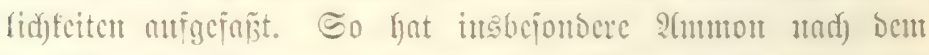

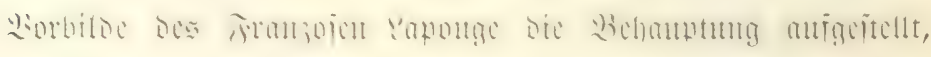

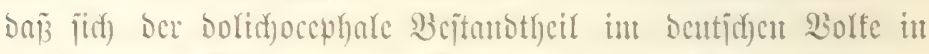

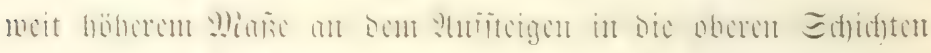

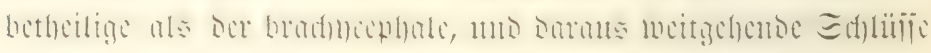

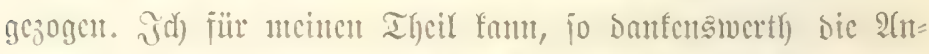

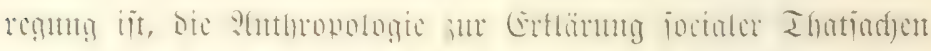

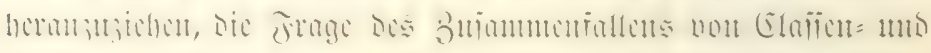

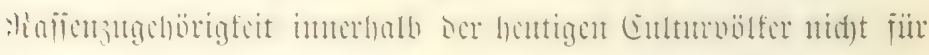

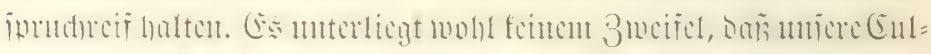

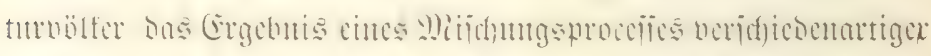

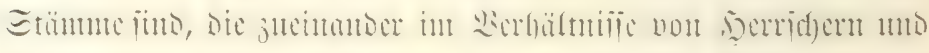

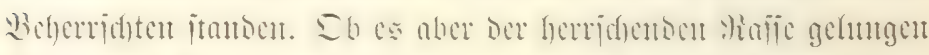

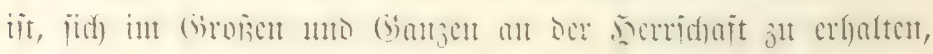

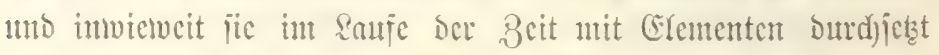

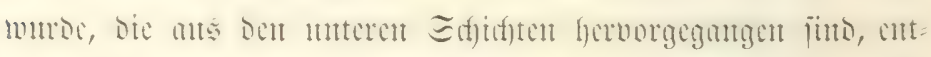

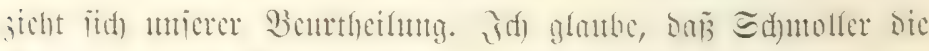

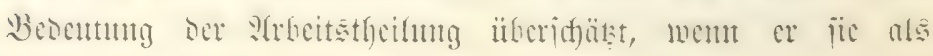




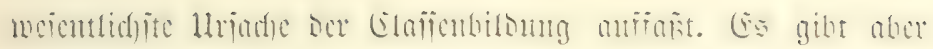
inmerfin zat benten, wemt, wic cr bemerft, won humbert Biantent

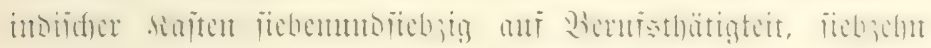

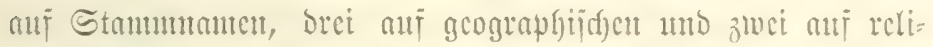

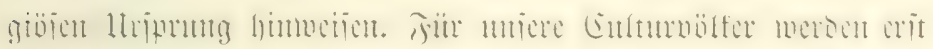

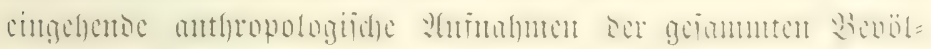

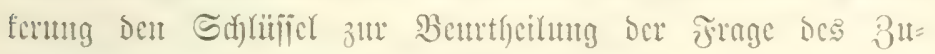

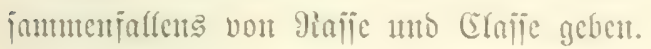

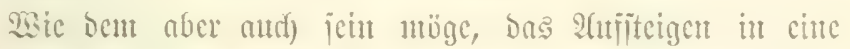

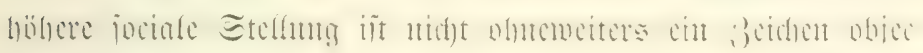

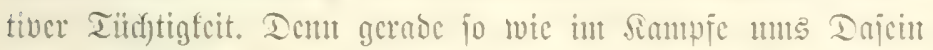

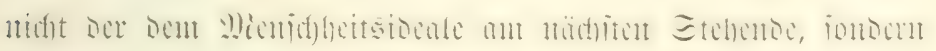

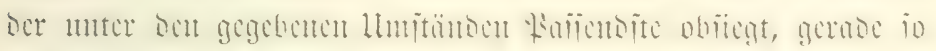

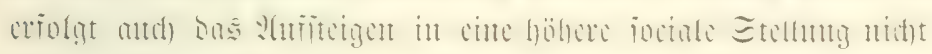

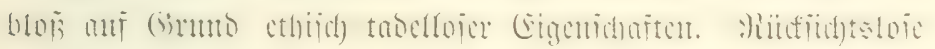

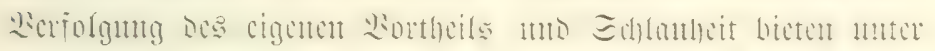

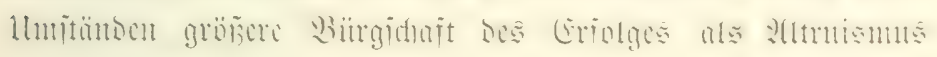

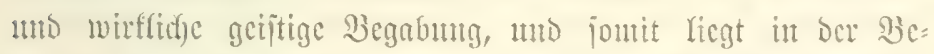

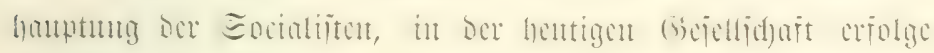

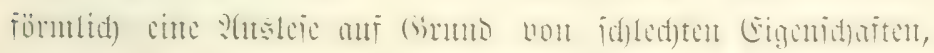

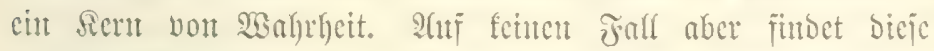

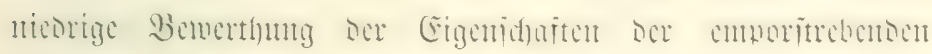

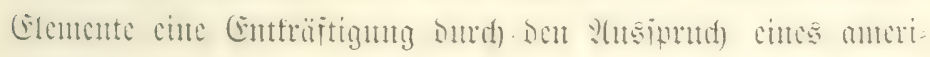
faniidenen Pationalöfononten, Der es ale cinen Jortidyritt ver=

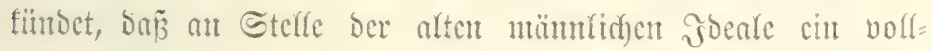
fontutencres gocal getreten jei, bas bce Miantes, bcl jidj jein Bermögen mad)t.

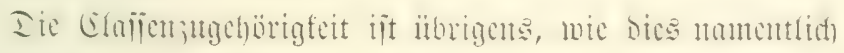

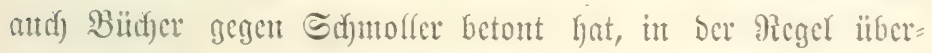

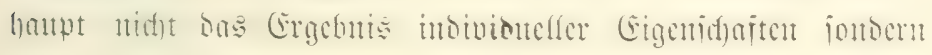




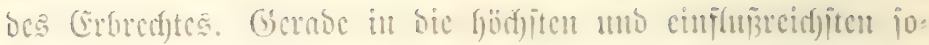

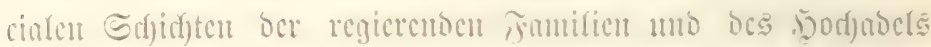

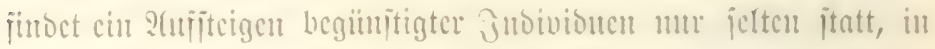

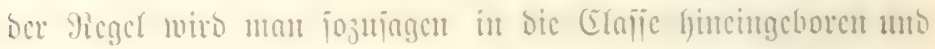

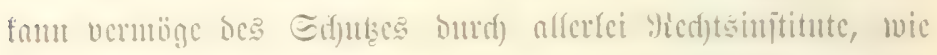

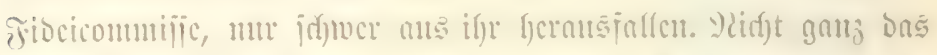

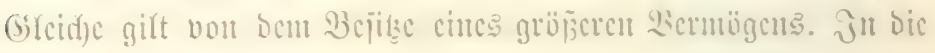

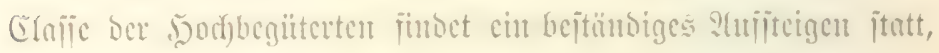

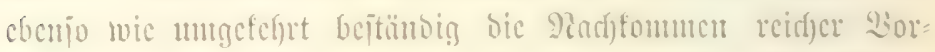
fafren verarmen. Eon vornefyerein bejetzen aber and bic Simber

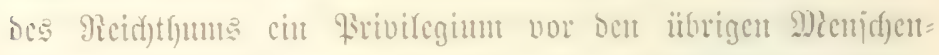

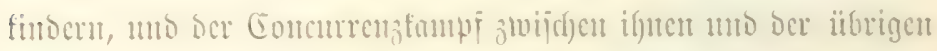

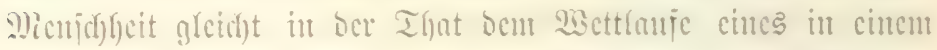

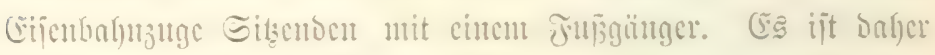
mu conjequent, wem Slämer, dic bem Socinlisnum jo jeru

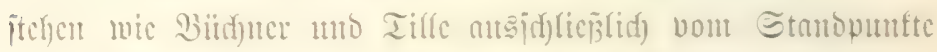
Der Eelection ats cinc Bejcitigumg des Ertured)tes any ifre Far)ne jurueiben.

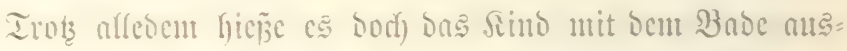

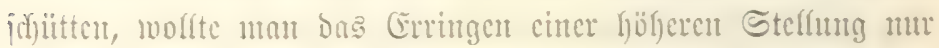

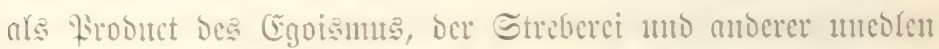

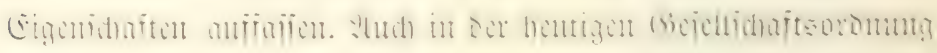

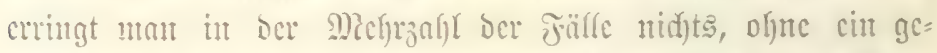

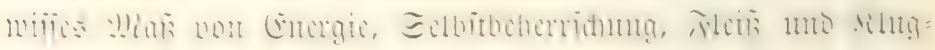

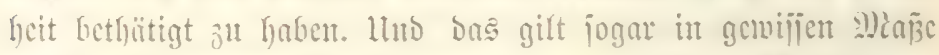

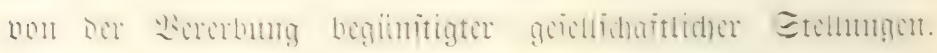

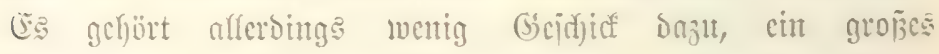

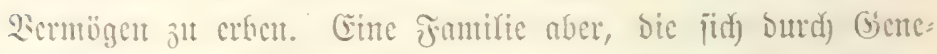

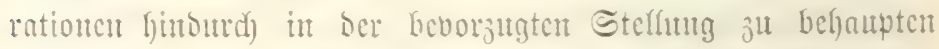

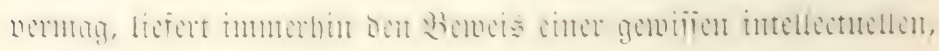




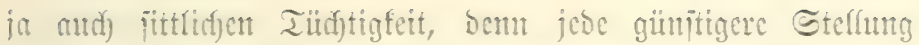

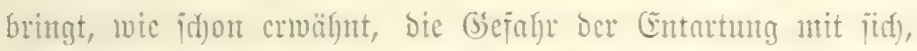

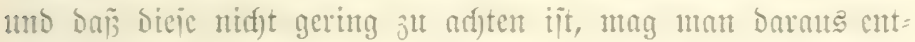

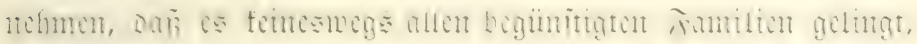

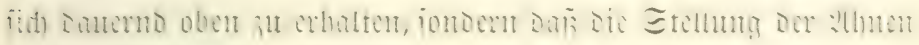

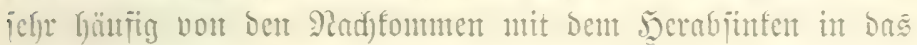

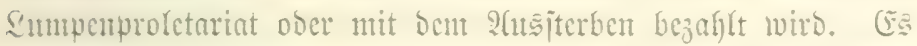

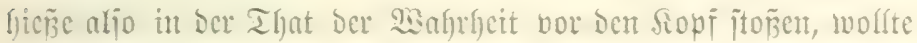

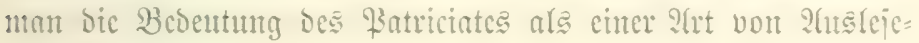
Hrobuct leugnen.

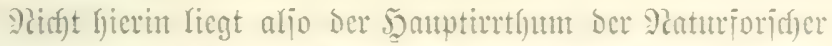

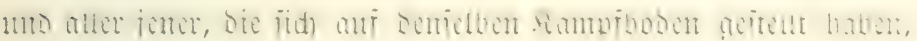

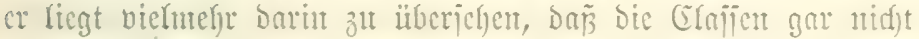
Das Product cincs Stampies ums Dajein int Eimte Darvin's, jondern cints Sampies um bie bevorzugte Stelfung jinto, wie Dies Eange zuerit genannt fat. Daraus ergibt jidj abcr bie

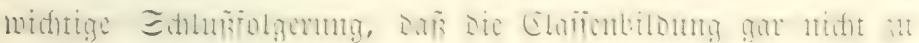

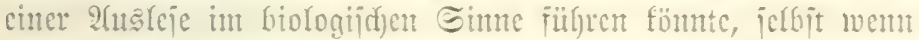

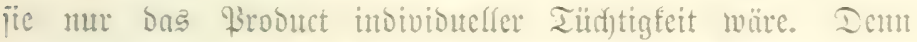

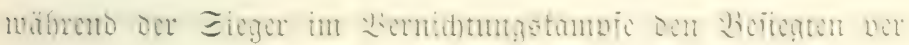

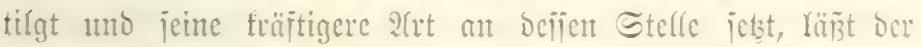
Sieger im Befjerridjungsfantpic Den Bejiegten nidjt bloj be= jteben, jondern er hat jogar bas anterejie, ifnu abjolut mo relatio

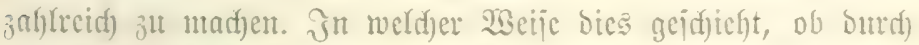

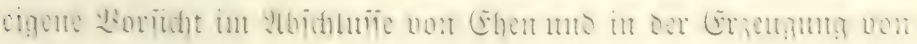

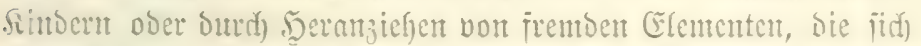

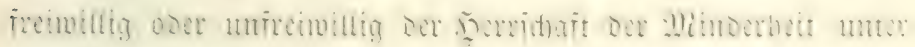

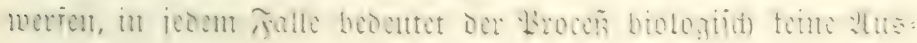

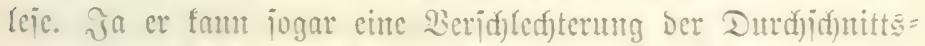

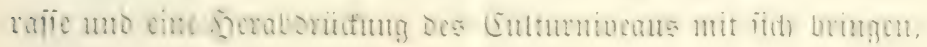




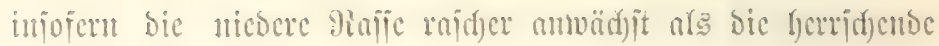

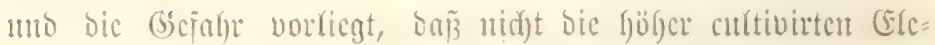

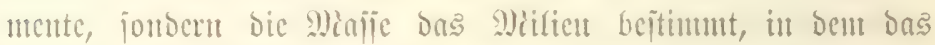

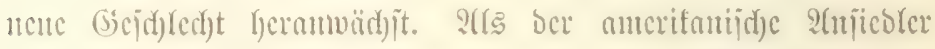

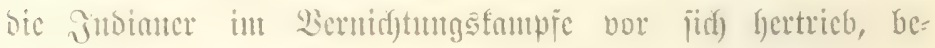

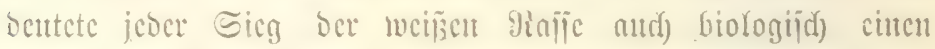

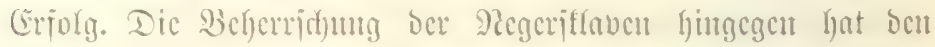

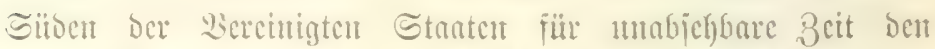

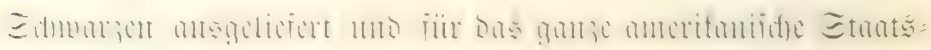

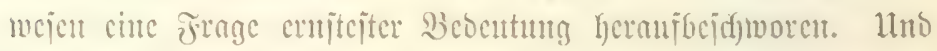

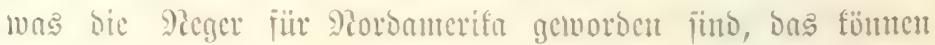
mutatis mutandis bic Bölfer Dittemopas rür bic פïlfer bes

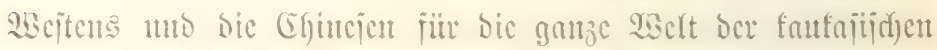

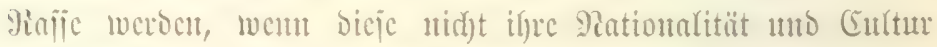

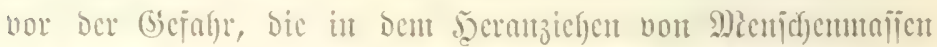

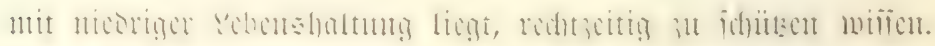

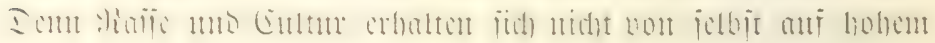
Pivecut, fonocrut jinto Sintituroducte.

Jill bie biologijide atusteje ber Jnbiviouen foum aljo

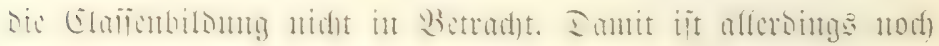

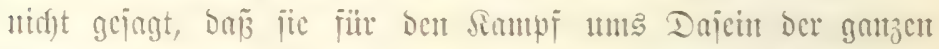

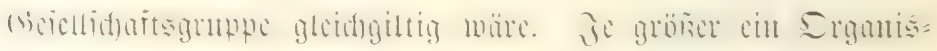

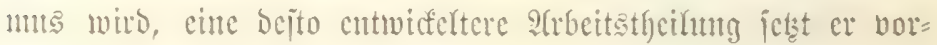

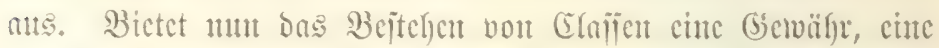

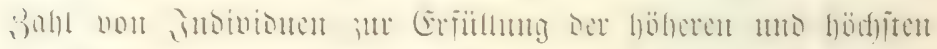

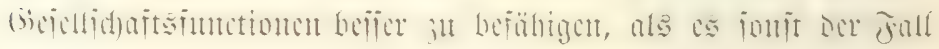

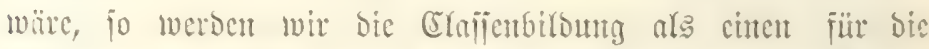

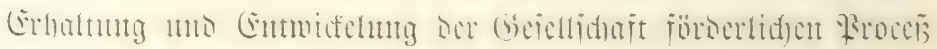

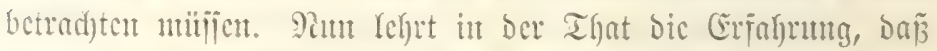

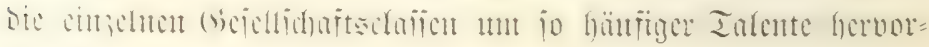




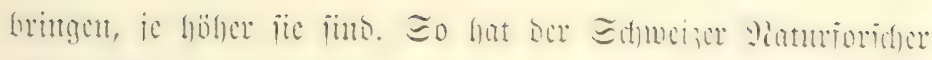

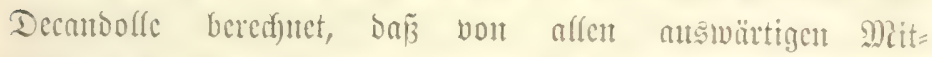

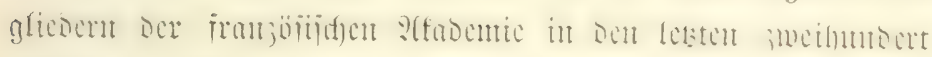

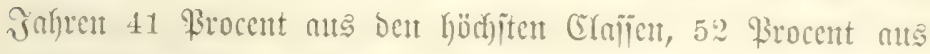

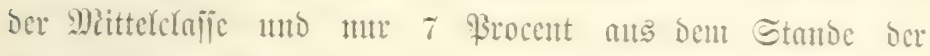

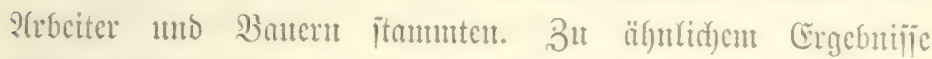

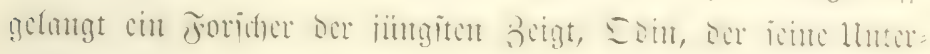

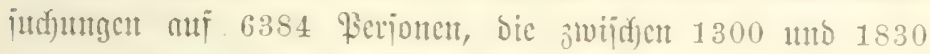

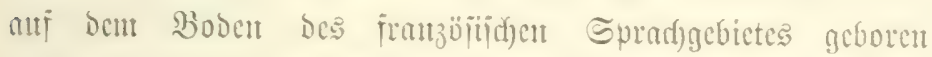

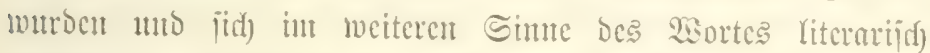

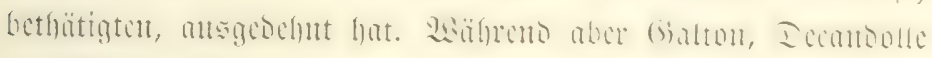

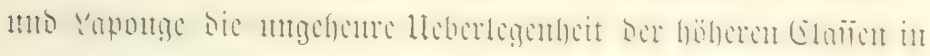

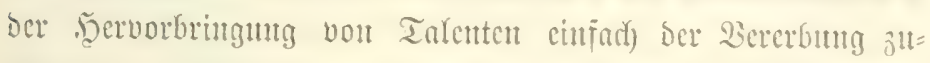

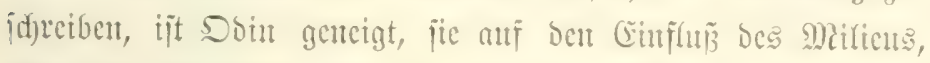

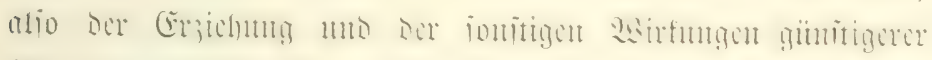
2.

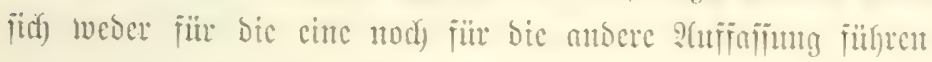

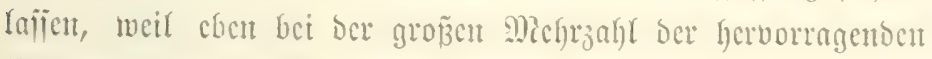
Miänucr nic wird feitgejtefft werben fömten, wie vide fie ber

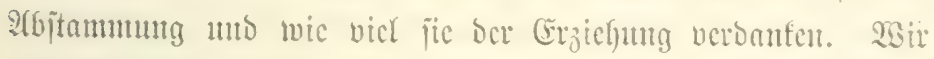

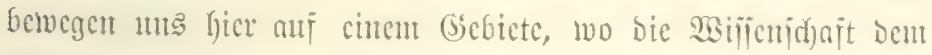

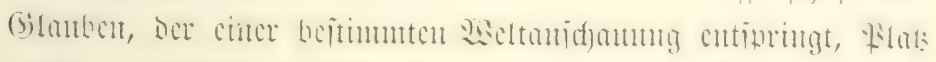

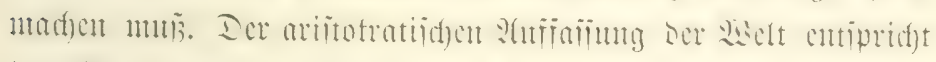

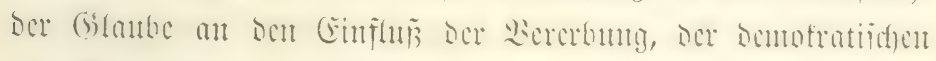
Der Gíaube an bic Bebeutung des jogenamutent Mificus.

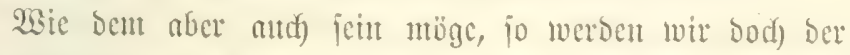

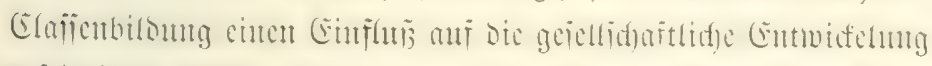

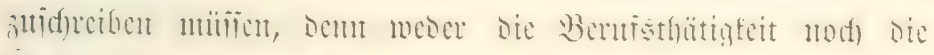

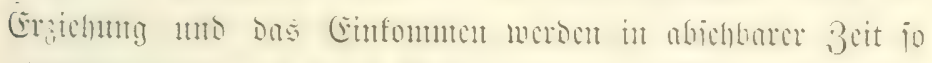

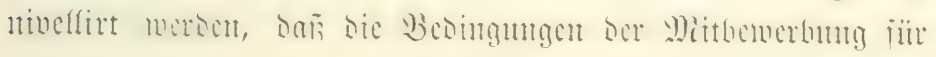




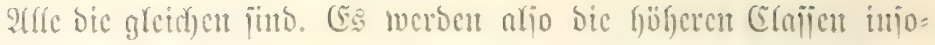

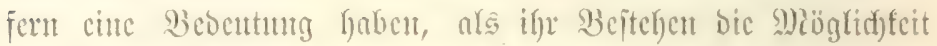

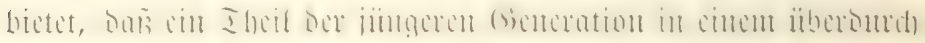

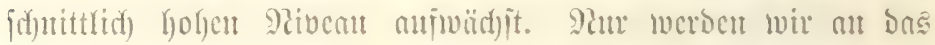

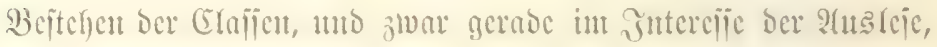

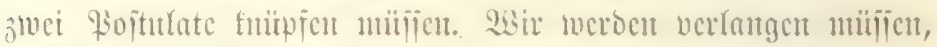

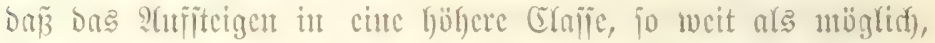

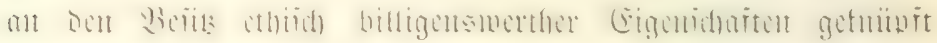

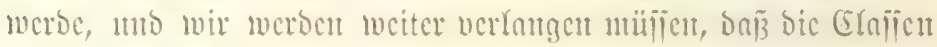

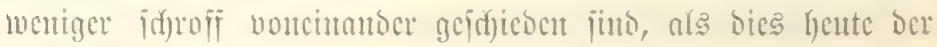
Jall iit.

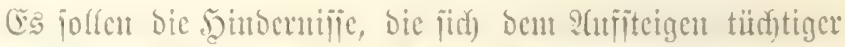

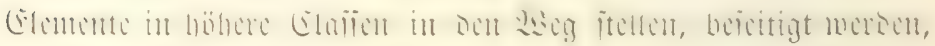
ntidyt ctwa beshalb, weil, wic man frülfer nmalym, in ber

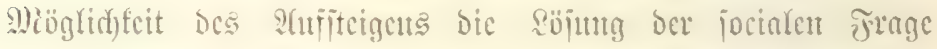
lïge, jonbern weil jic jum Sporn intoiviouefler ?tnjtrengung

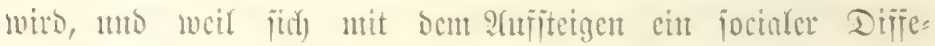

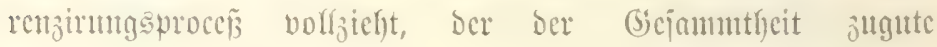
fonmt. Der Crafienunteridjed jolf aber aud ferner fein bes

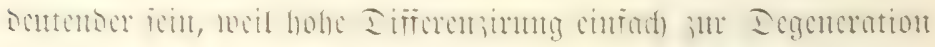
แmb foctulen Gräntoen füfret.

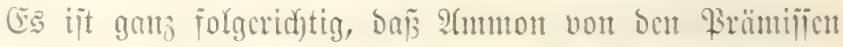

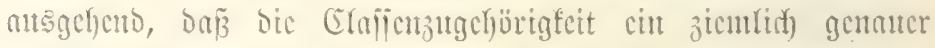

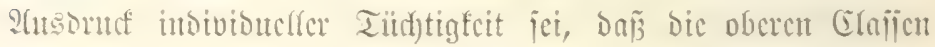

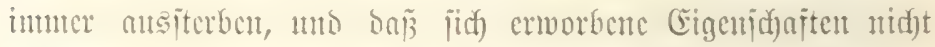

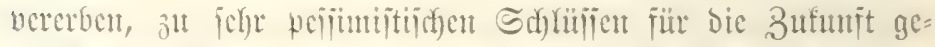

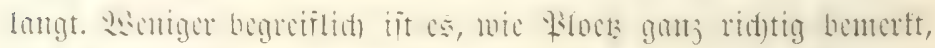

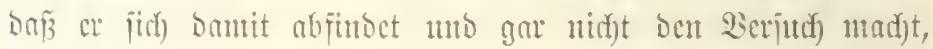

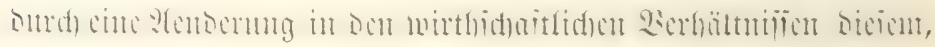




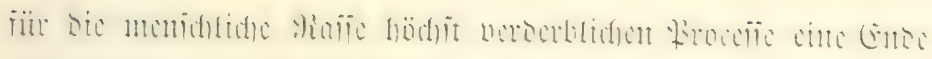

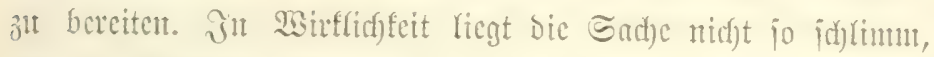

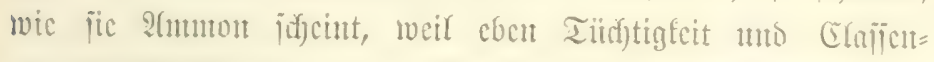

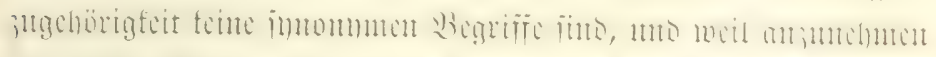

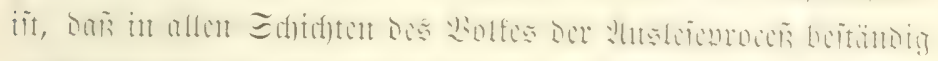

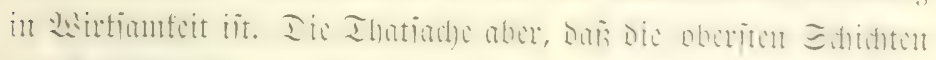

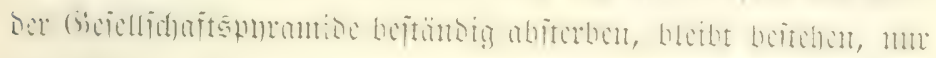
Darj jie uncocr, wic Epcncer meint, mit cemer angeblidy in Forge

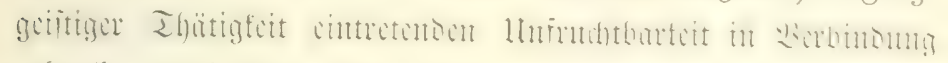

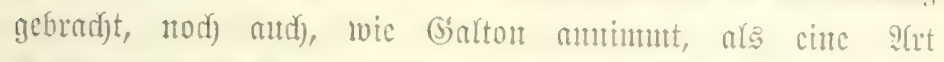

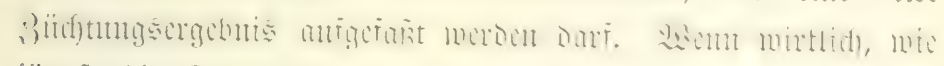

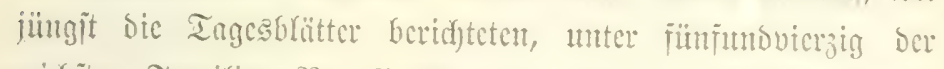

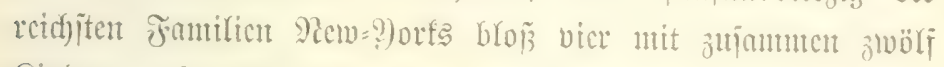
Sintorn gejegnet icin jorlent, io ijt cs jojuer, an andere als

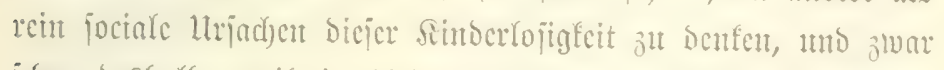

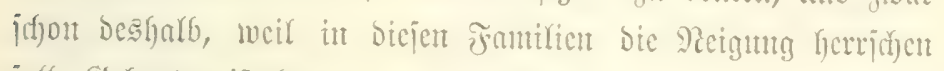

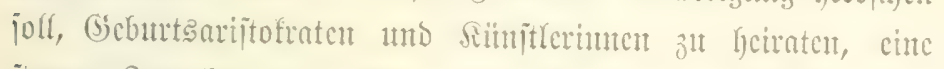

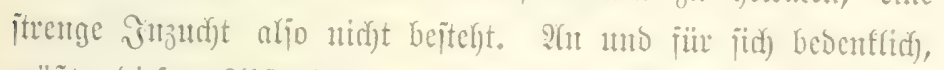

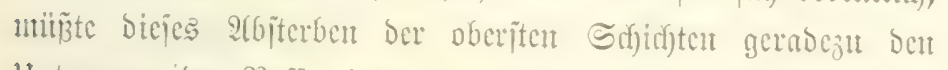
llutergang ber Bajie bebenten, went wirffidy Gsaranticn vor=

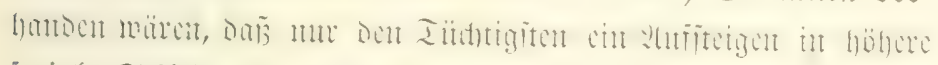
jociale Sdjidyten crutöglidyt wïroe.

Bont Stanopunfte Der Biologie ijt aljo DaS Bejtelfen

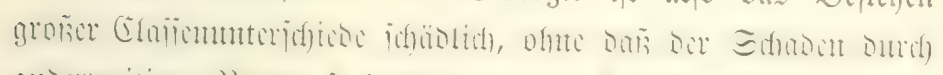

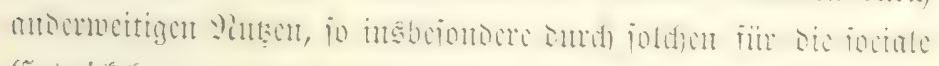

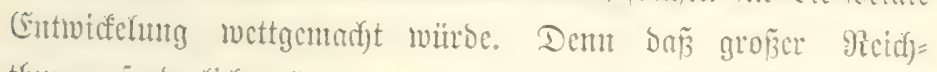

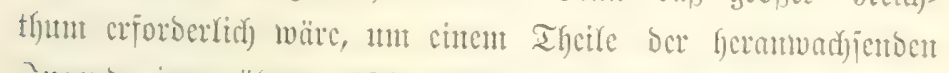

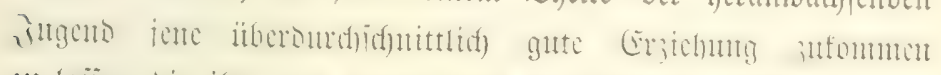

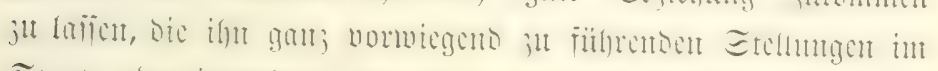

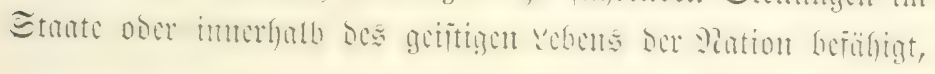




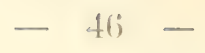

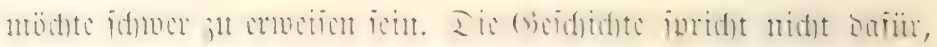

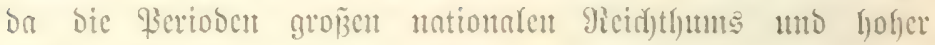
Člafiendifferenzinung Durdjants nidjt iumer mit ben ßerioben

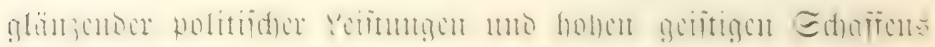

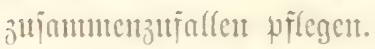

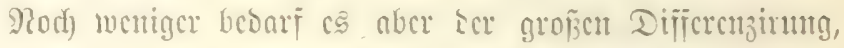

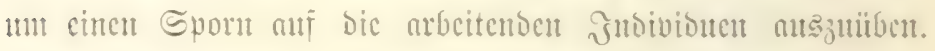

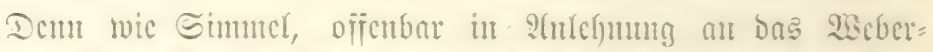

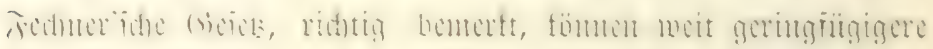

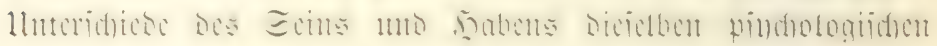
mat iontigun

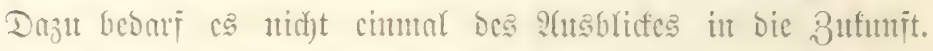

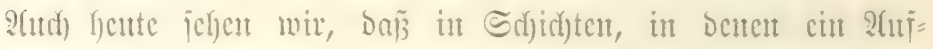

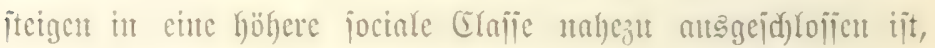

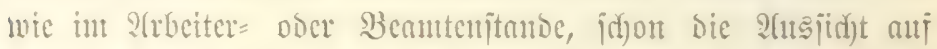

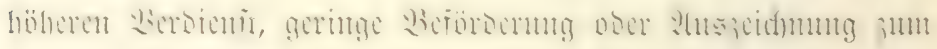

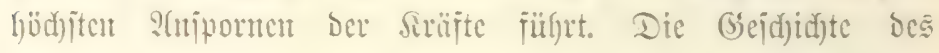
S(ltertfums fiefert uns bolfenos cinc Jülle von Beipielen

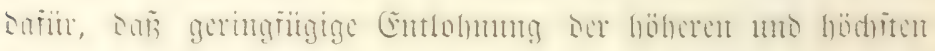

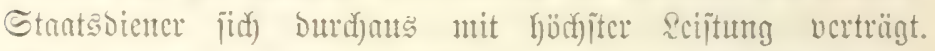

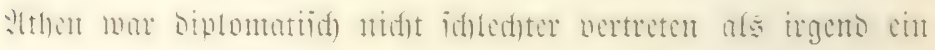

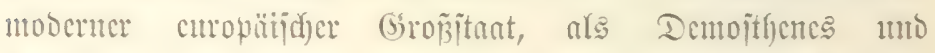

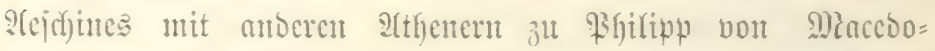

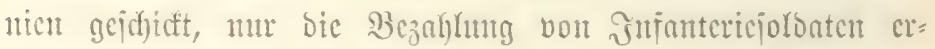

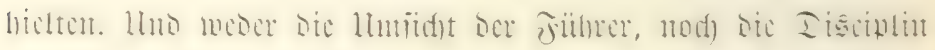

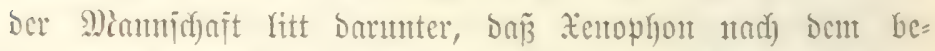

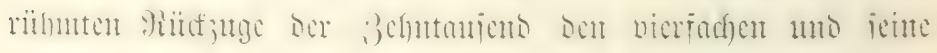

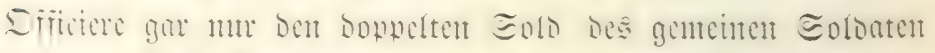

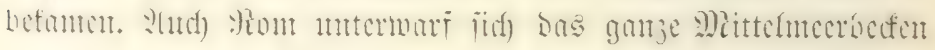
unt cincm Seere, in bent Der Centurio mu ben Dopperten \&ohn 
Des gentenen Eolonten bejog. Crit nadi) Dent Trimmuirat und in ber Saijerzeit trat cinte weitgefonde Difjerenzimung in

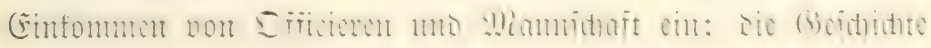

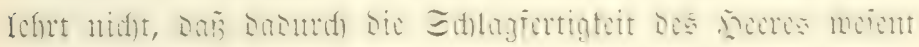
Yicf) vergrö̈zert wordon wäre.

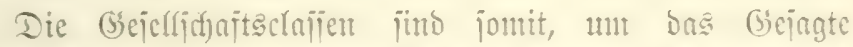

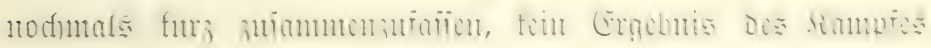
ums Dajein in Sime Darwin's. Ient too chit fimpi

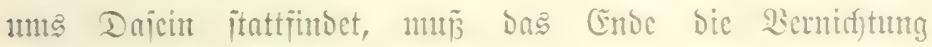
Des cinten odor bes anocren Theifes, Des mitberangepañten jein. WBill man aljo in ber Člafientbiloung cinc gewije Susleje jefen, jo ijt bicje ganj mocrer art als bic biolo=

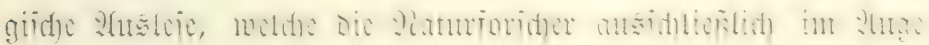

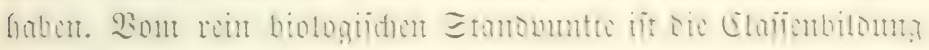

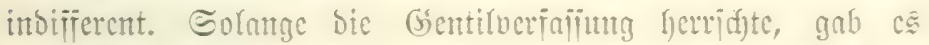

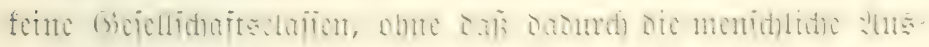

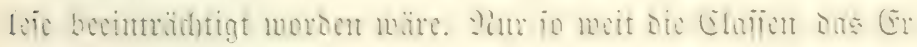

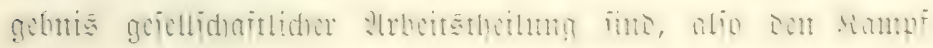

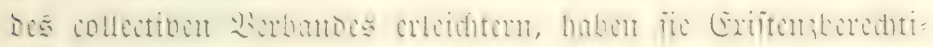

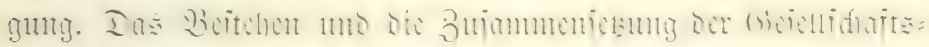

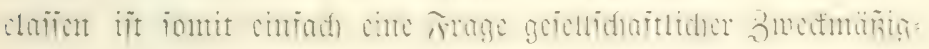

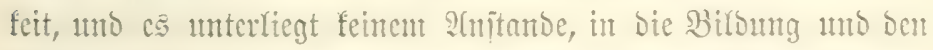
Bejtand biejer Cernijen cbenjo cinzugreifen, wic in alles antoere,

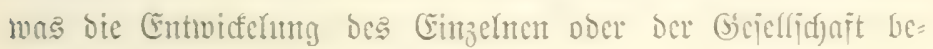

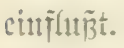

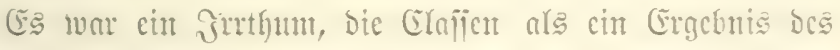

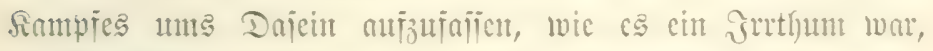
Die Roritelfungen, bie man von bicien fampie ums Dajem im

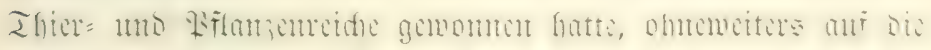

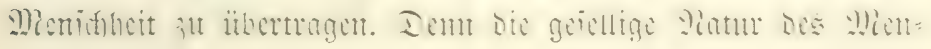




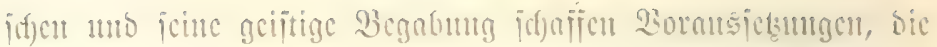

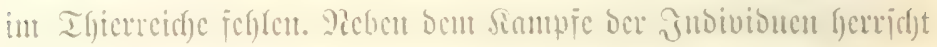

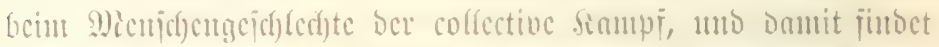

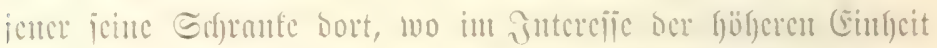

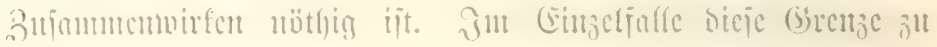

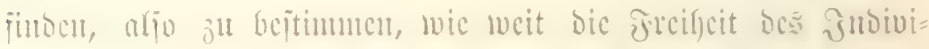

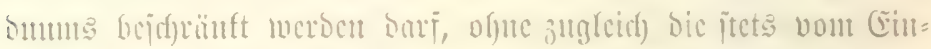

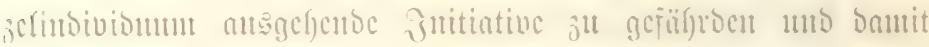

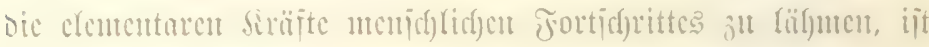

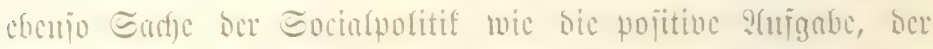

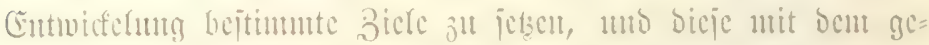

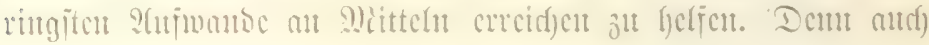

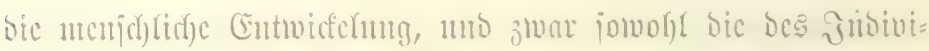

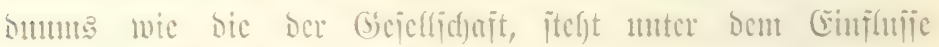

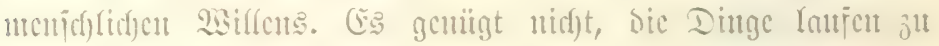

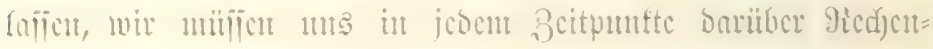
iffayt ablegen, wohin wir treiben, mo im Etronte Der CEnt=

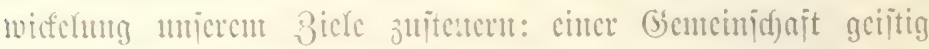

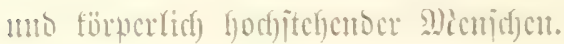

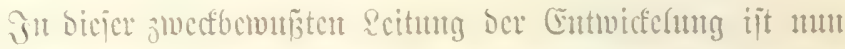

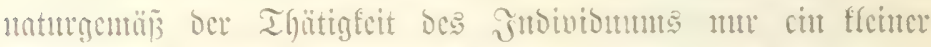

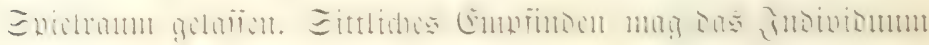

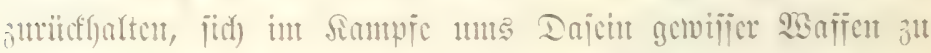

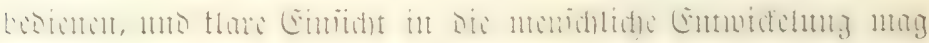

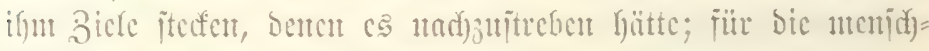

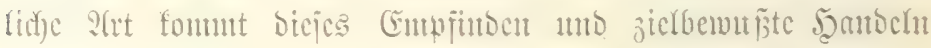
utidft in Betrad)t, jo fange es bereingelt ijt. Sam ber Colfectiv= wille fam ben SampF ber Cinzelnen int Jnterejic ber Biruppe

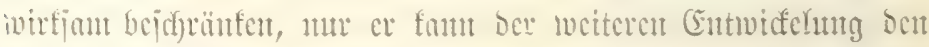

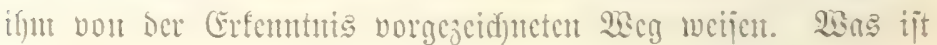


noel ber Colfectividffe, wic fonment er ju Etanbe? Jit $\mathrm{cr}$ ber

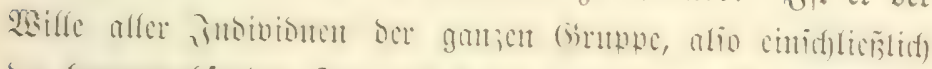

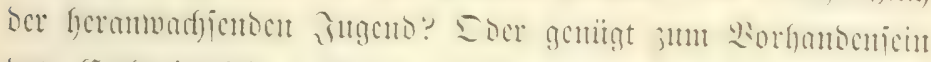

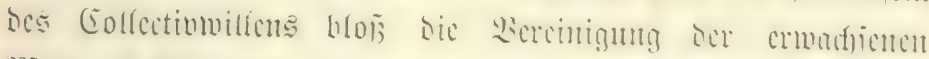

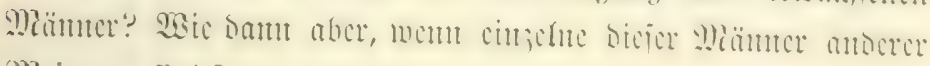
Micinutg j̈̈to?

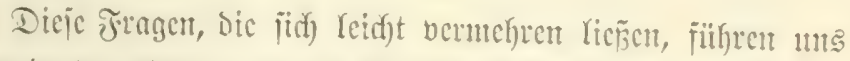
mitten in ben Etrcit, ob bic Gicillidart hrop bie Emmute aller

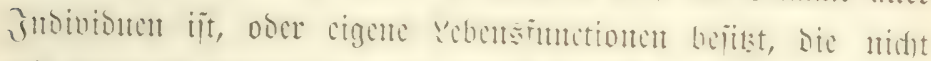

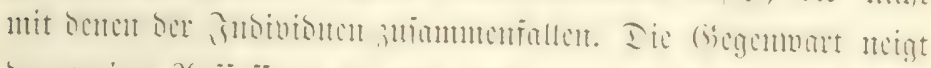

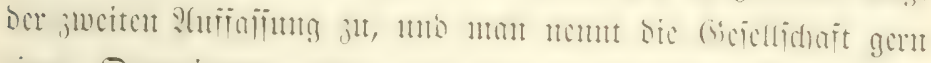

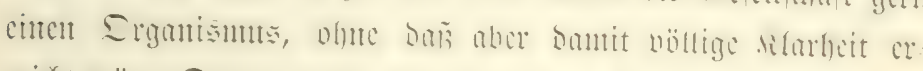

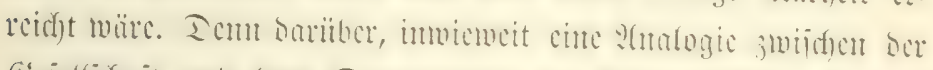

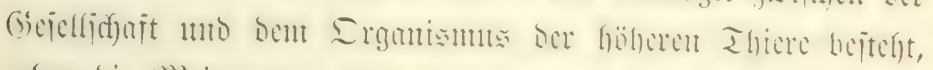

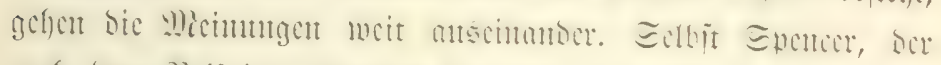

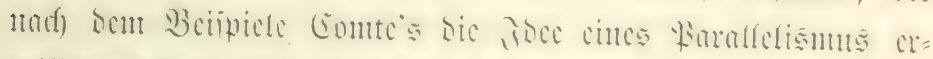

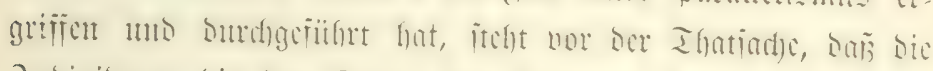

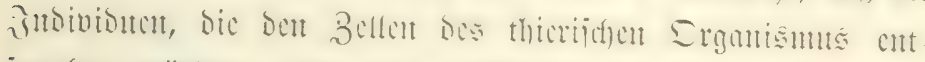

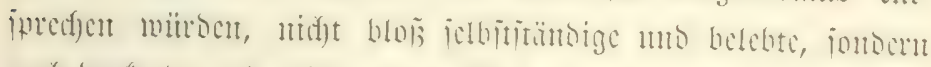

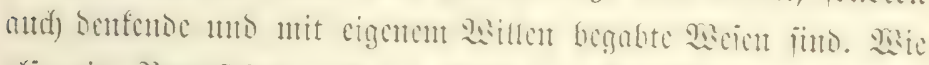

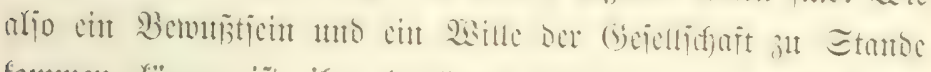

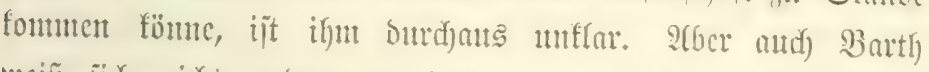

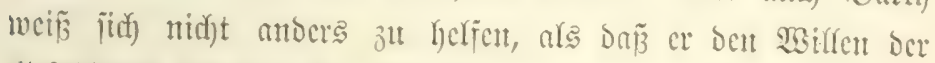

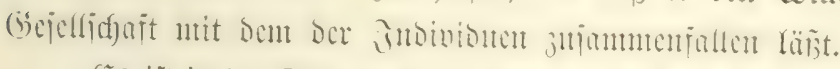

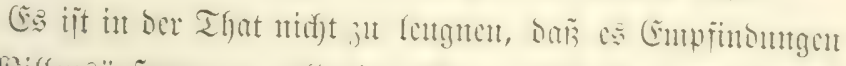

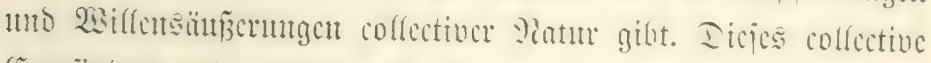
Entrintoen uno colfective 然olfen tritt am ftïrfiten herbor ant= gejicfts grojer 2orgünge in jocialen seben. Jut Siriegen, bei lut =

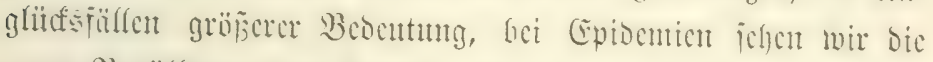

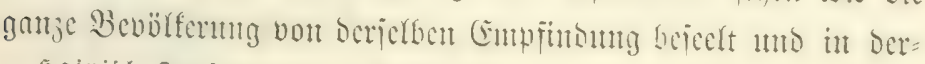




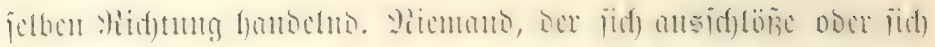

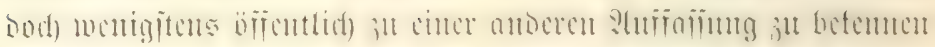

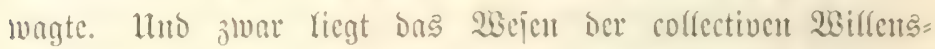

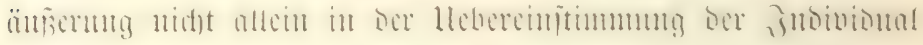

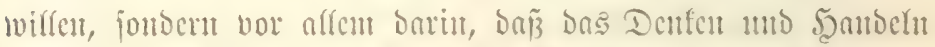

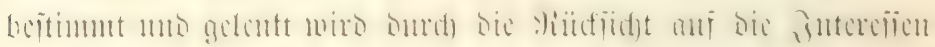

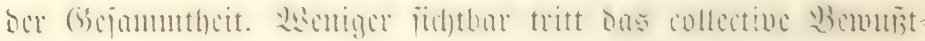

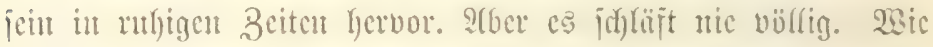

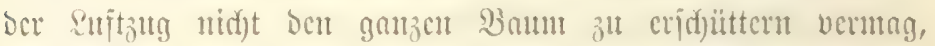

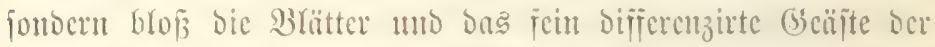
Sirouc bewegt, fo werden bie Siajien von Den Borgängen bes

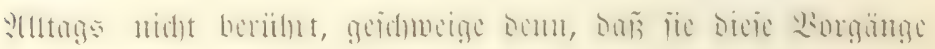

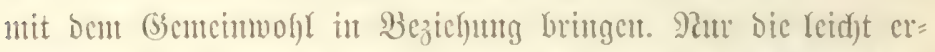

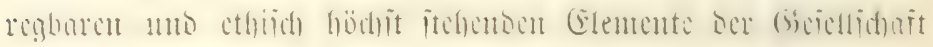

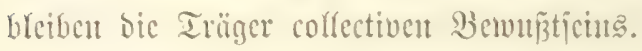

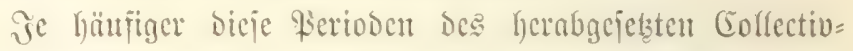

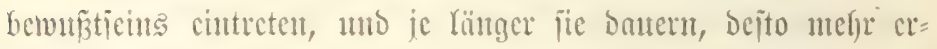

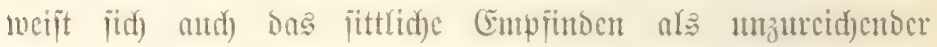

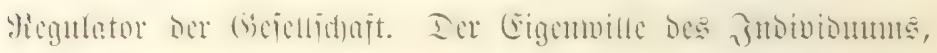

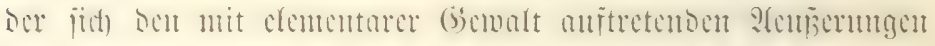

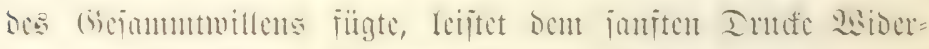

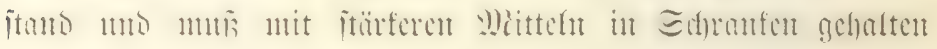
werben, burd) bic 3wonggnormen bes Red)tes. Der jittlid)e

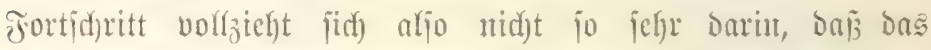

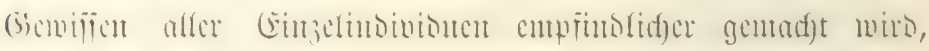

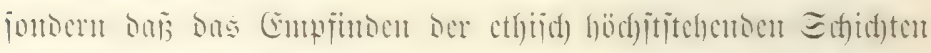

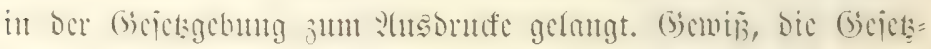

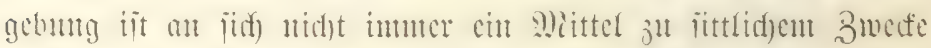

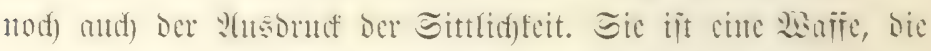

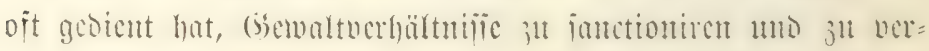




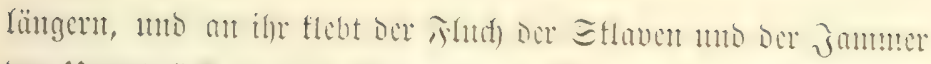

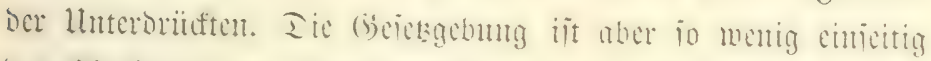

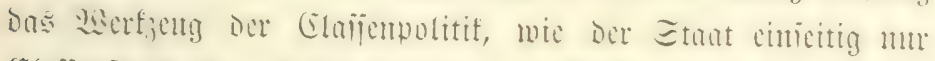

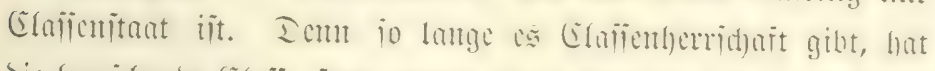

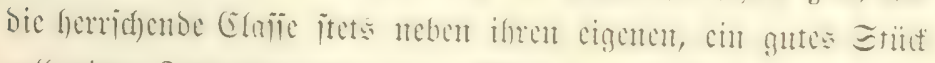

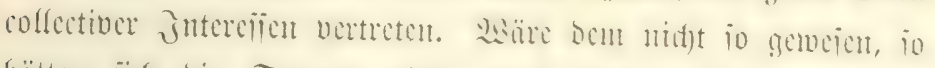

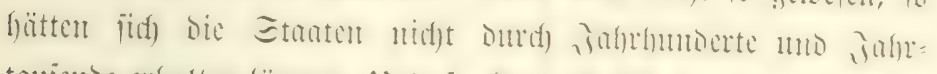

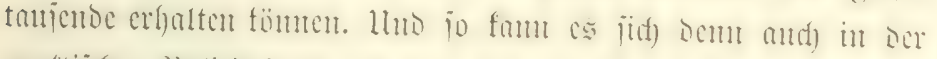

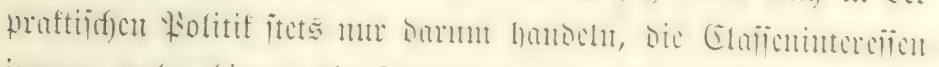

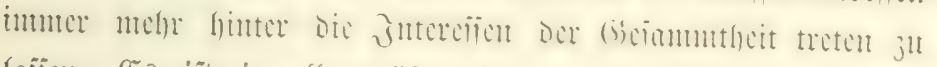

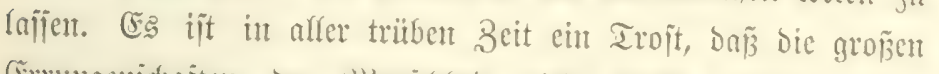

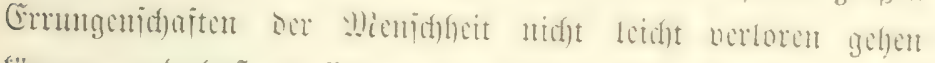

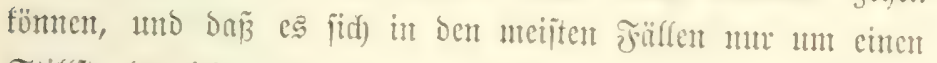
Stillitans, nidyt aher um cinen Rüdfidyritt handert.

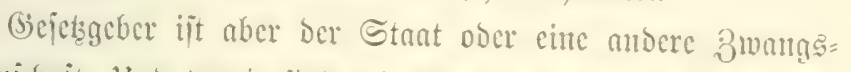

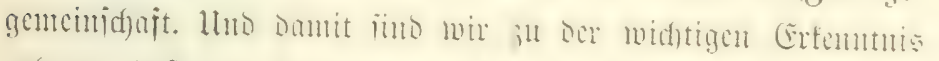

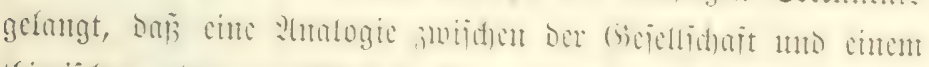

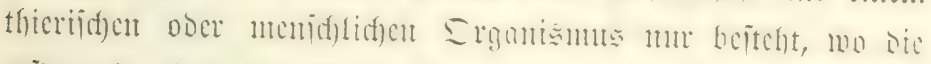

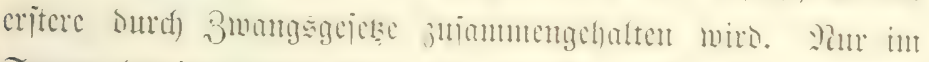

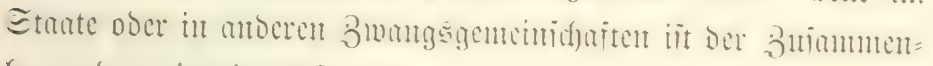
fonng ber einjelnen Theile ein jo fejter wie int antuntijody Sï̈rper, nur im Etante mo in ähnlid)en 3wangsgemeinidgaten fino Drgane vorhanben, die Dem Centrahervenjuitene cnt=

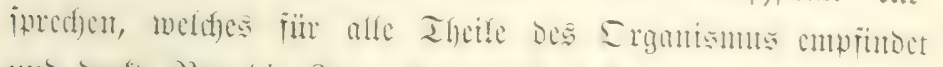

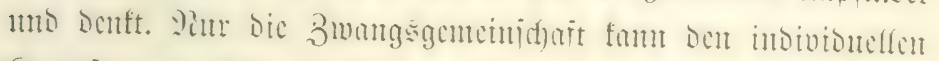

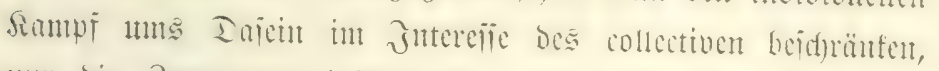
nur bie 3mangsgemeinidgät fam in jolge ihres contralen

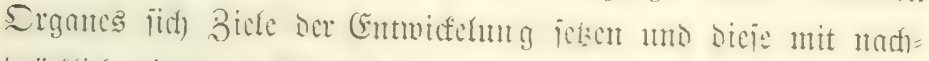

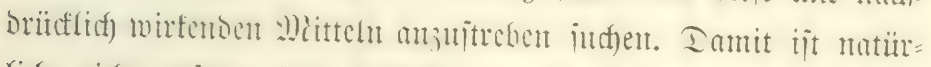

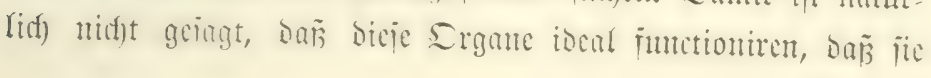




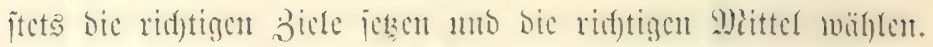

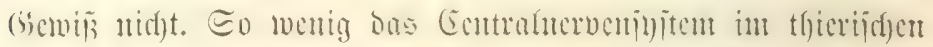

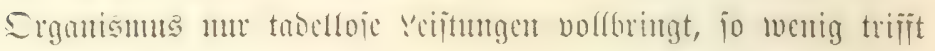
Dics and in Stante ju. Jut bem einen wie ben allocren Jalle

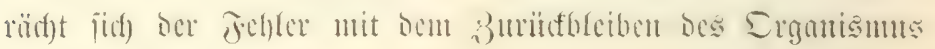
oder nit Den Tode.

刃ur hat $\mathfrak{c}$ ber Stant nod) mit ganz cigenen Sdywierigfeiten

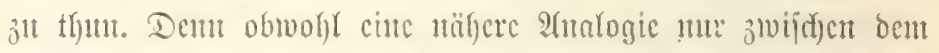
Etante unt ben thicriften Srganismus bejteht, io ijt jic bod) feinte volffommenc. Sdjon Epcncer hat, wic bereits cruälynt,

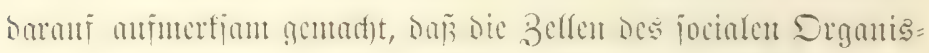

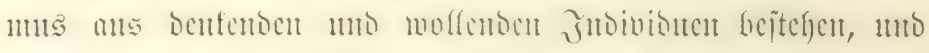

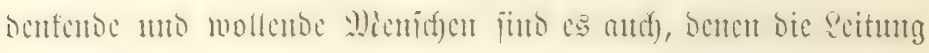
bes ganjen focialen Rörpers antvertrant ijt. Währento cs aljo int thicrifuch Srganismus cigene Rervengelfen gibt, Denen

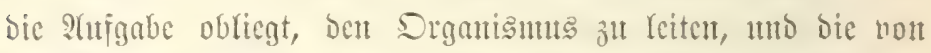

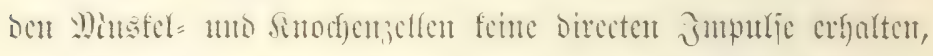

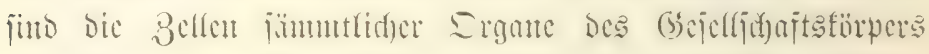

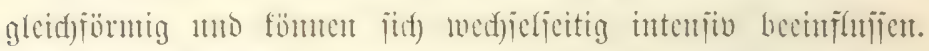

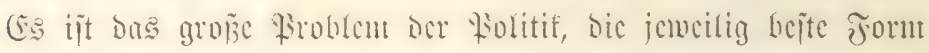

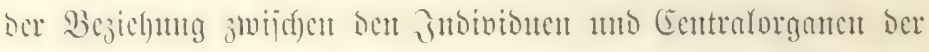

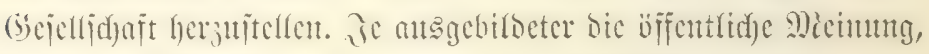
ic höher bic Jutelfigenj, je intenjuer bas Géühl der Solibarität

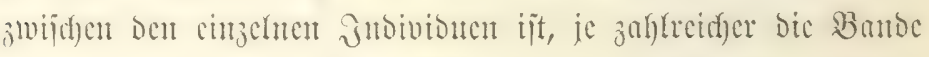

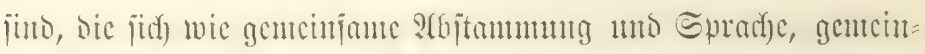

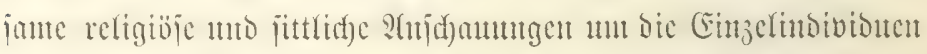

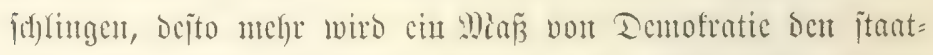

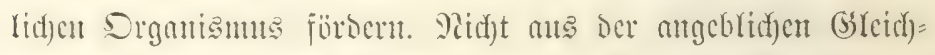
heit ber Memid)en, nod) ans bem gleid)en Red)te ser Jnoiviouen, wie bics bas Patured)t bes vorigen Jafhrfunderts amahu, 
mo wie bies nody lyeute in mandjen Sioppion iputt, Darf man Dentofratijd) Forderungen ableiten. Dem wie bas ?eben ber Gejell=

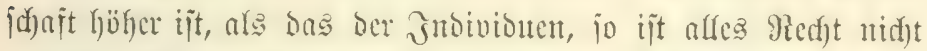

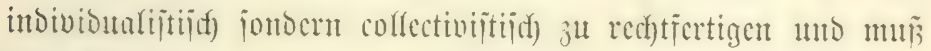

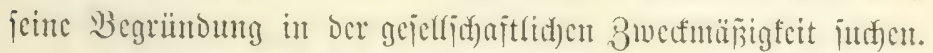

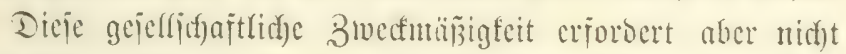

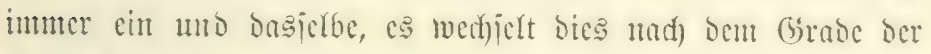

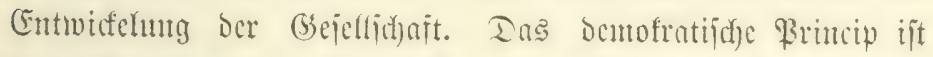

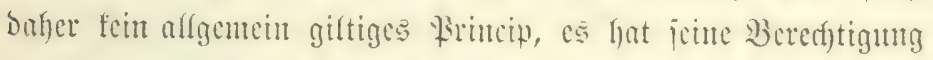

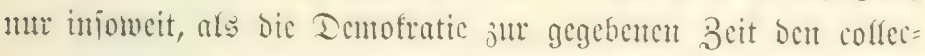

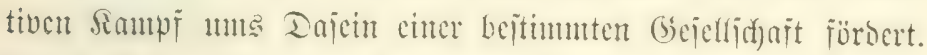

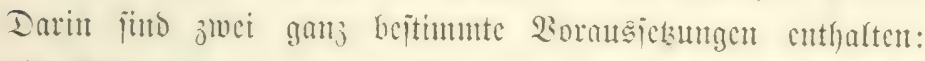

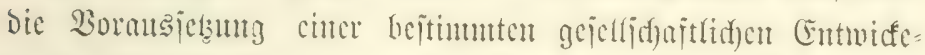

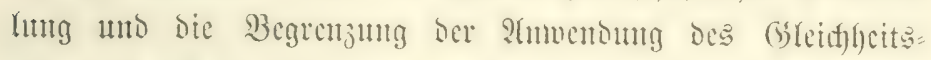
principes anj bic Deitglicoer ocr (íciellifturt, aljo anj alle jente, Die burd) Solibaritüsgerül)le mitcinanoc verbutoen finto. Nur wo beibe Eorantsjetsuttugen jutreffen, fann bic Ientofratic ben

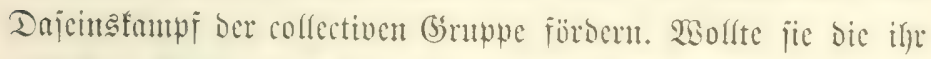

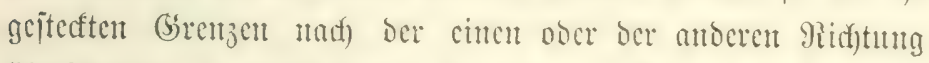

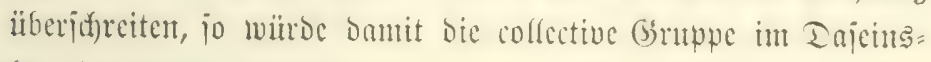

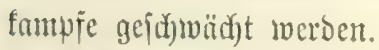

So fïfrt Denn in ber Ihat dic Betradytung bes Sampies

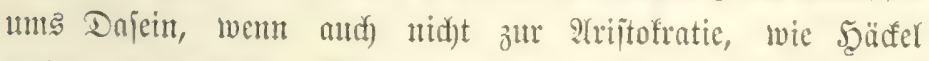

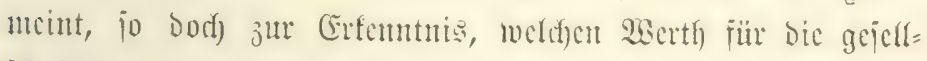

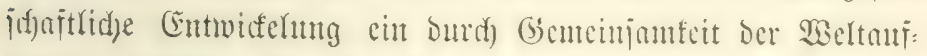

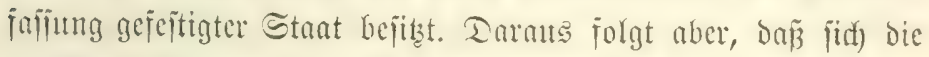
cinjeluen Staaten uno Staatengruppen ich)ärier voncinander

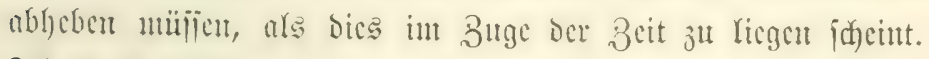

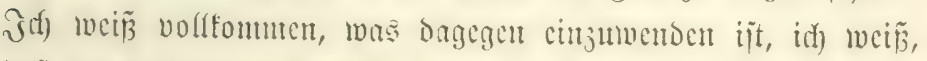

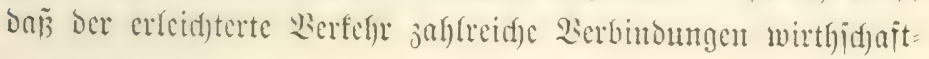




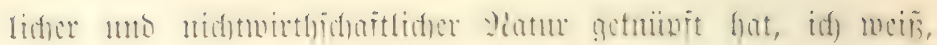

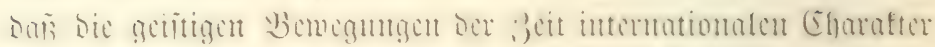

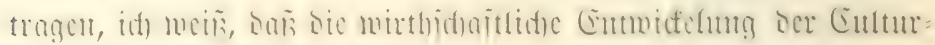

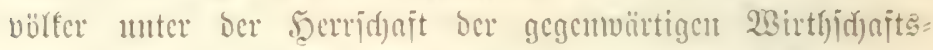

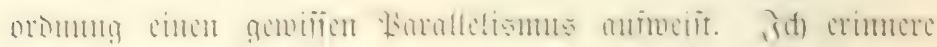

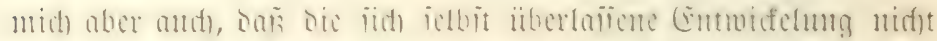

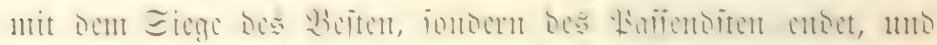

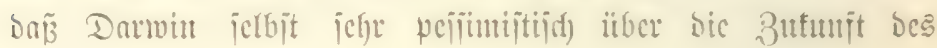
Micnidjengcidy)(ed)tes bad)te.

Der Sicg bes Rajicnojten ijt, wie wir wijien, nidjt jelten

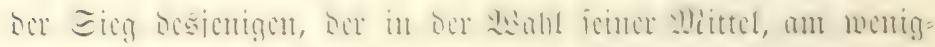

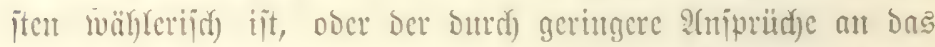

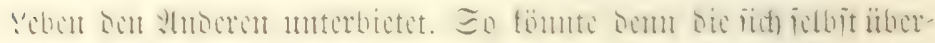

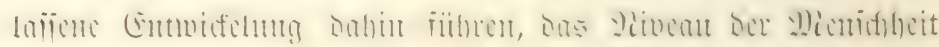

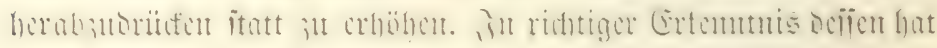

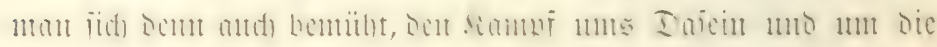

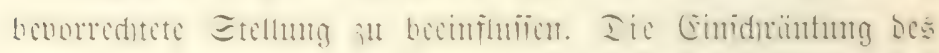

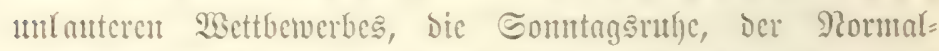

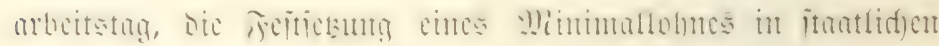

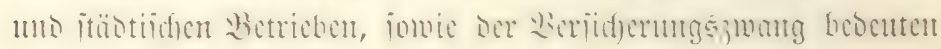

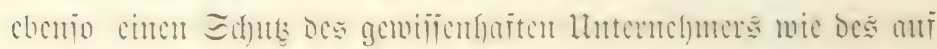

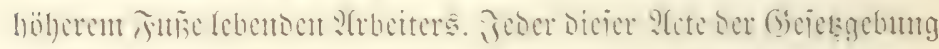

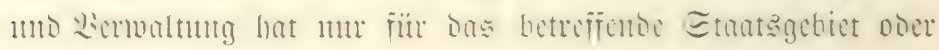

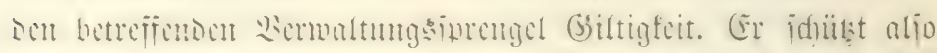

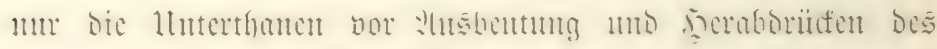

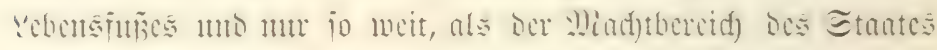

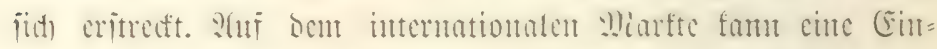

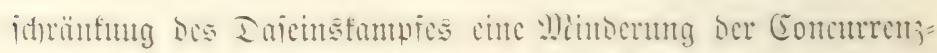

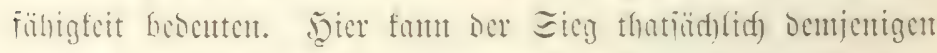

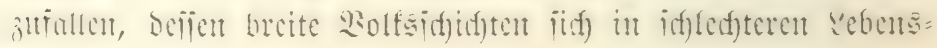




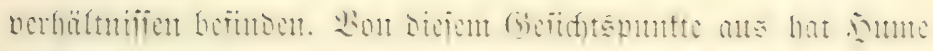

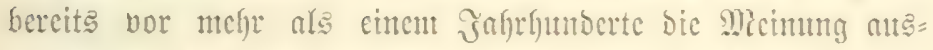

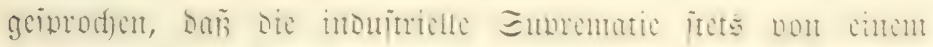
Bolfc añ bas antore übergeben mïije. Denn cin Bolf mit

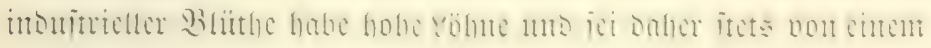

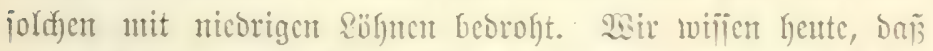

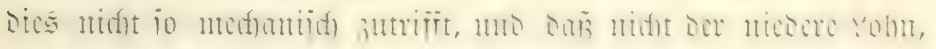

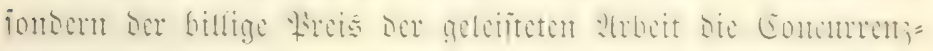

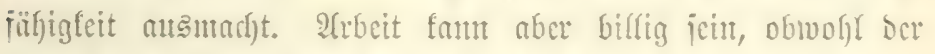

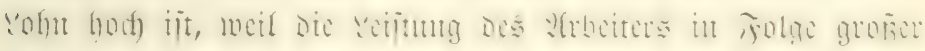
2(rbeitsintenjität obct 2ertuendung von N2aid)incn cint uns

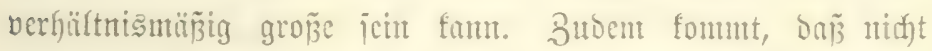
jebes Pand über cinc Srganijation bes J̃andele int weitciten ミame oc

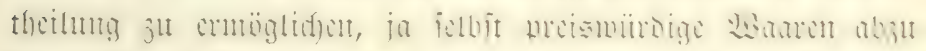

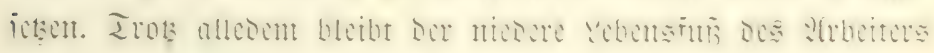

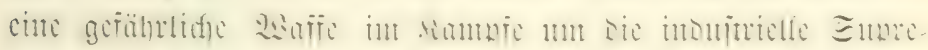

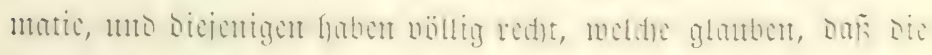

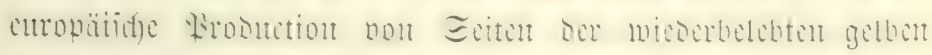

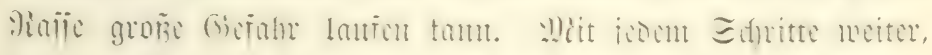

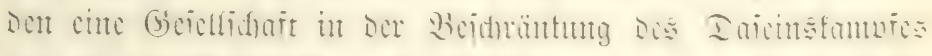

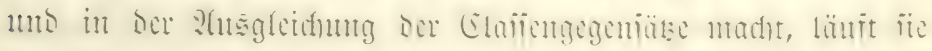

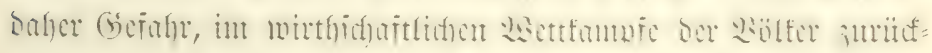

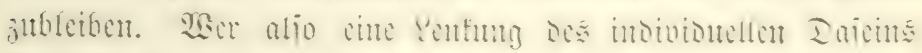

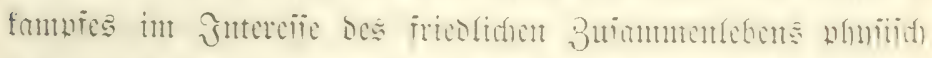

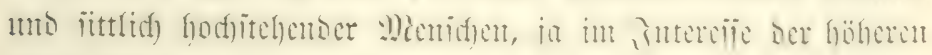

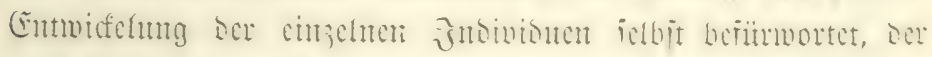

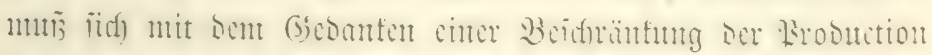

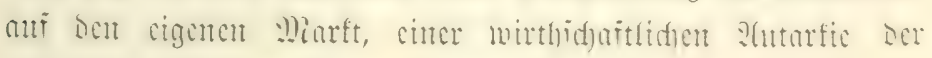
betrefiendent Ration vertrant madyen. 
Mian weife ben gegenïber nidjt nup bie raj(d) wadjenbe

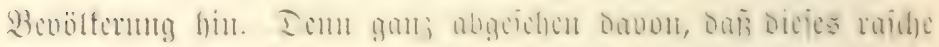

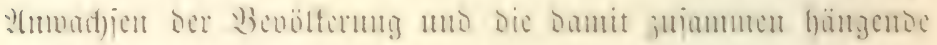

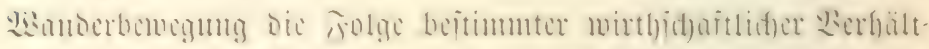

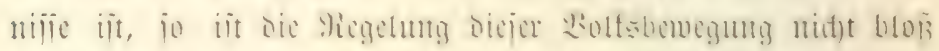

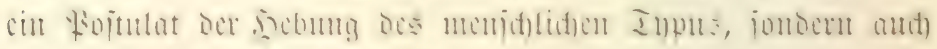
cin Behot rein mirthithuitlifter Siothmenoighteit. Eem niemano

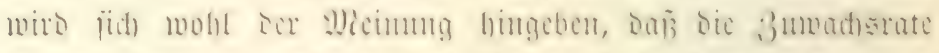

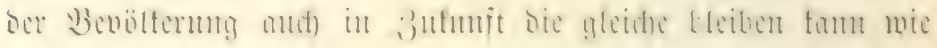

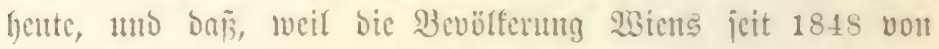

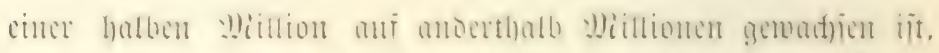

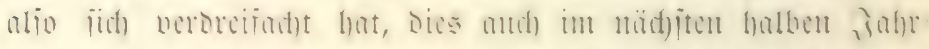

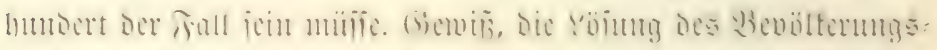

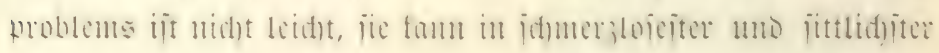

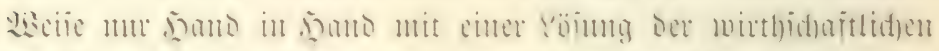

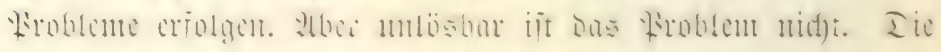

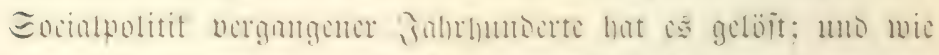

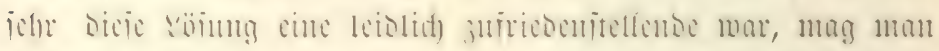

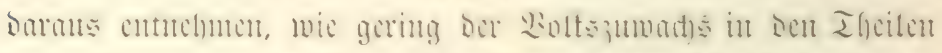

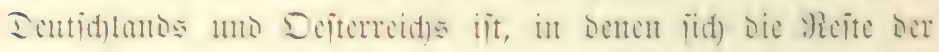

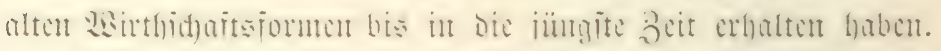

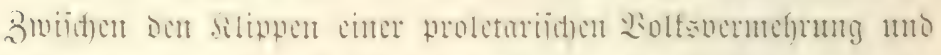

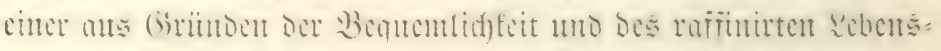

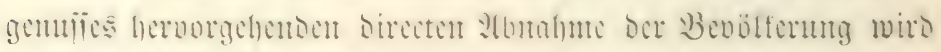

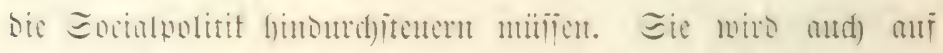

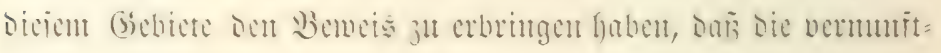

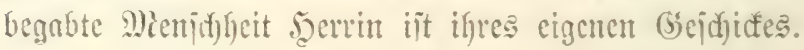




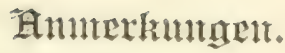

3u Seite 7. 9lidyt mit lluredjt madjt Stammler mif bent

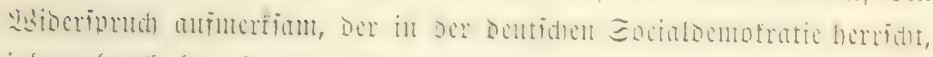

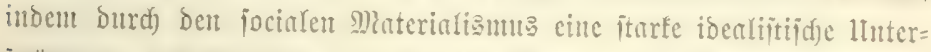

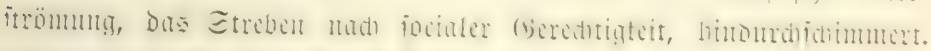

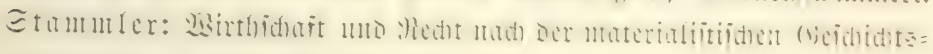
mแf̆aijutu. 2cipzig 1896 (ङ. 63).

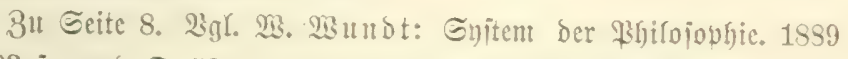

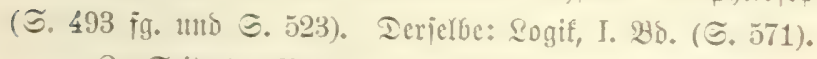

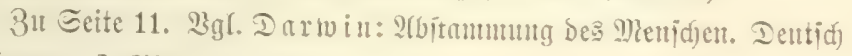
von (ธaris, I. Bb. (ङ. 154).

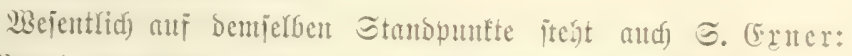
Die Moral ars Wanfe im Sampie me Injeit. Wien 1892. Snbes

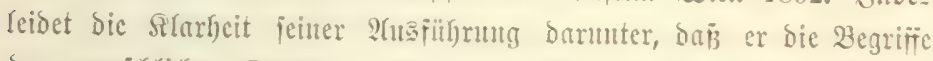

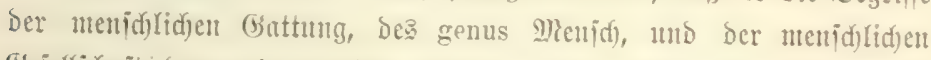

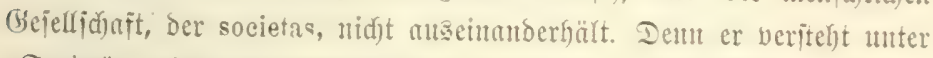

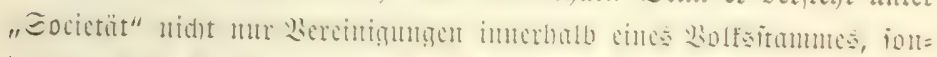

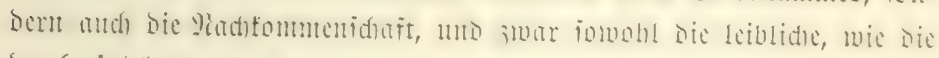
Durd) intellectuelfe Bande mit Den 23orfábren verfnitpfte. Dả̉ bic

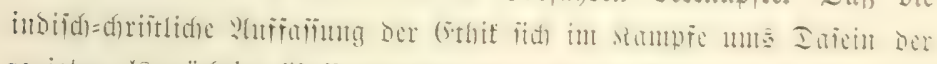

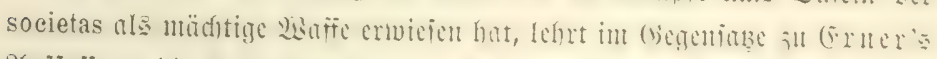

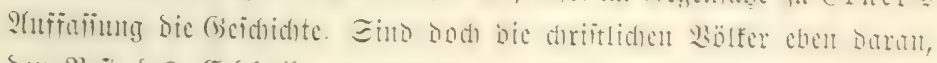
bent Meit bes (5robalfes aüzutfeilen. Ient gegentüber breht ïd) Der eigentidide Streit barum, ob nidft Die Durdjiïfrumg ber Joee menid)=

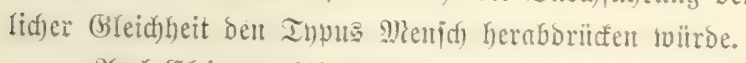

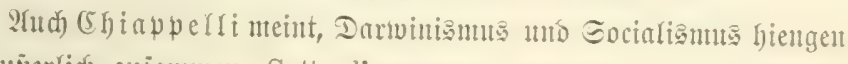
utr äuß̉erlidf) วujummet. Sotto l'apparente armonia si nasconde la 
profonda diversità dello spirito, che le anima. T. Ehioppclli: Darwinismo e Socialismo. Nuova Autologia, 1545, Nebruarheit (ङ. (6+1).

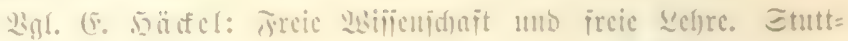

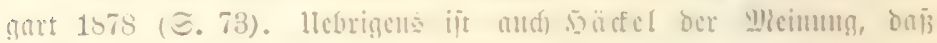

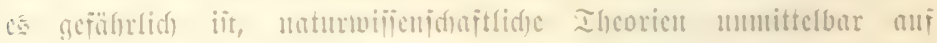

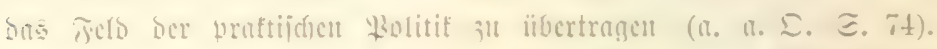

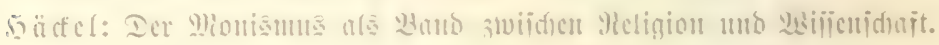
$183: 3$ (ङ. 31).

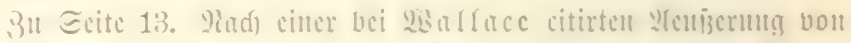

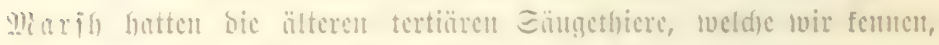

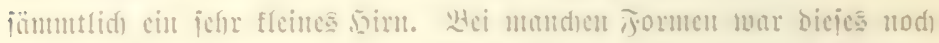

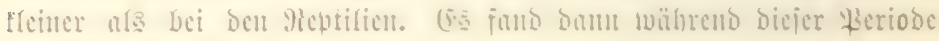

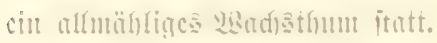

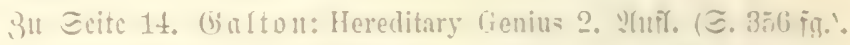

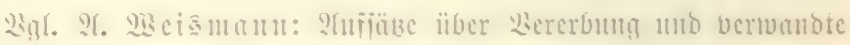
biologiäde Frugen. Ient 1992 (こ. 790).

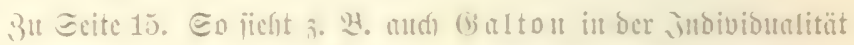

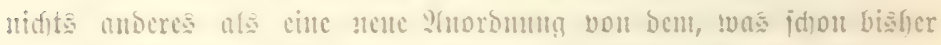

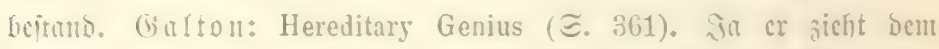

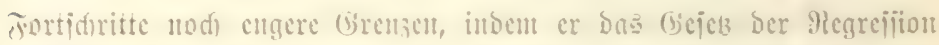

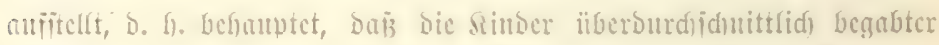

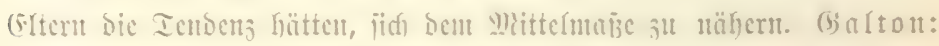

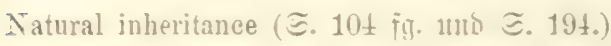

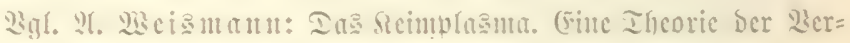

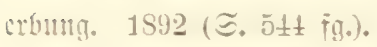

3u Scite 16. (j) alton: Hereditary Geuius (ङ. 352).

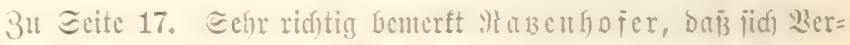
jiilumtumgen nidgt vererbent, uncil jic nid)t int ?rupoijungsintercjie ber

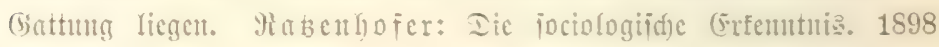
(ङ. 278).

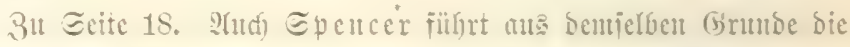

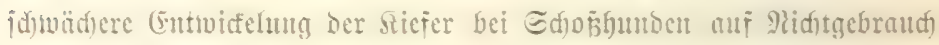

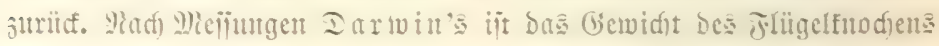

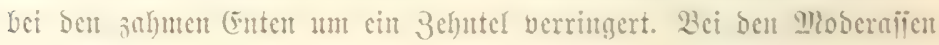




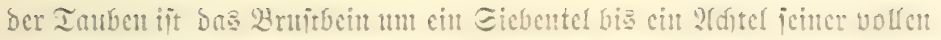

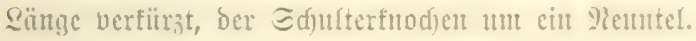

玉o beriditet

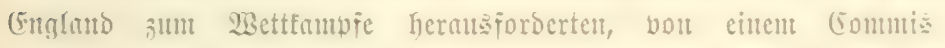

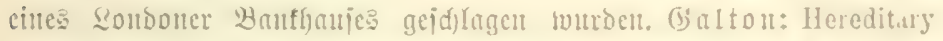

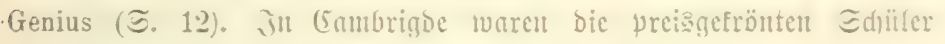
nicht feltelt jugleid) bic beiteit Muțerer (こ. 321).

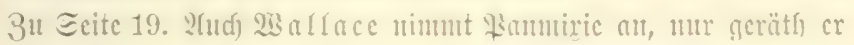

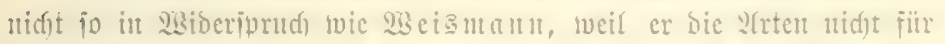

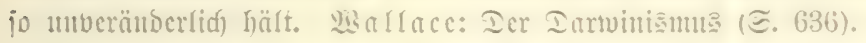

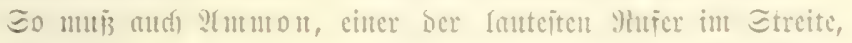

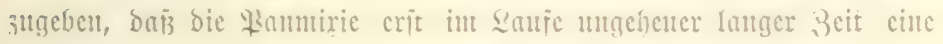

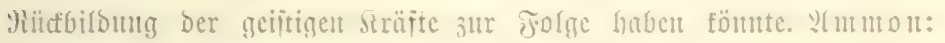

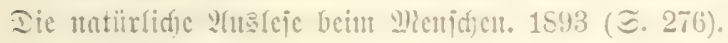

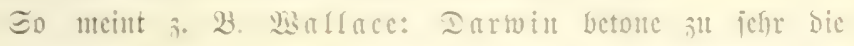

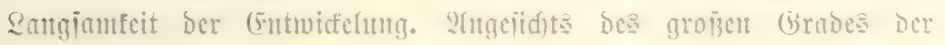

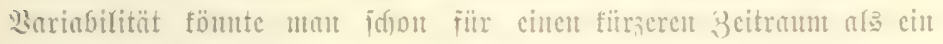

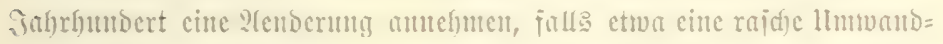

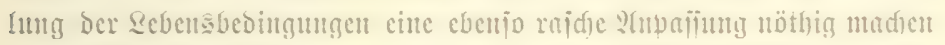

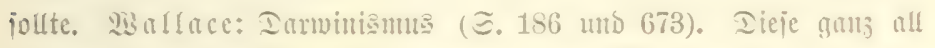

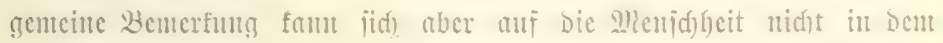
Wabe unic mif bie Thier= mo

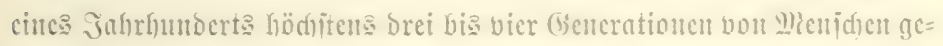

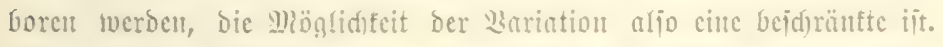

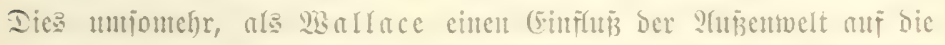

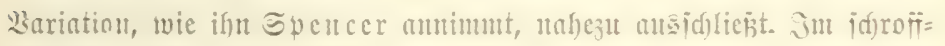

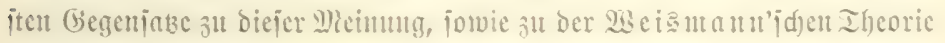

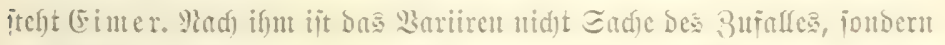

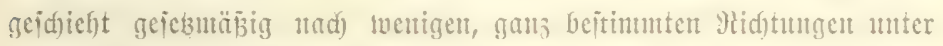

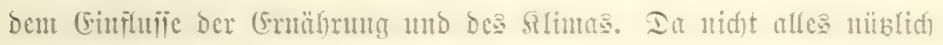

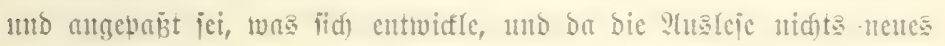

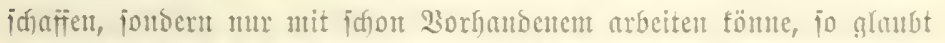

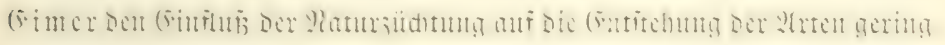

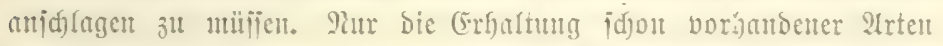
burd) natitrlidfe 3udgtwahl jei Dentbar. (5imer tritt aud) für bic 
2ererbung crworbener (Eigenifyaten cin. 23gl. Theodor (5imer:

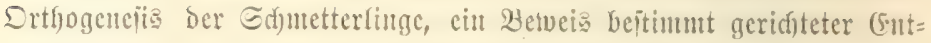

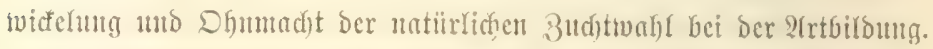

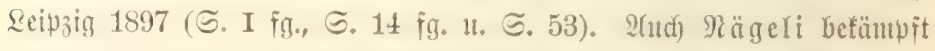

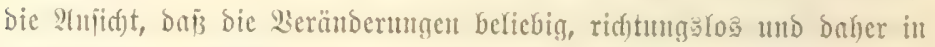
verichicdenten Inbividuen ungleid) jeien. Desgleidgen unteridyeidet er

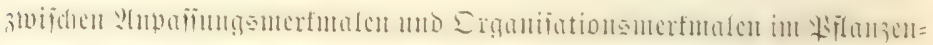

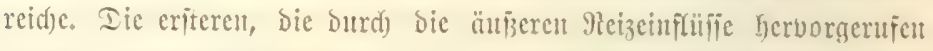

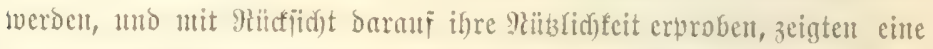

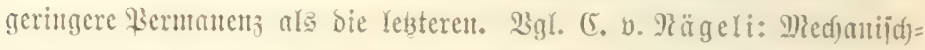

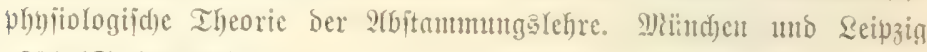
1884 (ธ. 286 แnठ 327).

3u Geite 20. Dicien Fehler begeht 3. 3. ein jo herborragentber

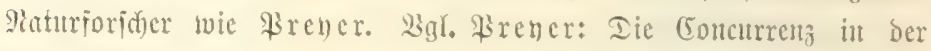

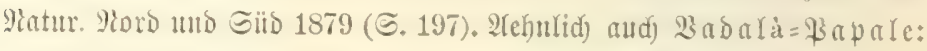
Darwinismo naturale e Darwinismo sociale. $18 \varepsilon 3$ (ङ. 273).

3u Seite 21. 2gl. Warrace: Der Dariuinismus (S. 52 bis 54 mo 162 bis 163) und (5. Strasburger: Die Iater dez Rebens. Dentid)e Munsid)nt, Jaunar 1899 (ङ. 92).

3u Geite 22. D. Efferb: 2rbeit und 20ben. Gruttorinien ciner Pouphryfiofratic, 1890 passim, inabej. I (ङ. 2t2).

Thomas 5urfen: Sociale (5ifuns. Beredtigte bentidye

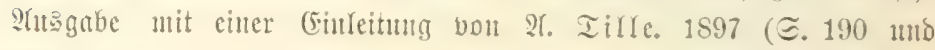
$225,9(1 m \ldots$.$) .$

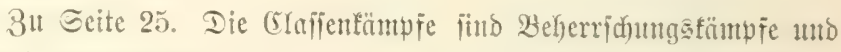

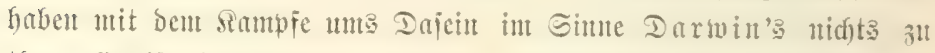

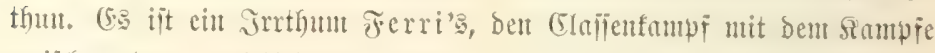

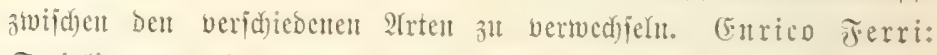

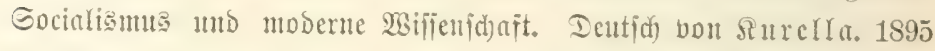

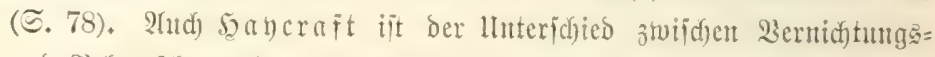
unto Beberridungafompi nidjt flar geworben. (Ex ipridyt bou eitem Sampie ung Drfeit, in bent bic Meichen Sieger bleiben, fïgt aber bei, Der menidjlidje Rampf uns Dajein unteridjeide jid) von Dem thierifden

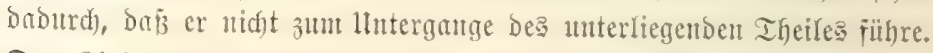

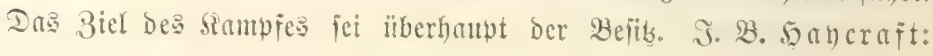




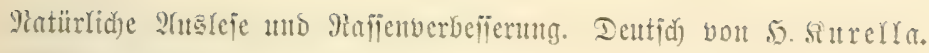
1895 (ธ. 135 ๆg.).

3u Geite 26. 9rad) (5omte beitefyt mur bie (bejellid)aft wirflidf),

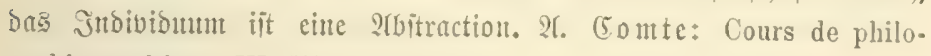
sophir positive, VI. BD. (S. 590).

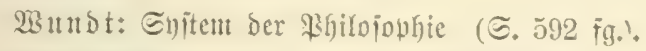

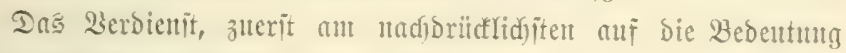

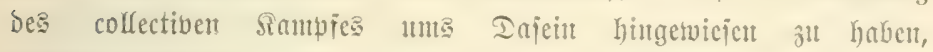

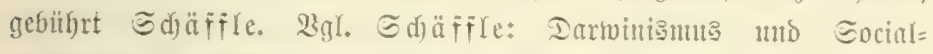

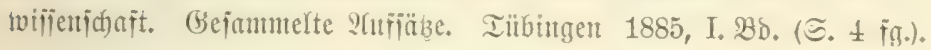

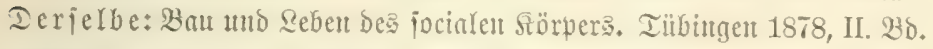
passim. Derielbe: Dentide Sent= und Beifragen. Berfin, 18yt

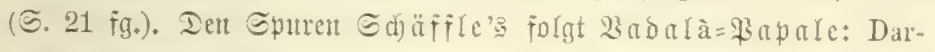
winismo naturale e Darwinismo sociale. 1883 (ङ. 344 ut passim). (5r

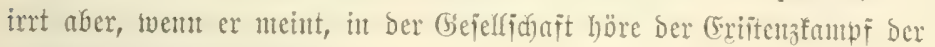
Inbibibuten alt (ङ. 393).

3u Seite 27. Eo jagt audi Saeger: "Der Sumpi umb Iajeit

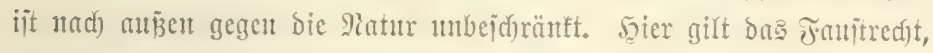

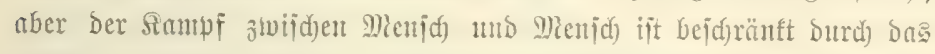

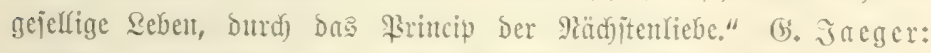

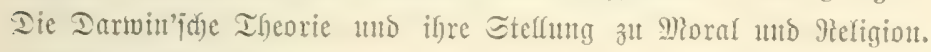
1869 (ธ. 109). 2fu cinte bolle Bejeitigntug Der individutlen Iajeitu=

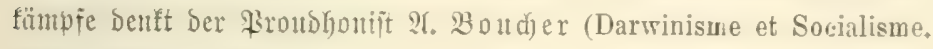

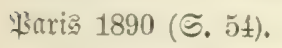

"Eolfte in einer Bejellidgät die Mieinung iuberhandutemen,

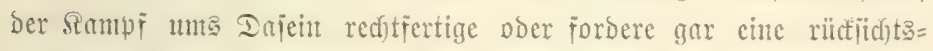
loje Seriolguntg ber eigenen Snterefïen, cine Interorïtüng mo

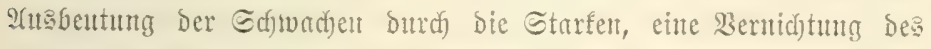

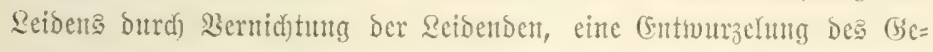

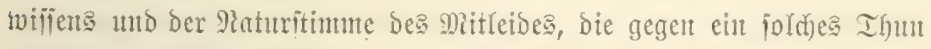
(Sinprache erfeben; follte in einer beferfichaft bie Selgitiucht fortge=

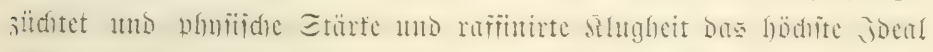
werben, jo witrbe ein joldjes Gemeinmejent bent lntergange nahe jein,

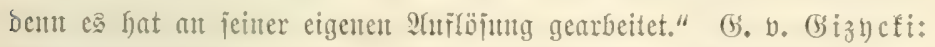

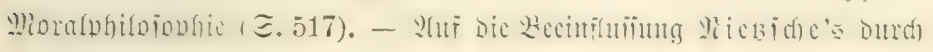




\section{$-\quad 62$}

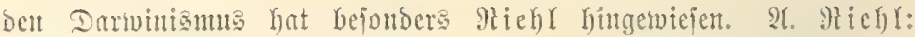

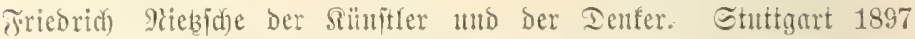

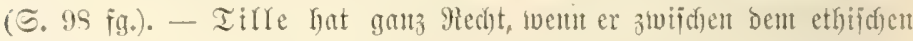

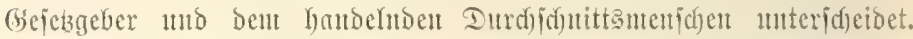

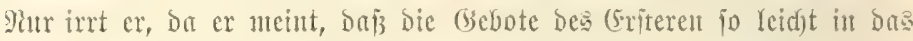

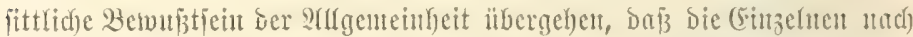

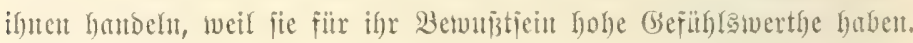

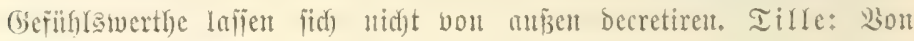
Darwin big 9riebijuche (5. 79).

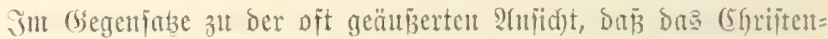

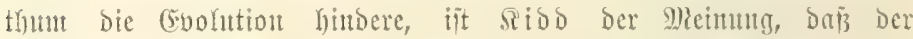

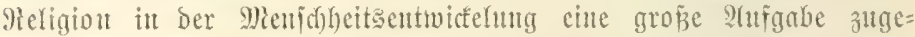
fallen jei. Dem Die Snterefien Der Gejammtheit fielen nidht, swie bic Ittifiturier meinten, mit benen ber Snbibibuent 3ummen. Sm Snterelie

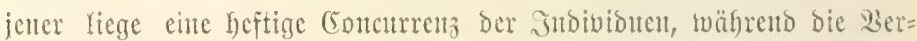

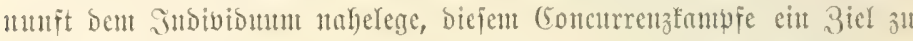

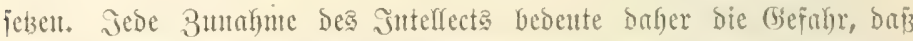
Die Triebfräte ber (Entwickełung gethemmt werden, fie mirfe antifociar. Iemgegenüber bringe Das religiöje (ETement bie lluterorbmutg Der indi=

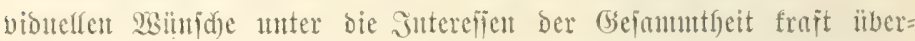
natiurfidyer Ennction mit fid). Der mäd)tigite Snebel Der (Entwicfelung

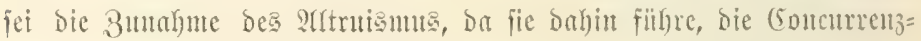
beditgumgen fïr 2ulle gleich) zut geitultent.

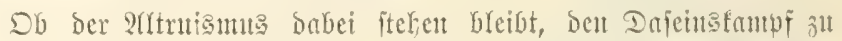

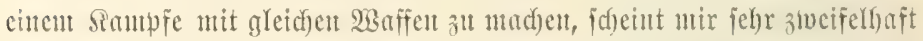

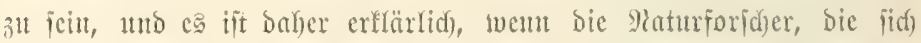

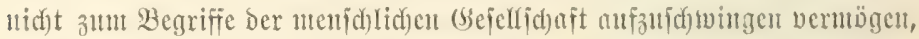

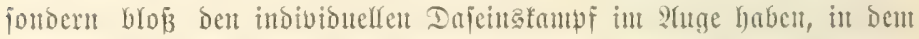

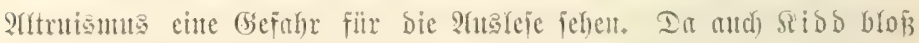

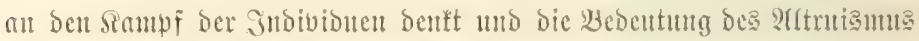

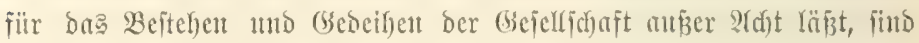

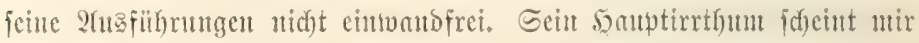
aber Darit zu liegen, Da jer trotz viełer richtiger Senterfutgen weder erfemt,

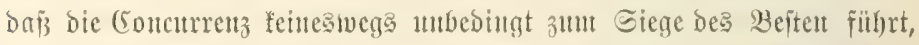

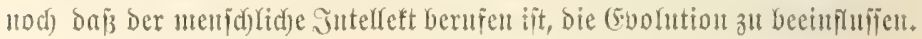




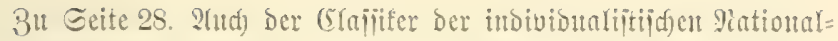

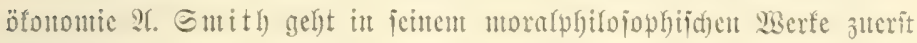

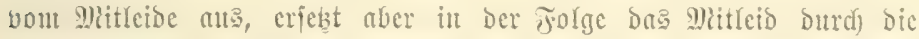

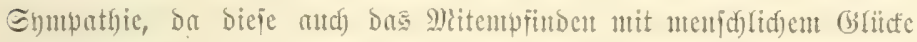

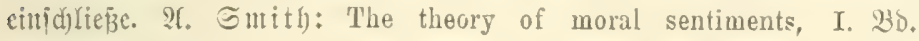
(ङ. 5).

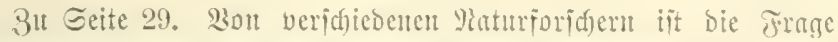

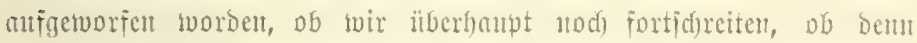
in ber hentigen (bejellidaft bon cinen Sautpie ums Iajein bie Mede

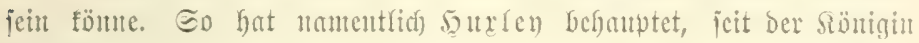

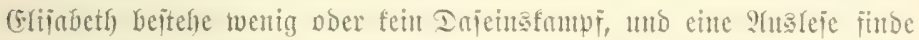

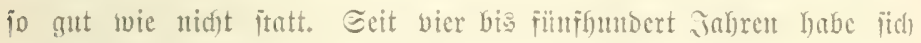

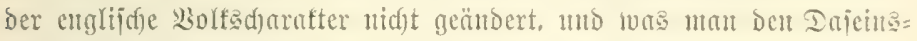

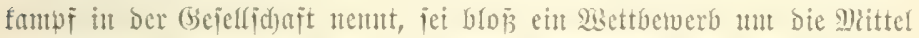

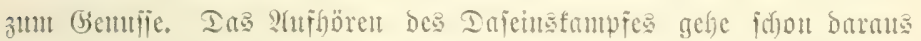

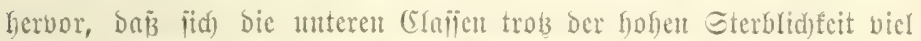

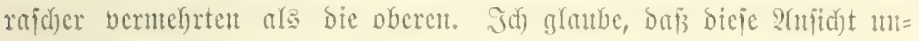

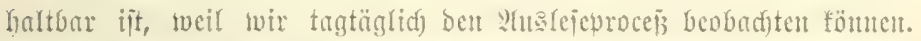

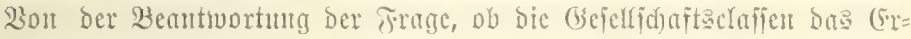
gebnis des Simpies nmb Dajein find, wolfen twir vorlünfig abjehen.

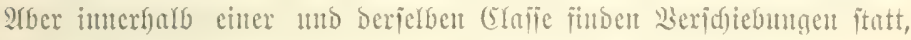

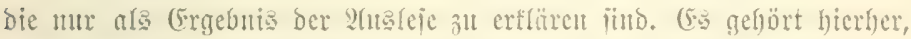

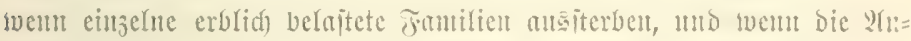

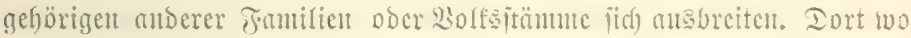

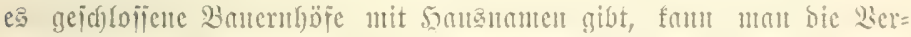

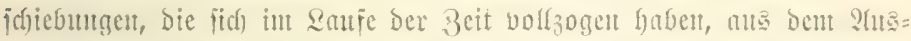

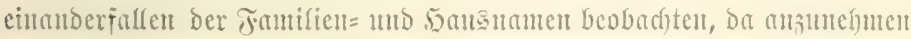

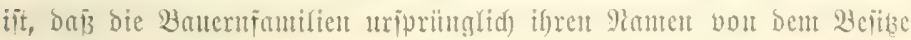
empïmgen, gerabeio wic una in ben Stäbten bes glittefalters ben Drt

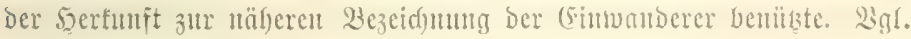

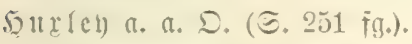

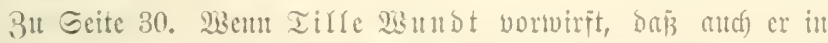

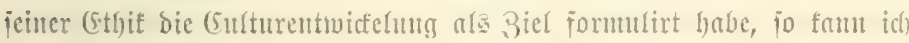

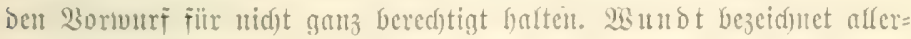

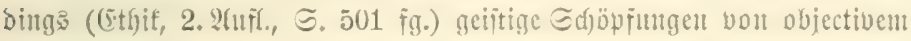




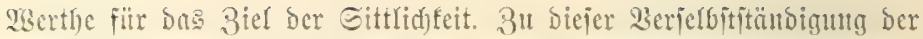

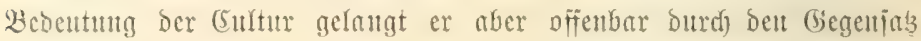

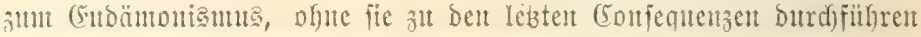

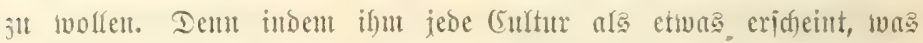
wieber auf Das (suzerreben zurïdwirtt, indent er aljo an eine lebhafte

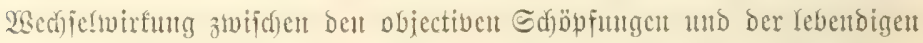

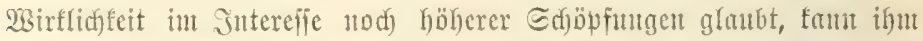
Dic Fähigleit, burdy bie (5ultur angeregt zu weroen, mid)t gleidfgiltig

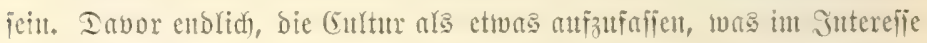

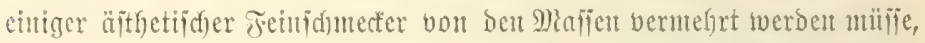
jelbit wenn fic saritber zugrumbe giengen, betonfrt inu jeine colfecti=

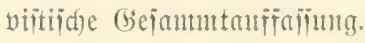

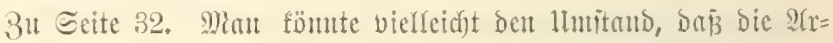
beiter ber jogenanten Afmazonentmeije Durdh Die Sflaberei ber 2robeit völfig entröhnt mutroen, als einc Degenerationserjacumng anfalien.

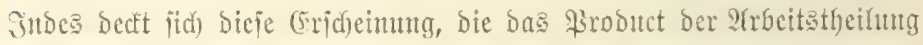
iit, nidft mit ber menid)lidfen Degeneration, Da bie 2trbeiter Der 2(ma=

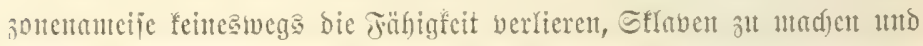

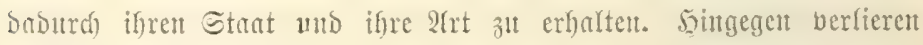

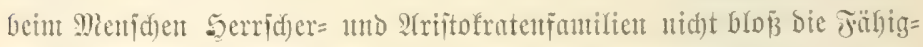
feit zu arbeiten, fondern pecielf bie Jähigfeit zu regieren.

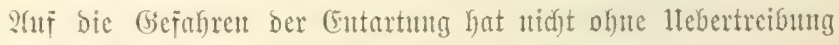

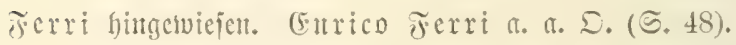

3u Eeite 33. Shering: Ier 3wed int Medt, I, 3S. (ธ. 25).

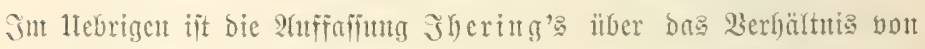

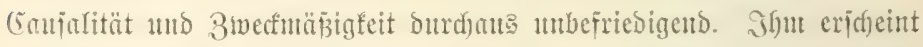

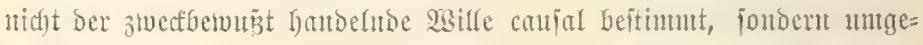

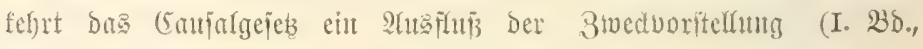
ङ. XII. fg.).

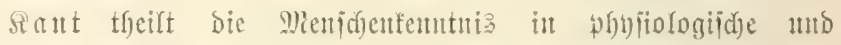
pragnatijace. Die eritere geht anf bie Eriporidnug Deflen, was bie

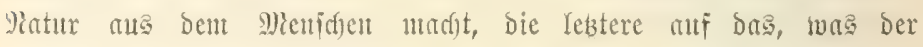

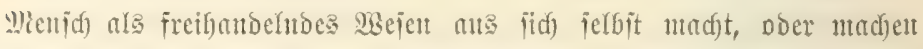

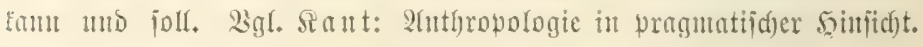

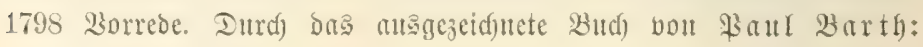




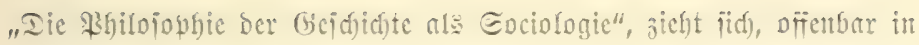

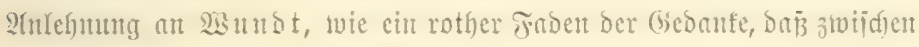

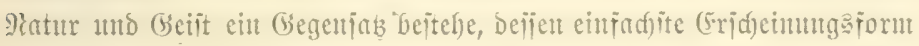

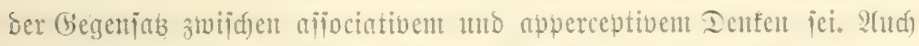

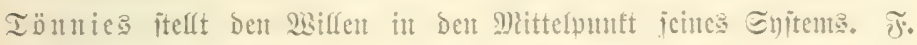

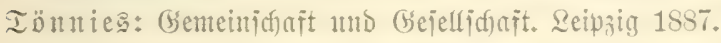

3 Seite 34. Sn ben Geijtestuifienijaften, bie fid mit ben

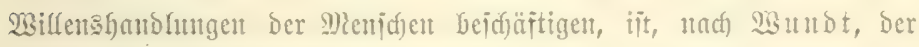

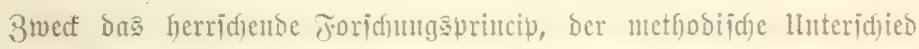

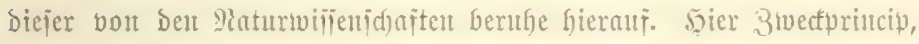

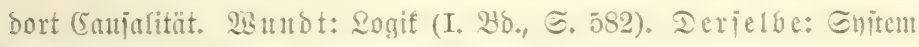

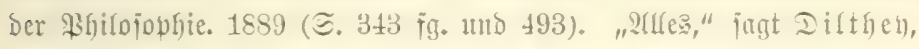

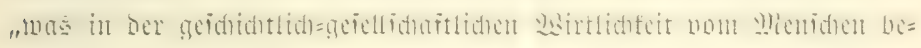
wirft wirb, gejefieht verntöge der Sprntugeder bes $23 i l f e n s ;$ it biejem

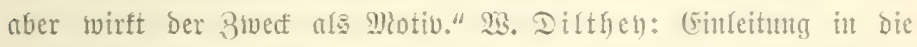

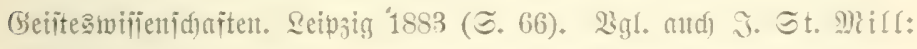
Snjten ber beductiven und inductiven Rogit. Ientid) bon (is omper子. IV. Budf. Rarl Nenger: Unterindutgent ïber Die Mietfobe ber

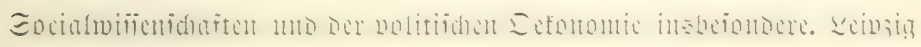
1883.

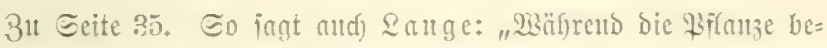

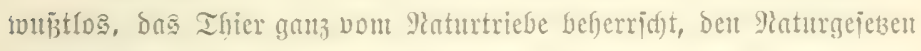

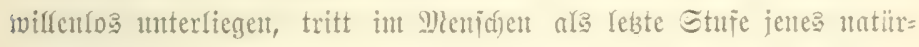

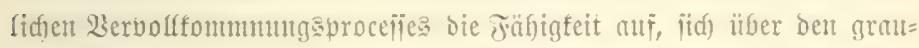

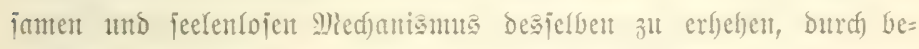

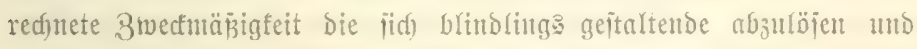

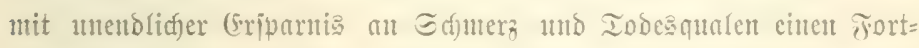

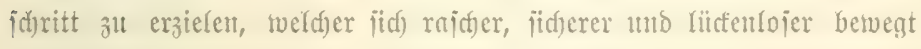

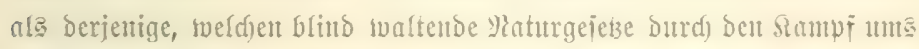

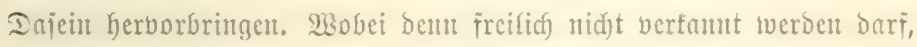
Daß niemala bölfig bou ben Wirtungen jener פiaturgejebe bejreien wirb."

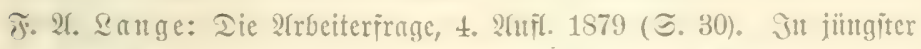

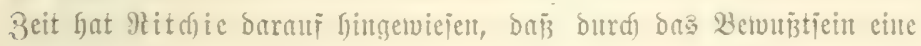

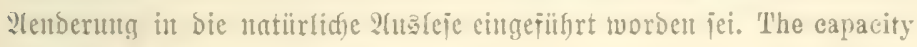


for thinking constitutes mans freedom. It is by thinking alone, that he ean rise above the position of natures slave. $2 g h$, Dabid G. Rit die: Darwinism and Politics. 3. 2uil. 1895 (ङ. 24 fg.). Fïr ente

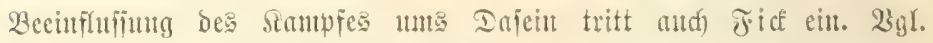

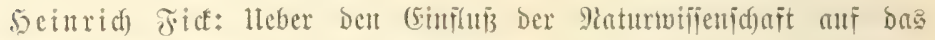
Medjt. Jahrbüdjer für Mationalöfonomic mo Statiftif, XVIII. BJo. 1872 (๘. 276).

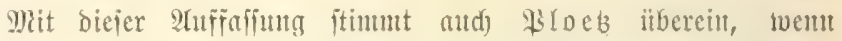

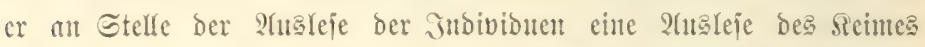

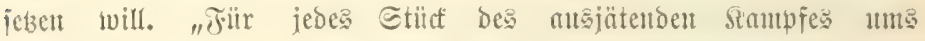
Dajeu", jagt er, "Das wix burdh Sngieue, buraf Therapentif, Durd)

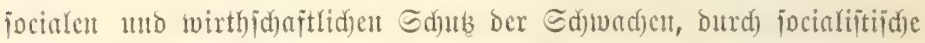

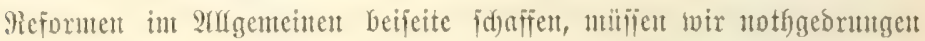
cin 2lequivalent bieten in Form von entipredtender Berbefierung ber

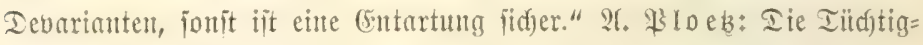
feit mierer Mafie und Der Gdub Der Gdytodden 1895 (S. 229). 2eht=

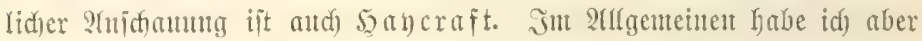

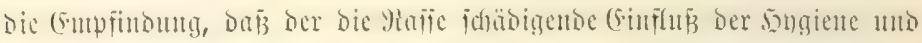

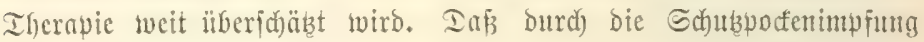
Die Majie beridsledtert worben jei, wird fum jemand beweijen wollen.

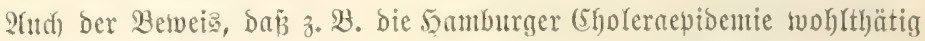

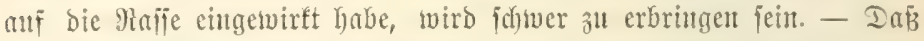

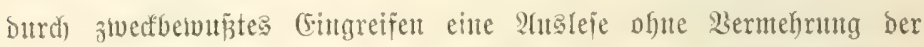

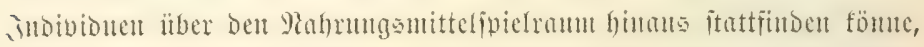

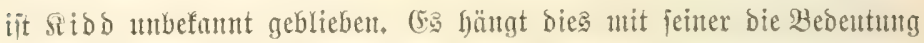

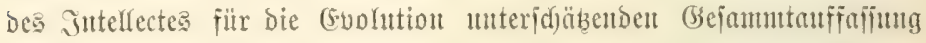

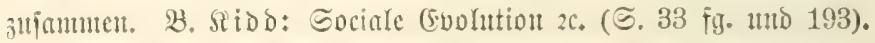

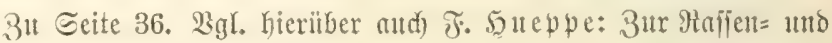
Sociallngiene der Gried)en in 9rterthum und it ber Begentwart. æiesbaden 1897.

3u Seite 37. Mlit tiefen Simmmer fieht Spencer bie fort=

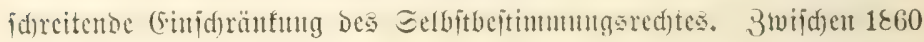

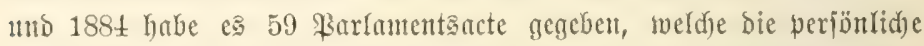
Jreiheit beiddräntten. Shnen folgten bis 1894 tveitere 43. 5. Spcncer: Principles of Sociolog5, III, 2D. (ङ. 591). 
(5: ijt bafer getwīi nidyt ridtig, wem Jacoby meint, bei

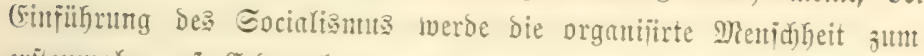

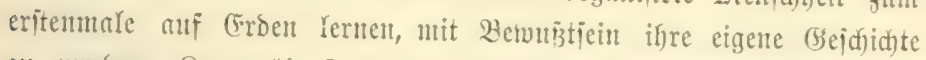

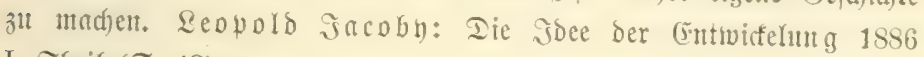
I. Theil (ङ. 43).

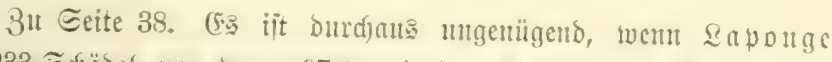

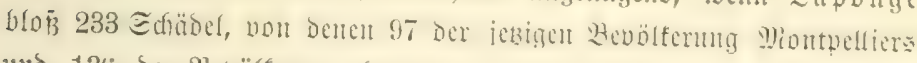
unto 136 ber Bevölferung des 18. Jahrhumberts angehören, genteīen hat, ober went er 20 Sääbel jebiger Bewohner wou Motre Dame de

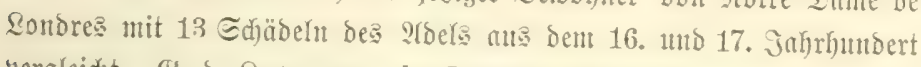
vergleid)t. (5. §. \&apouge: Le Darwinisme dans la seience sociale.

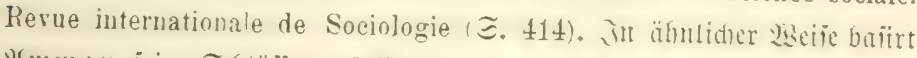
QImnon ieine $\Xi$ d)

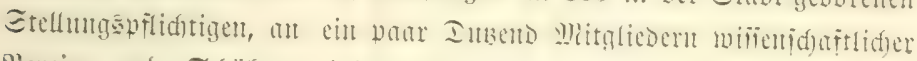

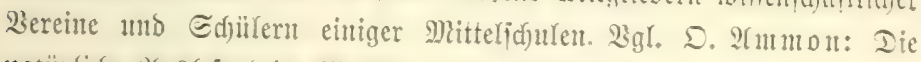

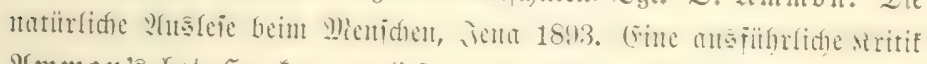
2tmmon's hat Sertuer gefiefert. 5. Serfuer: Die Prbeiterfrage,

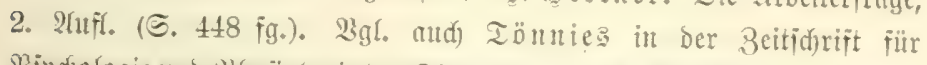

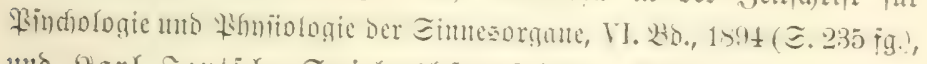
uno Karl Sentid): Socialangleje. Sritijde (blollen, Seipzig 1898 (ङ. $116 \mathrm{ig}$.).

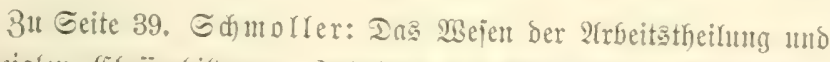

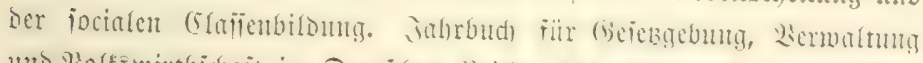

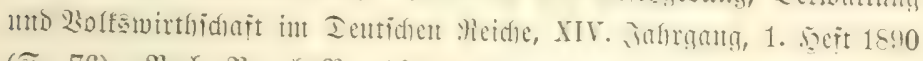

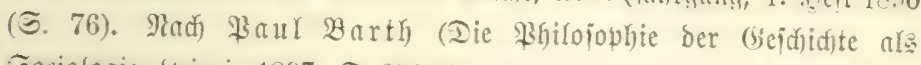

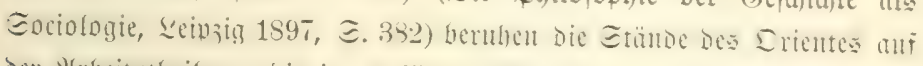

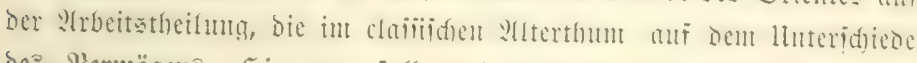

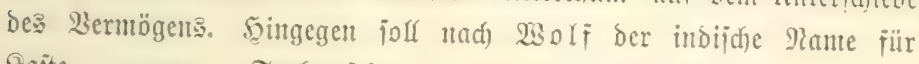
Sajte - varna - Farbe jein. Dies witrbe ani cinte nationale $2 e r=$

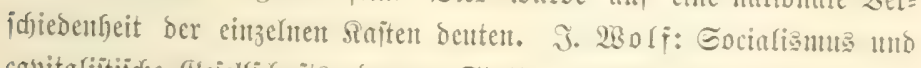

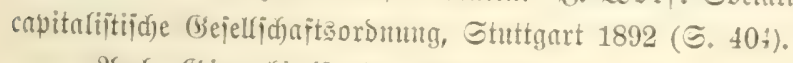

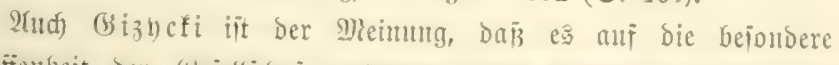

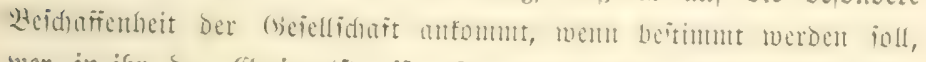
wer in ifr ber Geeignetite itt. (5). v. Gizbcti: Nhorafprifojopgite (ङ. 516). 
"The old notions of social distinetion are only now giving way to the mnch higher ideal and type of man, the maker of his own for-

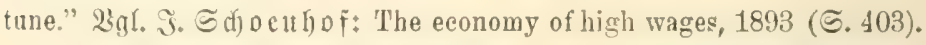

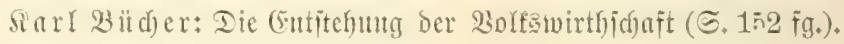

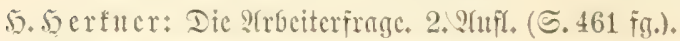

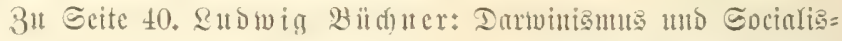

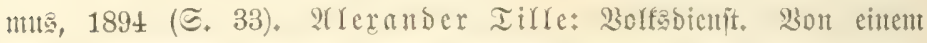
Socialarifofraten, 1893 (ङ. 199), แmo Derielbe: S3on Darivin bis Mi iekific)e, 1895 (ธ. 238!

3u Sette 41. 2Bemt Gumplowicz in geiftudler 2geije bie cigentlide bebentung ber focialen Frage in Deut Berjudje fintoet, an

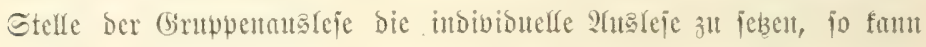

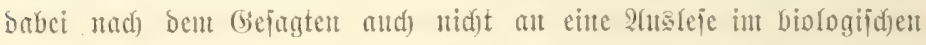

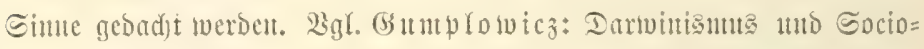
Iogie. Dic 3eit, MBien, VI. 2SD., 9ir. 70, 71 und 72; abgedrutt in bent Sociologifden (5ifats, Immbrutd 1899.

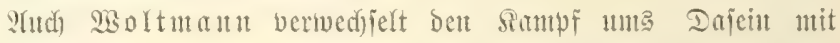

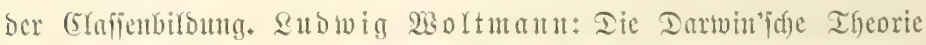
uns ber Socialisutu. Dilifeldorf 1899 (S. 333). Id) famt ben

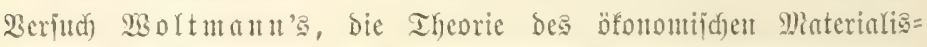

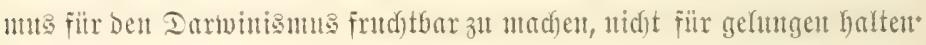

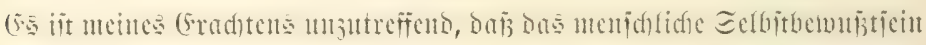

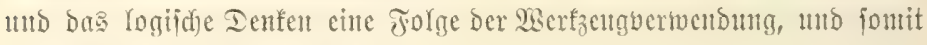

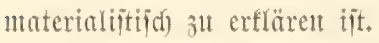

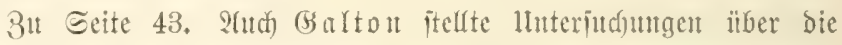

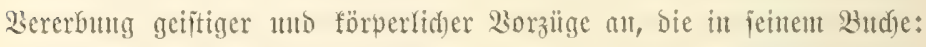
Hereditary Genius, weröffentridgt findo. (5. iit itbrigen fraglid), ob in unberen Ränbern ben oberen (Slafien cin ähntiches llebergetwidgt it ber Servorbringutg bou Ialenten 3ufoumt, wie in Franfreid). Gdjou ber

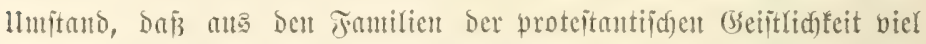

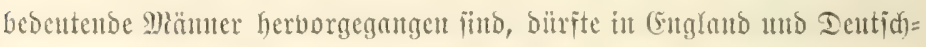

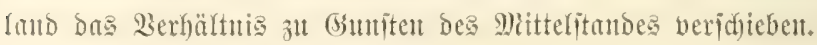

3u Seite 4t. Im P(atonijd)ent Strate folltent Durch bas 1trtheil ber Şerrid)er twïroige \$eripnen nieberer Stände in bie höheren anfge= nonแen, แmü̈rdige bagegen bechifirt iverden. 


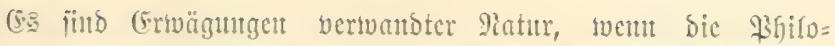

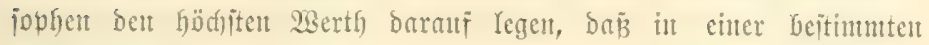

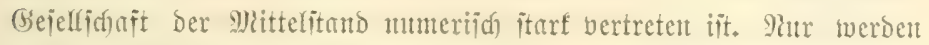

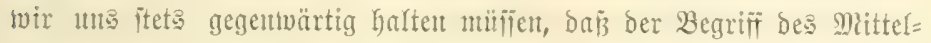

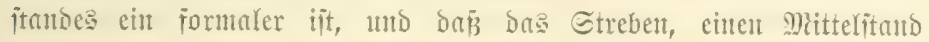

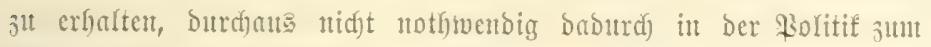

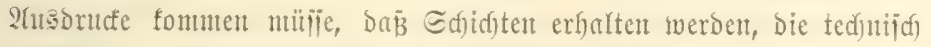

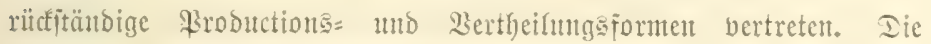

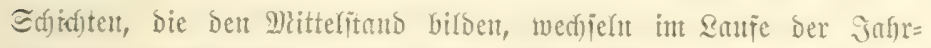

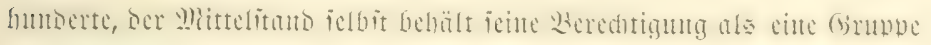

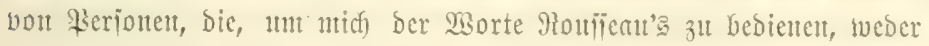

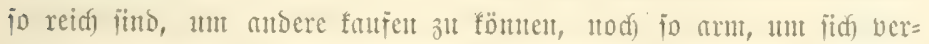

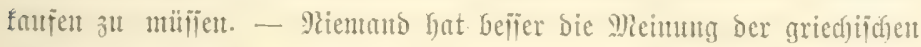
Whifojophen ïber bie Bebentung Deß Mittelitantes für bie Gejutoheit

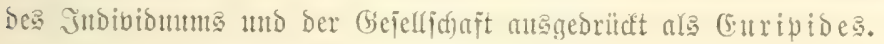

"... Sieber will idd) itillbeglïict

(5in M)ant im 2lolfe Yeben ale ein sönig jein,

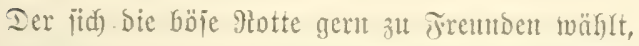
Itno vor bem Tobe zagento iteta bie Guttent hañt.

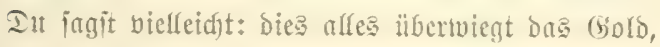

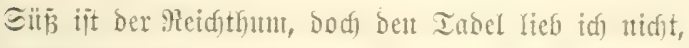
Dn Geld in 5ämben hütento, noch der Sorgen Dunt.

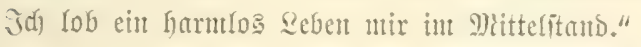
3o 11,2 ers 620 bia 627.

"Drei 2rtent Bürger gifte $\mathrm{e}$ ja: Die Reidfen find Miemtandent uilibe, tradjten fetes uad) Miefrerem. Ier 2(rme, Dent bes Rebens lunterbalt gebrid)t,

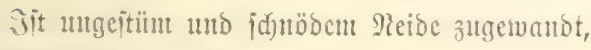
ミdjuelft herber 3utge Stadfelu au Sermögende,

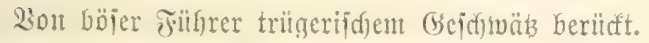
Ioci) ber it beiber Mitte fteft, beichirmt die Strbt,

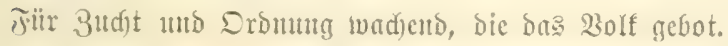

Die Edukfichenden, 23ers 229 bis 236.

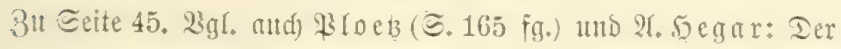

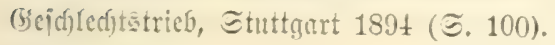


31t Seite 46 . "Die größ̈ten Dentichen Didjter haben fid vor hut

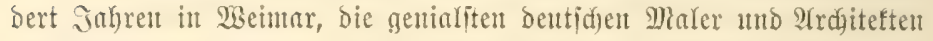

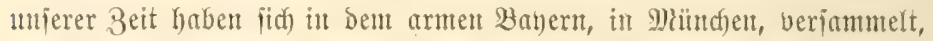

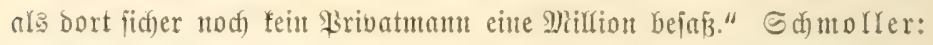

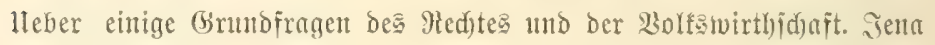
1875 (ङ. 111).

(6). Simmel: lleber jociale Differenzirutg, 1890 (క. 99). Bgl. aud) \&ange: Die 2rbeiterirage, 4. 2utfl., 1879 (ङ. 114).

3u Seite 47. Dns rhobijaje Seeredjt, bne in ipätrömiijder Beit aufgezeid)net wurbe, fenut unter anderemt audf bie Bezanflung ber Matroien im Antheil an ber Frud)t. Die Frad)t murbe in gleidje Theile getheilt, von benen ber (5apitün 2, øer Steuermau, ber Sdfiffzzimmer=

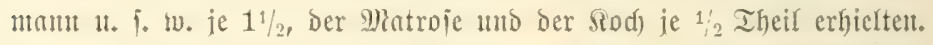
Iemgegeniiber erhält bei bem heutigen norbanterifantijd)en Walfijd)=

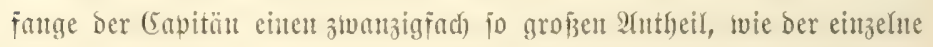

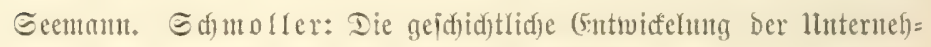

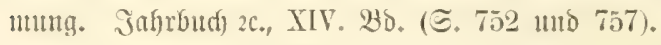

3u Seite 48. Mad) 21 riftoteles joll ber Stant ciue Bereinigutg

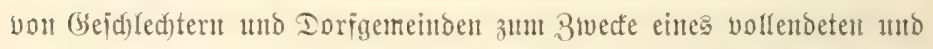
iid) jelbit genügenden Dajems pein. Ar rijtoteles: Politif, III. Butd). "Īn mehr als zweitaujendjähriger Gedanfentabeit der bejten

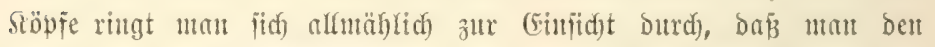

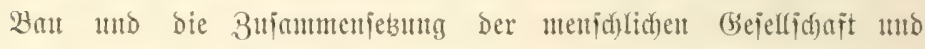

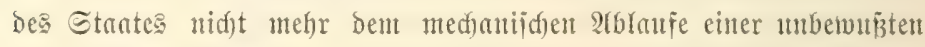

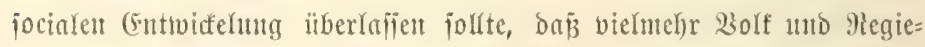

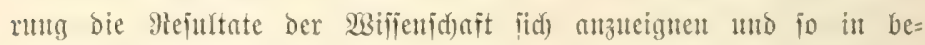

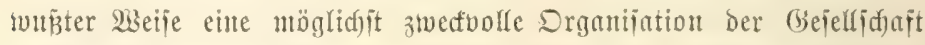
małitreben hätten." \&ubivig Stcin: Die fociule Frnge im Ridute

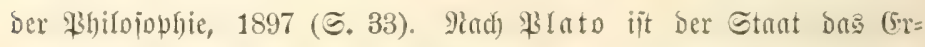
gebnis des Sudjens nadj Geredjtigfeit. Die Staten werben bem Soeale mur unhefommen, went entweber bie \$bilojophen sïnige werden ober bie siönge ă philofowhiren beginnen.

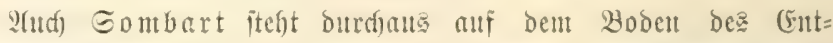
whifelungagedantens. Yiur entrimmt er feine soenle bem wirth=

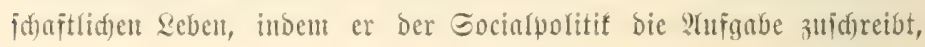




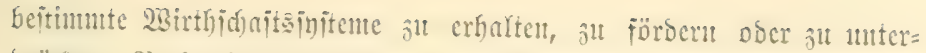

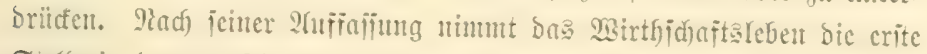

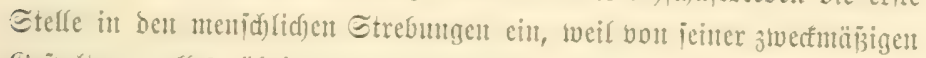
Geitultung alfes übrige menjuliche Iajein abyängt. Ientu nidit dic

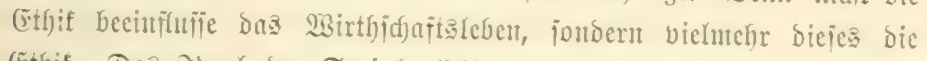
(Ethif. Ias Joeal ber Eocialpolitif jei jomit bas MBirthidjaftsinitent

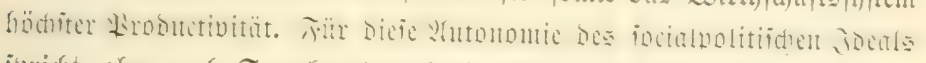
iprid)t aber nacf Sombart nod) ein Grmb formaler Matur. Sntom

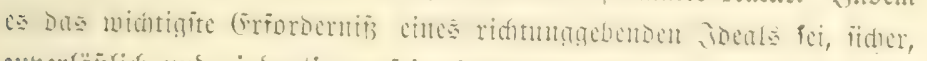

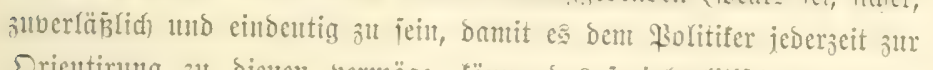
Orientinung ân bienten vermöge, förne Daß jocialpolitijaje Joeal ber (Ethif nicfit cutnomuten merben. Ienn bie etfiiffen Enjteme peicu wanbelfor.

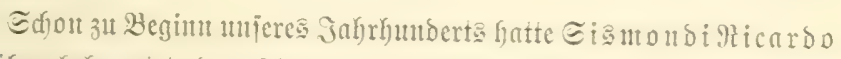

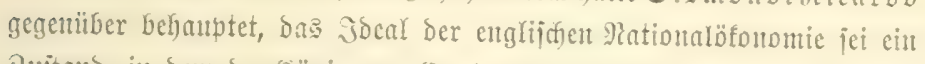

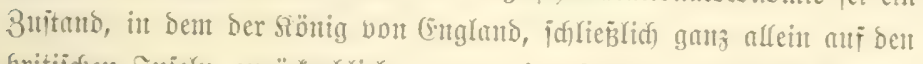

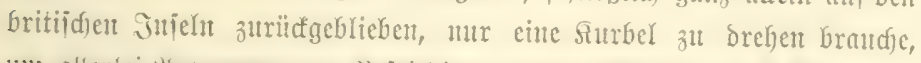

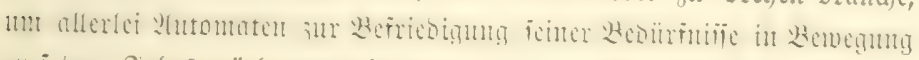
3 jebent. Sndes mirde nan Sombart luredft thut, toolfte man biejen 3ujtand Der hödjiten Probuctibität fïr jein Goeal falten. Ienn er

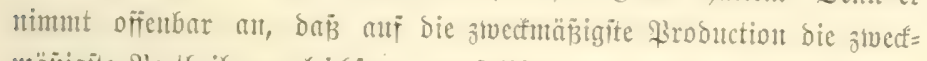
määigite 2ertheilung gleidjon von felbit folgen miific. Iamit itellt $\mathrm{cr}$

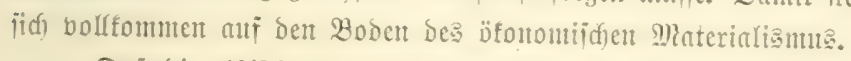

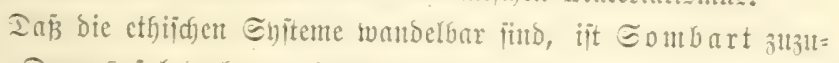
gebent. Intme folgt aber nod) nidjt, baỉ bie (strjif ungeeignet jei, bas

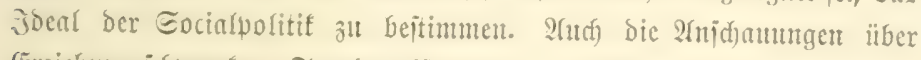

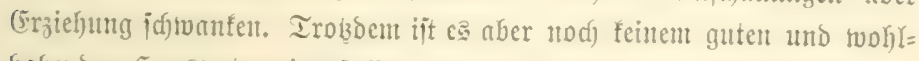

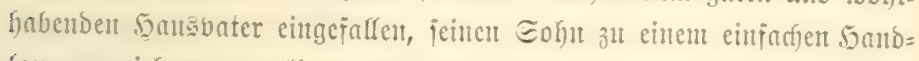

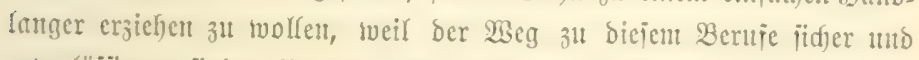

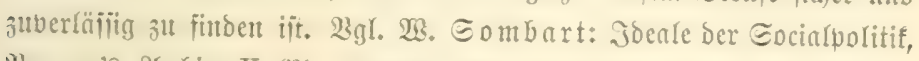

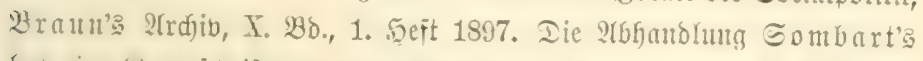

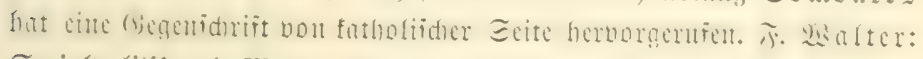
ミocialpolitif utno Mhoral. Freiburg i. 2. 1899.

Ier (5inzelute, jagt Ģalton, gleidft ciuter Suth, bie ant

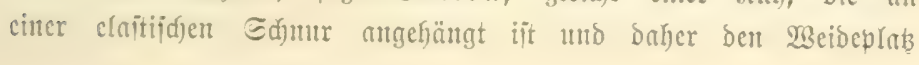


mur in beiduränter $28 c i j e$ erweitern fam. Die (Bejellid)ait hingegen jei

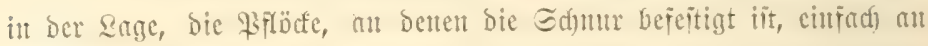

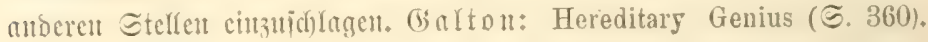

3u Ecite 49. IBund: Eniten (ธ. 599). Spencer gelaugt

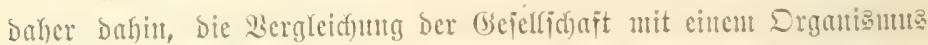

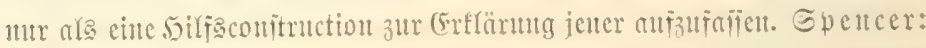

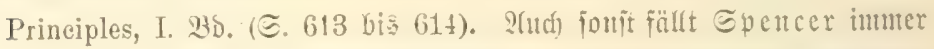

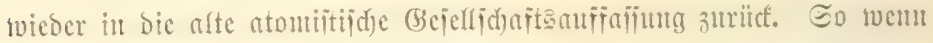

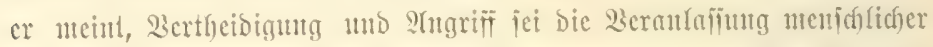

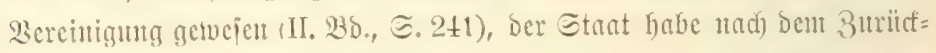

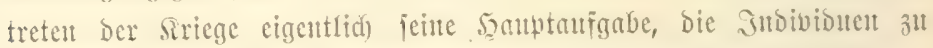

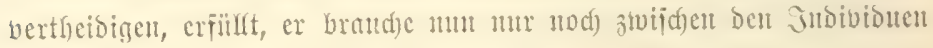

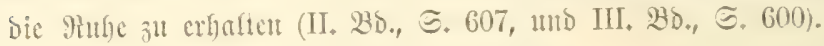

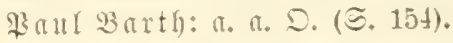

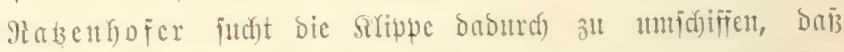

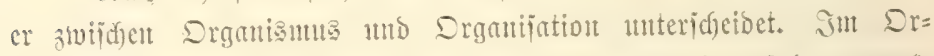

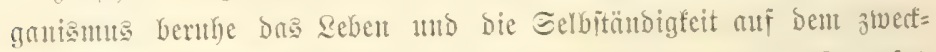
cinfeitfichen Bufanmentwirfen Der Drgute; jeber imtere Begenjaba iit sirmtfeit. Dic jociale Drgantijation geitatte bingegen ifren Snbi=

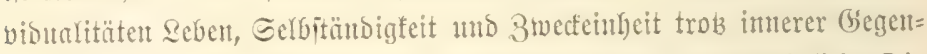
fäbe. Dieje jeien bem Gedeifen des Gebildes jogar mentbefrlida. Die

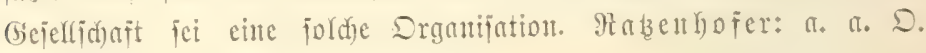
(ङ. 294).

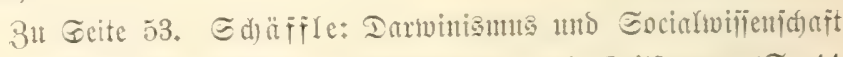

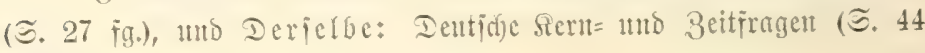
bis 49).

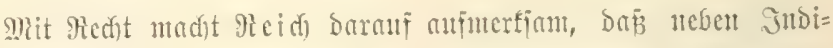

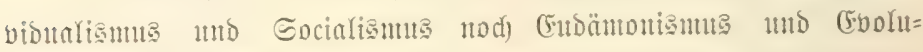

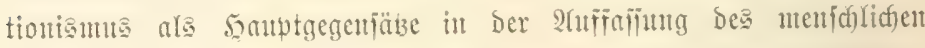
Sebens getreten jeien. Dabei zeigten semofiatioge Midutungent oft theo= retija) eine bebentlidje 3uneigung fïr ben prattent (Gnbämonisnms.

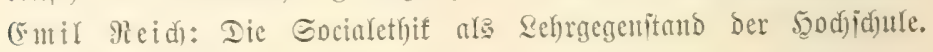

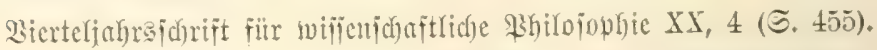

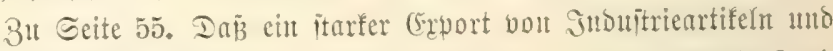

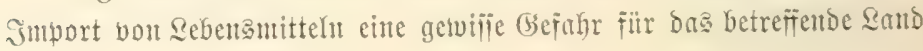




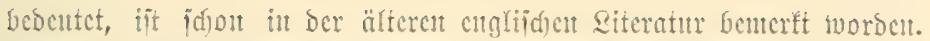

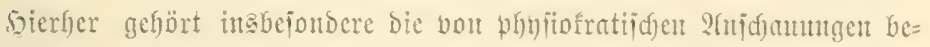

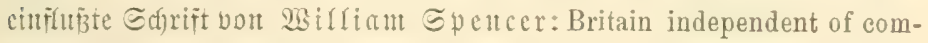

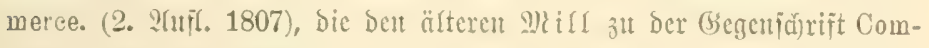
merce defended (1808) beranläte. Sti neneiter Beit hat Srbenberg

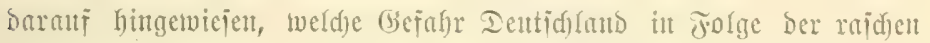

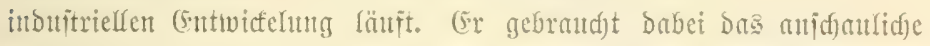

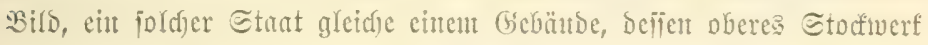

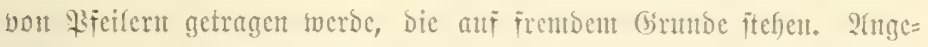

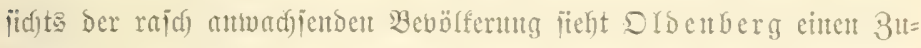
itand vorats, in bent bie broterzengenden Sänder Den Sndtitrieländen bictirent.

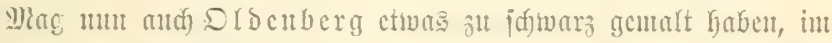

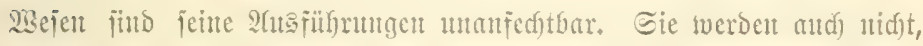

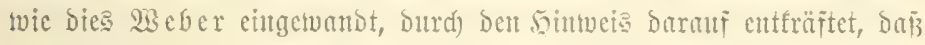
Der Sanpterport Ientid)lands nad) Englanto itattrinde, bent Darats

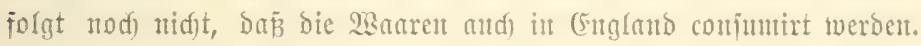

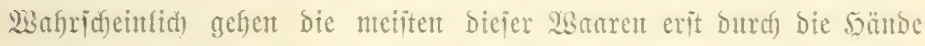
entglijher (Exportente an bie wirffident (5onfuntenten ïber. $2 g r$. $\Omega$.

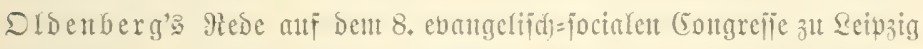
(10. แnd 11. Inti 1897). Jn allerjüngiter 3cit hat ङombart die

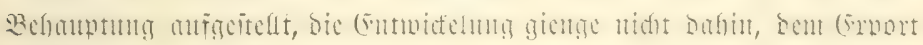
eine itets wnadjente Snote Der Rrobuction âuzuneijen. Sndes harte

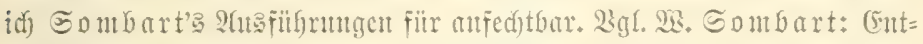
wicfeln wir un: 3un (Exportinduitricitate? Sociale firaxis bon

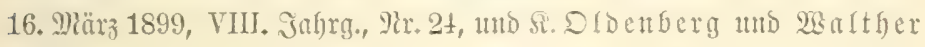
Bergius: Sociale Fraxis vont 13. 2tpril 1899, VJII. Jahrg., 9r. 29.

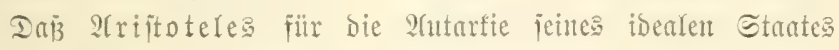
cintritt, mag ans Der antifen 23irthid)aftsuerfäjung erflärt werden

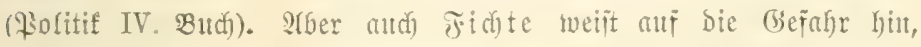
Dic cin Etant int internationalen Bertehx Ianie. Die mentanti=

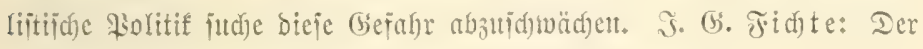

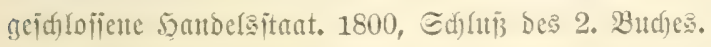

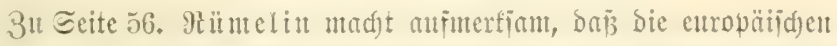

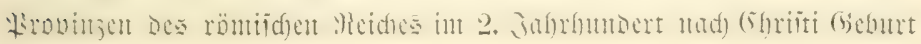




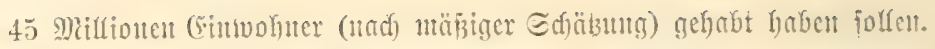

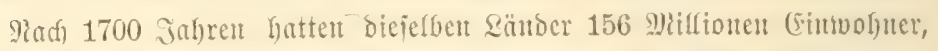

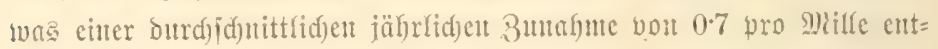

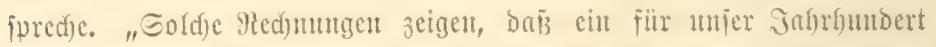

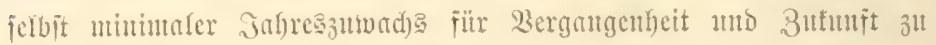

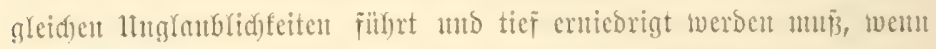
cr alf Meifen vout Sahrhmberten antwentbar twerben folf. Rümelin

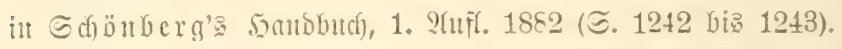

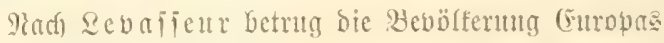

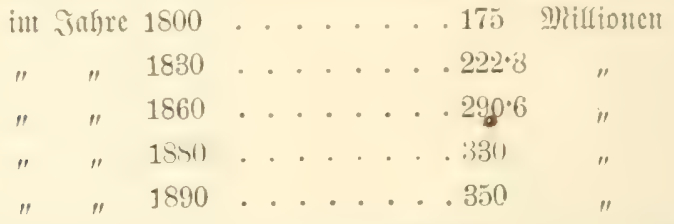

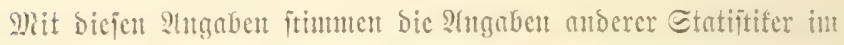

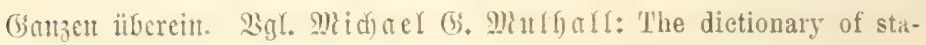
tistics, Rontont 1892 (ङ. 442).

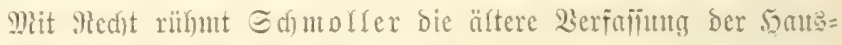
indutrie, weil jie bie 3ahl ber 3ierfeger mo sacimarbeiter ber burd)= fd)

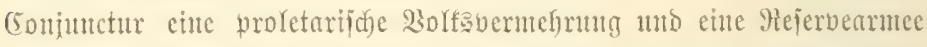
fumgernber Scimarbeiter jülife, fïr weldye 2Trbeit at verjorgen, bie

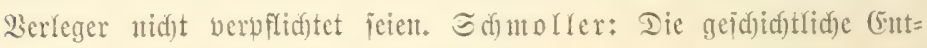

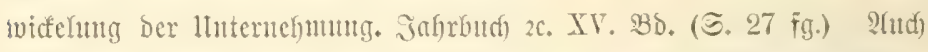

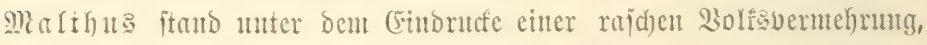

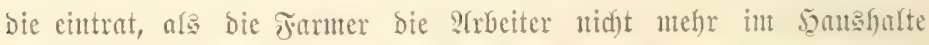
haben wolften. Während friber mur bic 9rbeiter heiratent fomten,

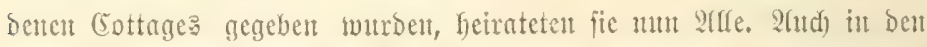

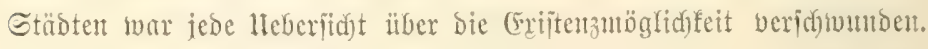
2. Tomnbec: Lectures on the industrial revolution of the 18th century in England. 4. 9uț. 1894 (

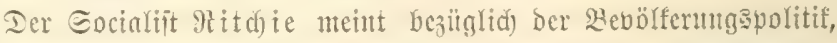

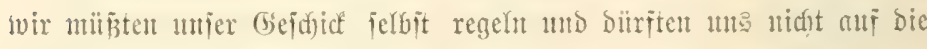
gütige Soriehung verfafien; Dent die Meimung vieler Socialijten, baîs

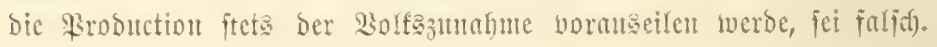




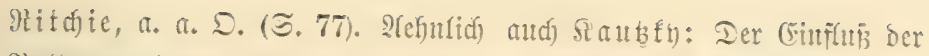

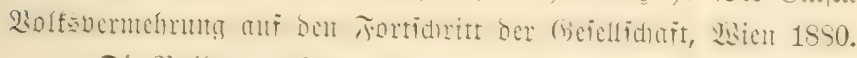

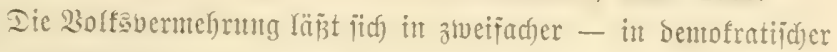

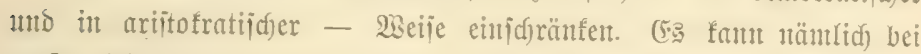

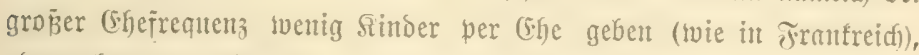
Doer aber man font bei grop̈ent Sinderreichthum bie 3aht Der (Effent

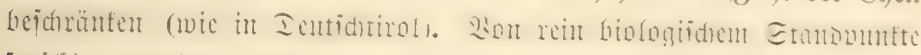

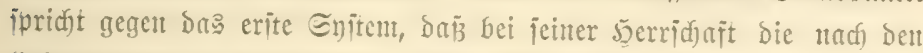

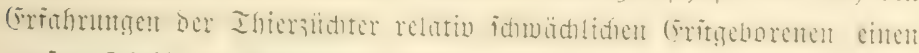

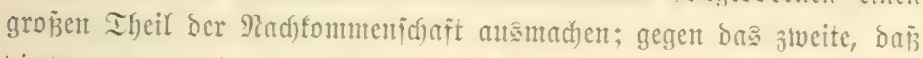

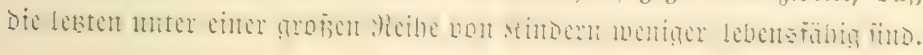





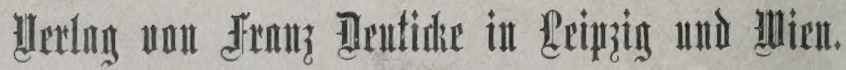

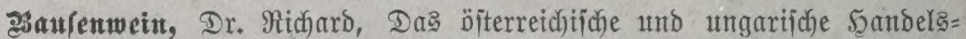
redit in vergYeidjender Daritellung. (Fin furzgefaşter Reitfaden für Das Stubium Diejer Rechte. 1894. ff. $3.60=\mathfrak{M}$.6.-.

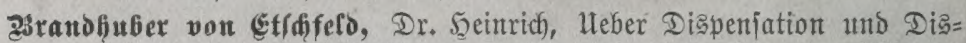
penfationgredyt utad fatholifichem Sirchenrecht. 1888. fl. $1.80=$ M. 3.

Gerényi, $\mathfrak{F}_{+}$Die Trinferajnle (5ntglanos mo die projectinte Trinferanitalt für Rieder= Deiterreich bom Standpumte Der 2(dominifitration. 1893. fl. $1,20=\mathfrak{R} .2 .-$.

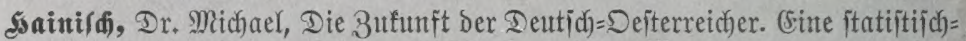

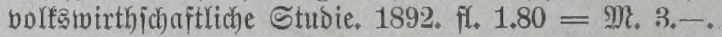

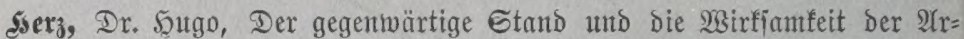
beiterichutiggejekgebunt in Defterreich). 1898. fl. $1.20=\mathfrak{M}$. 2.-.

Ssifer, Dr. Sarl, Disciplintaritrafent in Dent B̈fterreidfifinen Strafamitartent

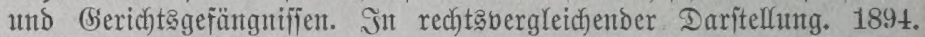
fl. $2.40=$ Mi. $4 .-$.

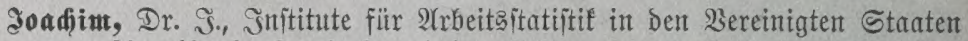
bon 2Tmerifa, in Englamb und ber Sd)weiz. 1890. fl. 1,20= Mi. 2 -.

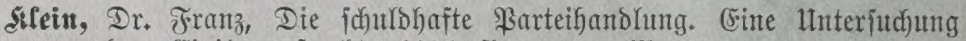

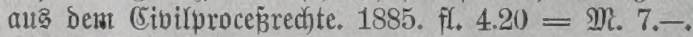

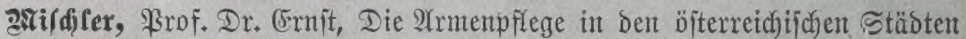
utlo ifre Reform. 1890. fl. $1.20=2 .-$.

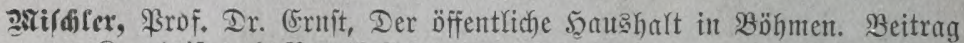

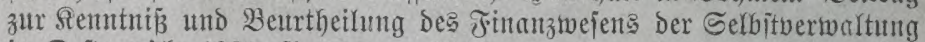
in Seiterreidy. 1887. fl. $3.60=\mathfrak{M}, 6,-$.

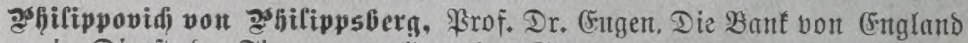

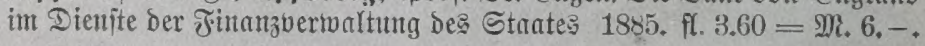

Sdievifiaven, Dr. J. van, Wom Reben unb Sterben. Das Geitern und

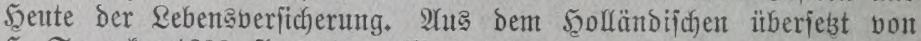
5.. Tarnfe. 1898. ff. 5,40= M. 9.-.

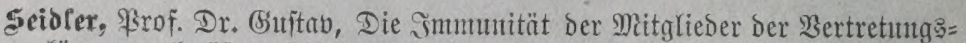

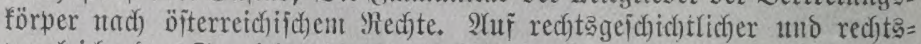

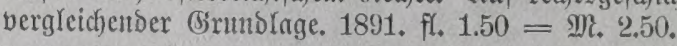

Stein, Dr. Rorenz von, Die Randwirthichaft in ber Berwaltung uno Dag

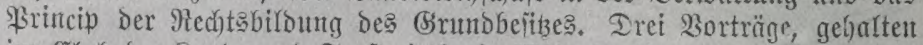

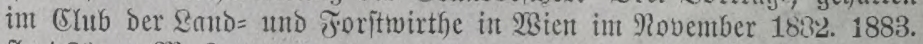
fl. $1.20=\mathfrak{M} .2$.

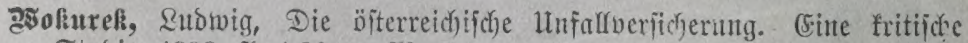
Stubie. 1898. fl. $120=$ M. 2,-.

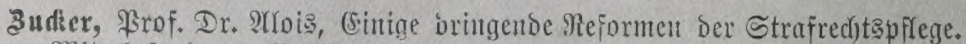

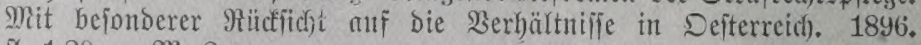
fl. $1.20=$ M. $2 .--$. 


\section{PLEASE DO NOT REMOVE \\ CARDS OR SLIPS FROM THIS POCKET}

\section{UNIVERSITY OF TORONTO LIBRARY}

QH Hainisch, Michael

366 Der Kampf ums Dasein und

H4 die Socialpolitik

BioMed 
